\title{
Furnace and Water Heater Venting Field Demonstration
}

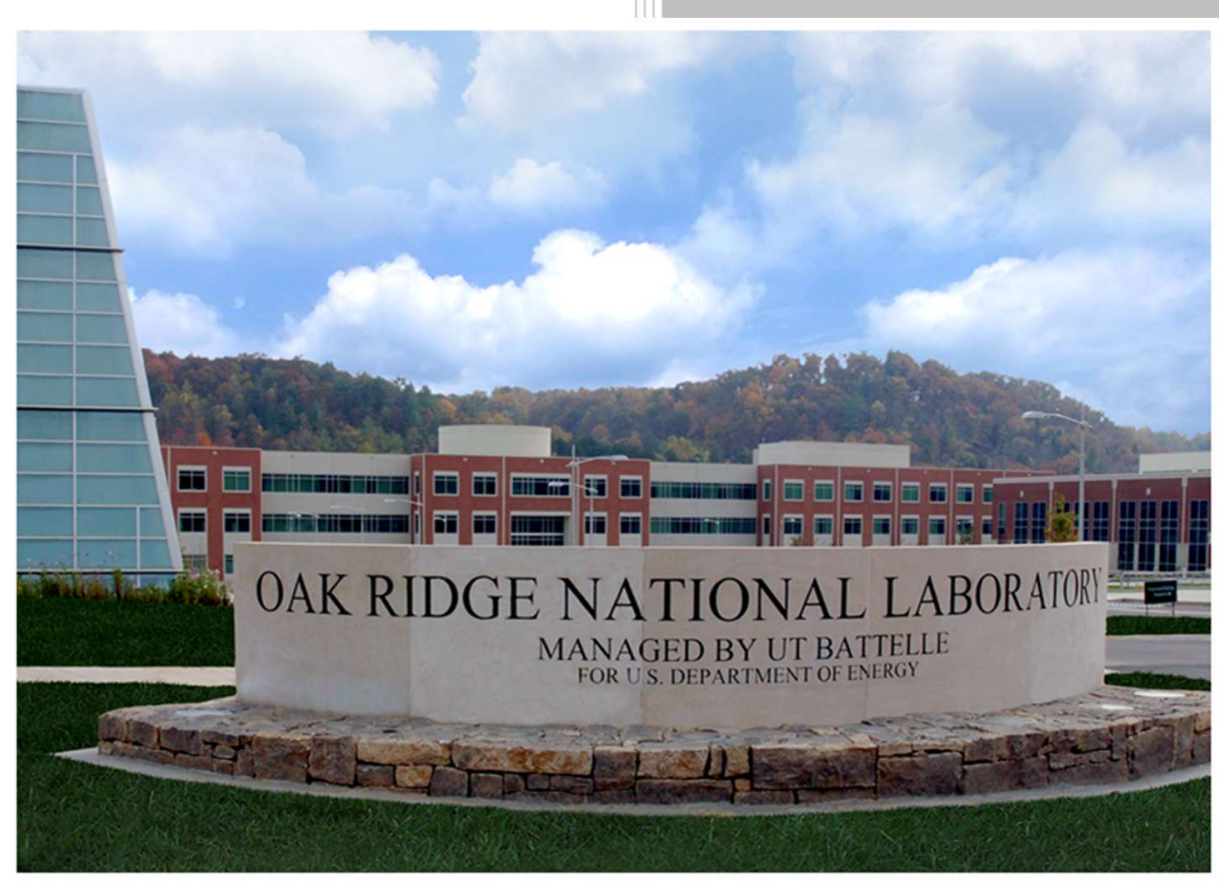

Mark Ternes Jeffrey Munk Mini Malhotra Anthony Gehl

May 2019 


\section{DOCUMENT AVAILABILITY}

Reports produced after January 1, 1996, are generally available free via US Department of Energy (DOE) SciTech Connect.

Website www.osti.gov

Reports produced before January 1, 1996, may be purchased by members of the public from the following source:

National Technical Information Service

5285 Port Royal Road

Springfield, VA 22161

Telephone 703-605-6000 (1-800-553-6847)

TDD 703-487-4639

Fax 703-605-6900

E-mail info@ntis.gov

Website http://classic.ntis.gov/

Reports are available to DOE employees, DOE contractors, Energy Technology Data Exchange representatives, and International Nuclear Information System representatives from the following source:

Office of Scientific and Technical Information

PO Box 62

Oak Ridge, TN 37831

Telephone 865-576-8401

Fax 865-576-5728

E-mail reports@osti.gov

Website http://www.osti.gov/contact.html

This report was prepared as an account of work sponsored by an agency of the United States Government. Neither the United States Government nor any agency thereof, nor any of their employees, makes any warranty, express or implied, or assumes any legal liability or responsibility for the accuracy, completeness, or usefulness of any information, apparatus, product, or process disclosed, or represents that its use would not infringe privately owned rights. Reference herein to any specific commercial product, process, or service by trade name, trademark, manufacturer, or otherwise, does not necessarily constitute or imply its endorsement, recommendation, or favoring by the United States Government or any agency thereof. The views and opinions of authors expressed herein do not necessarily state or reflect those of the United States Government or any agency thereof. 
Energy and Transportation Science Division

\title{
FURNACE AND WATER HEATER VENTING FIELD DEMONSTRATION
}

\author{
Mark Ternes \\ Jeffrey Munk \\ Mini Malhotra \\ Anthony Gehl
}

May 2019

Prepared by

OAK RIDGE NATIONAL LABORATORY

Oak Ridge, TN 37831-6283

managed by

UT-BATTELLE, LLC

for the

US DEPARTMENT OF ENERGY

under contract DE-AC05-00OR22725 



\section{CONTENTS}

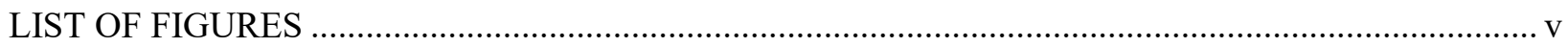

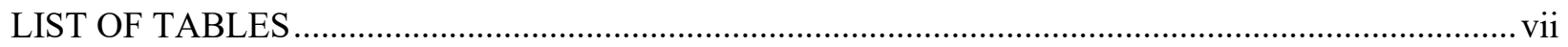

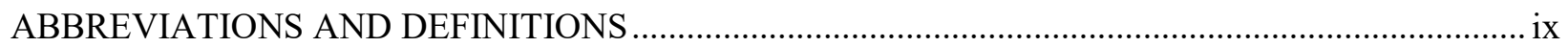

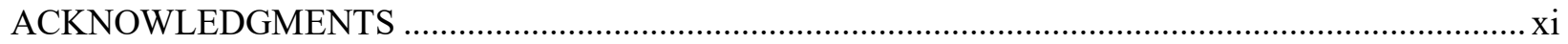

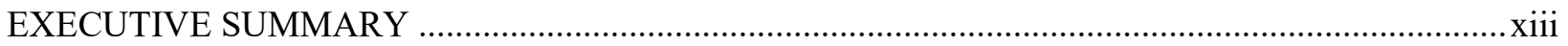

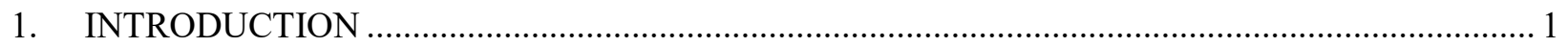

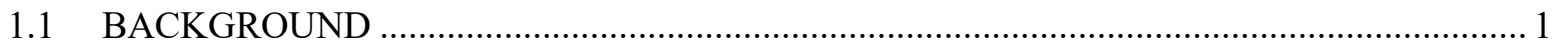

1.2 PROJECT OBJECTIVES ….............................................................................. 2

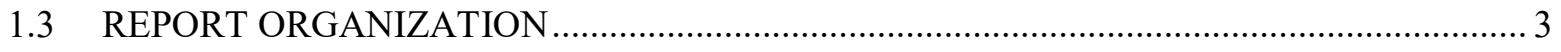

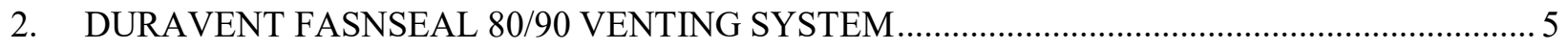

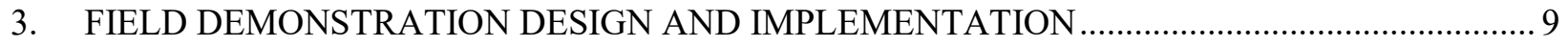

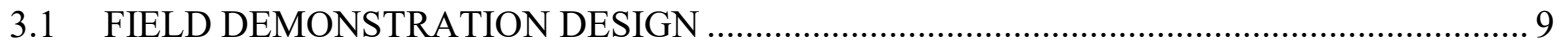

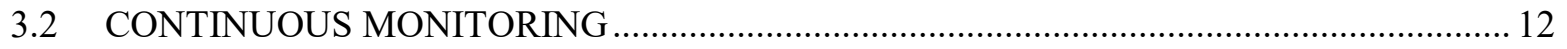

3.3 WORST-CASE DEPRESSURIZATION VENTING DIAGNOSTIC TEST ......................... 15

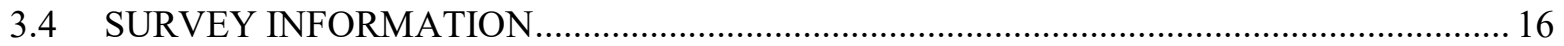

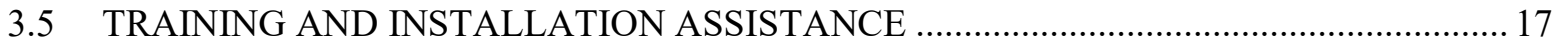

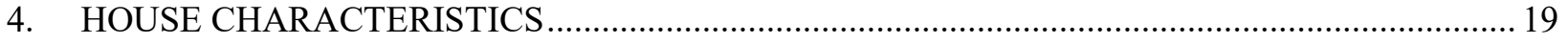

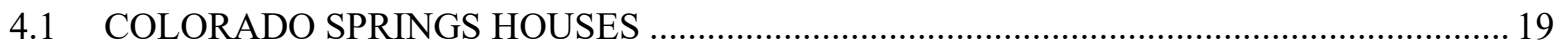

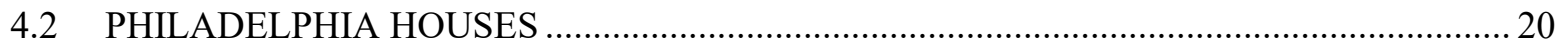

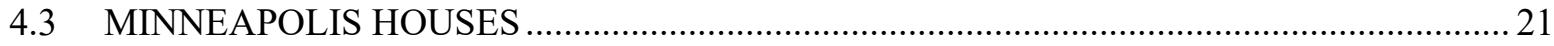

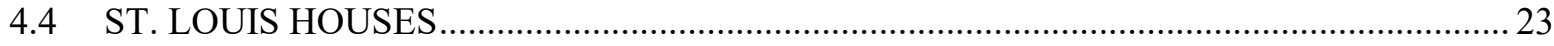

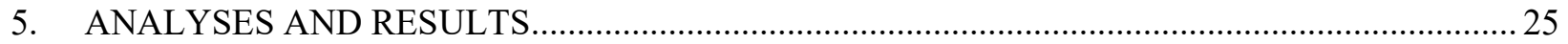

5.1 PRE- AND POST-RETROFIT WATER HEATER OPERATION …...................................25

5.2 WORST-CASE DEPRESSURIZATION VENTING DIAGNOSTIC TEST RESULTS ........28

5.3 DETERMINATION OF SPILLAGE EVENTS AND THEIR DURATION …....................... 30

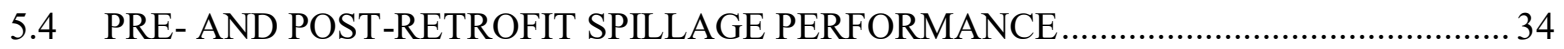

5.5 VENTING PERFORMANCE IN INDIVIDUAL HOMES .............................................. 44

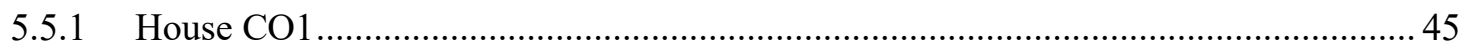

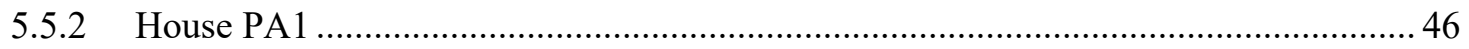

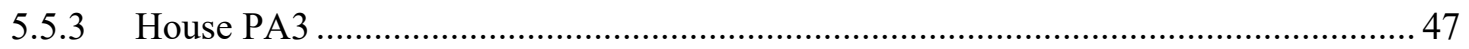

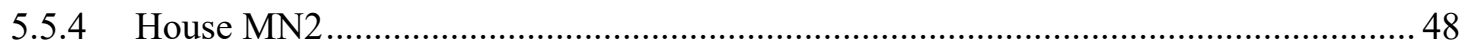

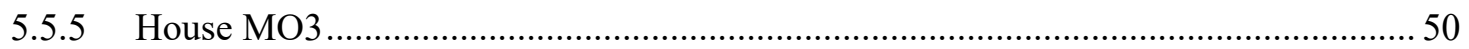

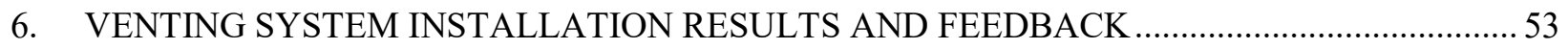

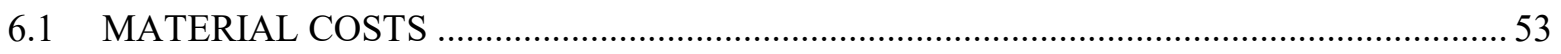

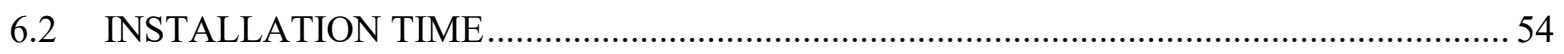

6.3 COMPARISON OF COSTS TO OTHER VENTING OPTIONS .......................................... 54

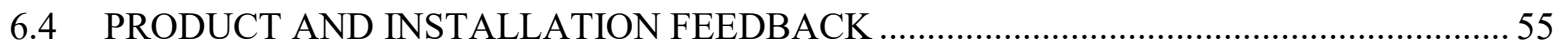

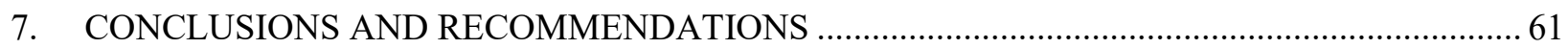

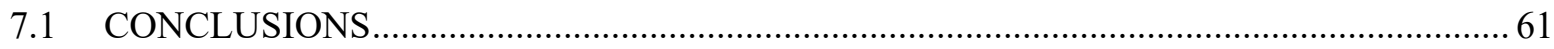

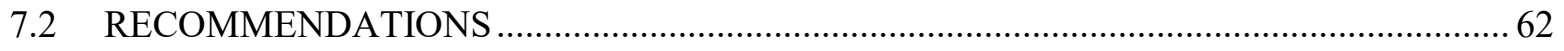

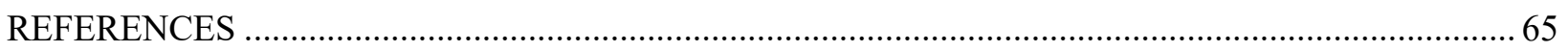

APPENDIX A. WORST-CASE DEPRESSURIZATION VENTING DIAGNOSTIC TEST

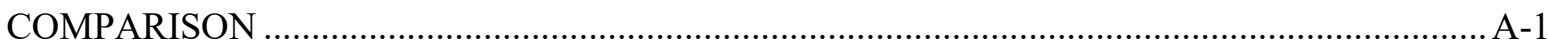

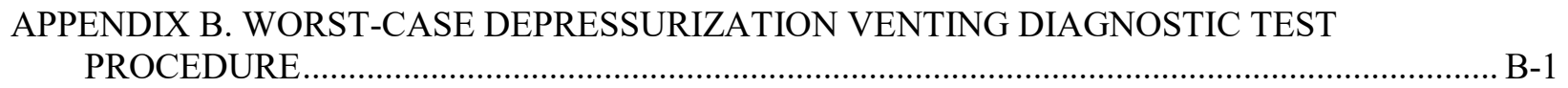

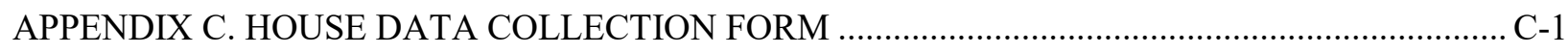

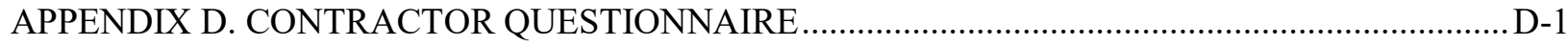

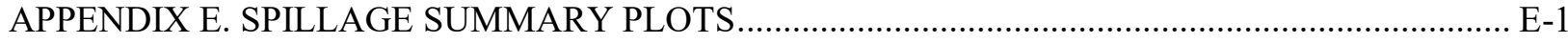




\section{LIST OF FIGURES}

Figure 2.1. DuraVent FasNSeal 80/90 venting system before and after installation diagrams. .................. 5

Figure 2.2. M\&G DuraVent FasNSeal 80/90 venting system installation process.................................... 7

Figure 3.1. Locations of the homes used in the field demonstration. ...................................................... 9

Figure 3.2. Pre- and post-retrofit monitoring periods for the demonstration houses............................... 12

Figure 3.3. Thermocouple array to measure the dilution air temperature surrounding the water

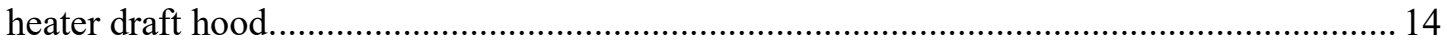

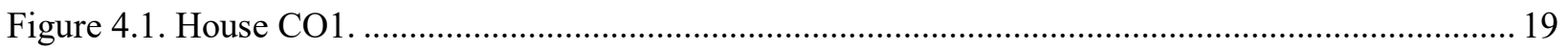

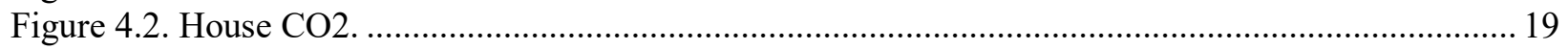

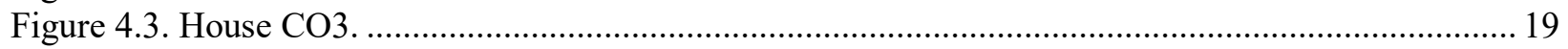

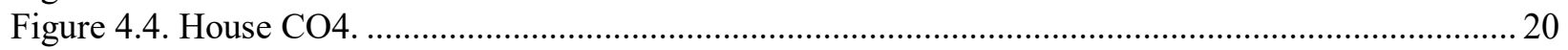

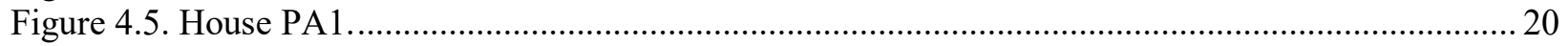

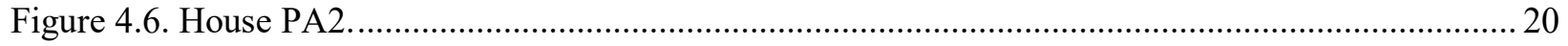

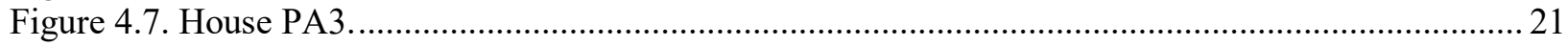

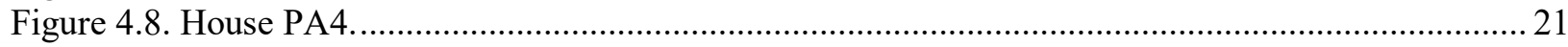

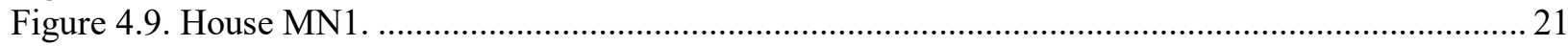

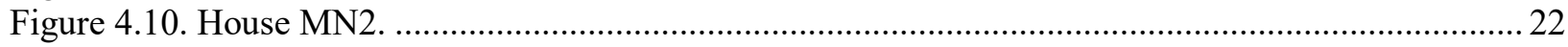

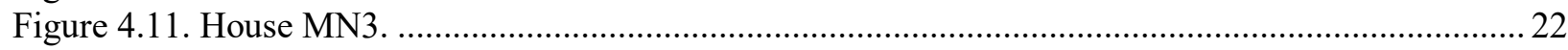

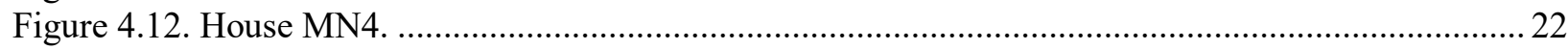

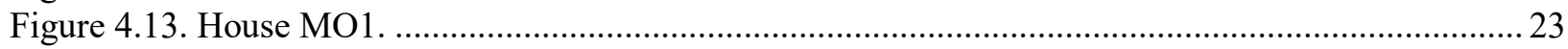

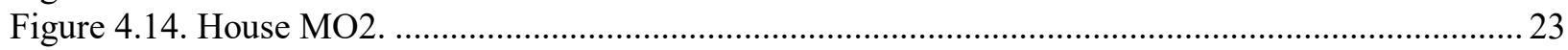

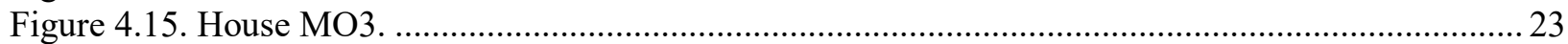

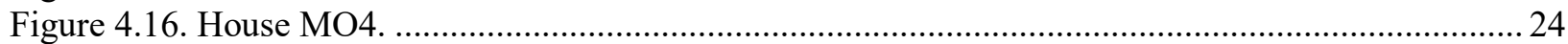

Figure 5.1. Trend of water heater runtime per day during the monitoring period. ................................... 26

Figure 5.2. Comparison of water heater operation during the pre- and post-retrofit periods. ....................27

Figure 5.3. Spillage detected by DP, DT, and $\mathrm{CO}_{2}$ at the start of one 12 minute water heater cycle. ........ 31

Figure 5.4. Two spillage events detected by DP, DT, and $\mathrm{CO}_{2}$ in the middle of a 10 minute water

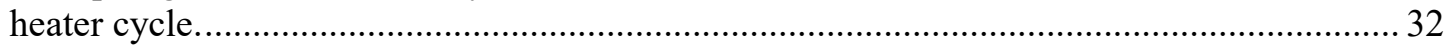

Figure 5.5. Alignment of the DT, DP, and $\mathrm{CO}_{2}$ methods for detecting spillage over a week................... 33

Figure 5.6. Spillage summary plots based on DP (left) and DT (right) methods for House CO4 ............. 35

Figure 5.7. High average spillage time caused by one or two water heater cycles.................................... 36

Figure 5.8. Spillage summary plots for the Colorado Springs houses. ................................................. 37

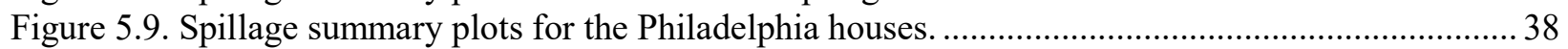

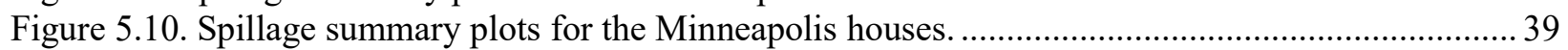

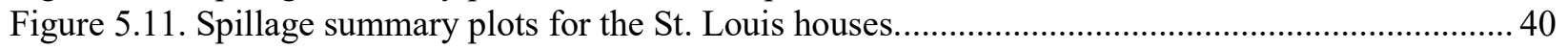

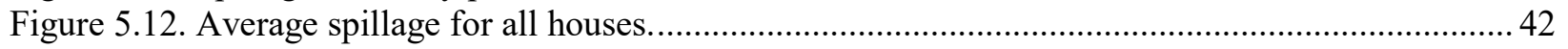

Figure 5.13. Three inch vent connector (left) upgraded to a 4 inch vent connector (right) in House

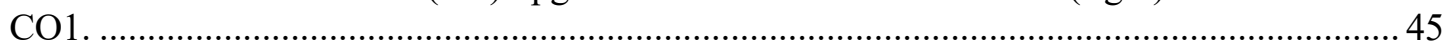

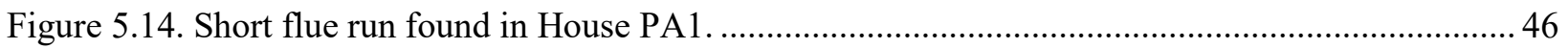

Figure 5.15. House MN2 furnace closet. .......................................................................................... 48

Figure 5.16. Daily average pressure differences between the CAZ and the outdoors in House MN2.

Figure 5.17. Post-retrofit CAZ and vent pressures during supply air blower operation during furnace operation (left) and air-conditioner operation (right) in House MN2 ....................... 49

Figure 5.18. Basement equipment rooms in House MO3 ................................................................. 51

Figure 6.1. Alternative methods of connecting the PolyPro to the furnace ...........................................5 56

Figure 6.2. Vent cap's worm-drive hose clamp that becomes oval when tightened...............................57

Figure 6.3. Loose fit in the 2 in. fire stop compared with the 3 in. fire stop.......................................... 58 


\section{LIST OF TABLES}

Table 3.1. Dates defining the pre- and post-retrofit periods for the houses.............................................. 11

Table 3.2. Dates when the worst-case depressurization venting diagnostic test was performed in

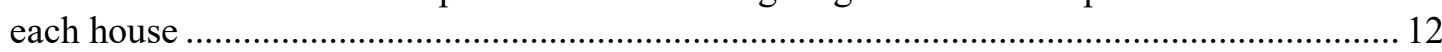

Table 3.3. Instrumentation and data acquisition system specifications ................................................. 15

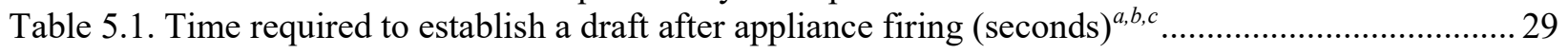

Table 5.2. Outdoor temperature ranges used to calculate values in Figure 5.12 .................................. 42

Table 5.3. Total and startup spillage times for the pre- and post-retrofit periods .................................... 44 



\section{ABBREVIATIONS AND DEFINITIONS}

BPI

Building Performance Institute

CAASTLC

Community Action Agency, St. Louis County

CAZ

Combustion air zone: the room or immediate vicinity in which the combustion appliances are installed

Category I Gas appliances, such as non-condensing furnaces and naturally vented water heaters, based on natural-draft venting served by negative static pressure vents designed so that vent gas temperature remains high enough to avoid excessive condensation in the vent.

Category IV Gas appliances, such as condensing furnaces, based on forced draft combustion served by positive static pressure vents

$\mathrm{CO}_{2}$

Carbon dioxide

$\mathrm{CO}$

Carbon monoxide

DOE

DP

Department of Energy

DT

Differential pressure

ECA

Differential temperature

ERC

Energy Coordinating Agency

Firing

Energy Resource Center

Furnace

Term used to indicate when a fuel mixture is being burned by the burner within an appliance, producing heat and combustion by-products.

Furnace $\quad$ For purposes of this report, a device that provides space heating through an air distribution system, is fueled by natural gas or propane, with a heat input rating of $<225,000 \mathrm{Btu} / \mathrm{h}$, but excluding special classes also covered by existing standards such as mobile home furnaces or small furnaces $(<45,000 \mathrm{Btu} / \mathrm{h})$

ORNL Oak Ridge National Laboratory

NFPA National Fire Protection Association

PVC Polyvinyl chloride

SRC Sustainable Resources Center

B Vent Metal vent of double-wall construction with the inner wall typically being aluminum and the outer being galvanized steel; commonly used with Category I appliances 



\section{ACKNOWLEDGMENTS}

The authors wish to acknowledge the US Department of Energy's (DOE's) Building Technologies Program, which funded this field demonstration.

The authors are especially grateful to the four community action agencies who participated in this field demonstration by identifying households, gaining homeowner participation, helping to install instrumentation, installing the new furnaces and venting systems, and performing intermittent worst-case depressurization venting diagnostic tests. Without their involvement, the field demonstration would not have been possible. The agencies and their project leads were as follows:

- $\quad$ Energy Resource Center, Colorado Springs, CO - Ken Hall

- Energy Coordinating Agency of Philadelphia, Philadelphia, PA - Steve Luxton and Chuck Graves

- Community Action Agency, St. Louis County, St. Louis, MO - George Robnett, James Trout, and Tim Huber

- Sustainable Resources Center, Minneapolis, MN - Dan Roberts and Celest Roth

The authors would also like to acknowledge the following DuraVent staff, representatives, and distributors who answered questions, expedited orders, coordinated field assistance, and/or visited homes during the installation process to provide insight and assistance: Eric Dufour, Matt Bertler, Todd Lampey, Brian Barclay, Howard Berman, Mark Emory (East Coast Metals), Mike Carmosino (Kasco Sales), Jon Schroeder (Schroeder Sales Company), Lenny Gephart (Schroeder Sales Company), Colin Fein (Associated Marketing), and Jack Barry (Hercules Industries). 



\section{EXECUTIVE SUMMARY}

With an estimated annual primary energy use of 3.89 quadrillion BTU in 2019, natural gas and propane consumption for residential space-heating represents a large opportunity for energy savings potential. Replacing non-condensing furnaces with condensing furnaces can achieve a $10 \%$ or more reduction in the use of natural gas and propane, but the furnaces have different venting requirements that can complicate the replacement. When a non-condensing furnace that shares a common combustion exhaust vent with a natural-draft water heater is replaced with a condensing furnace in an existing home, the condensing furnace is typically installed with its own new vent system that vents through a side wall while the natural-draft water heater remains vented using the existing vertical flue or chimney. However, side-wall venting is not always possible, especially in an existing home. When side-wall venting is not feasible in a home, a condensing furnace must be vented vertically through the roof separately from the vertical vent used to vent a natural-draft water heater also installed in the home. In an existing home, a second vertical chase may not be able to be created, either based on structural or economic criteria. The purpose of this study was to determine if a technically viable and more economic option exists for these homes that require unique venting solutions.

A field demonstration was performed to evaluate the venting performance of the FasNSeal 80/90 venting system developed by M\&G DuraVent - a new system that uses a unique pipe-within-a-pipe design to vent a condensing furnace and a natural draft water heater. The field demonstration also included assessing the installation process, identifying design improvements, and determining installation time and costs.

The FasNSeal 80/90 venting system can enable a condensing furnace to be installed in homes in which it could not otherwise be installed due venting constraints. Designed primarily for existing homes in which a non-condensing furnace and natural draft water heater are vented through a common B Vent (a metal vent of double-wall construction commonly used with such appliances), the FasNSeal 80/90 venting system allows both a replacement condensing furnace and the existing water heater to be vented in the same space occupied by the existing B Vent. A flexible, stainless-steel inner liner inserted down the existing B Vent is used to vent the condensing furnace, while the annular space between the inner liner and the B Vent is used to vent the water heater.

The field demonstration of the FasNSeal 80/90 venting system was performed in 16 houses located in four cities (four houses per city): Colorado Springs, CO; Philadelphia, PA; Minneapolis, MN; and St. Louis, MO. The houses included a mix of heights (one and two story), foundations (basement, crawlspace, and slab), and furnace and water heater locations (conditioned space or non-conditioned space).

Local community action agencies located in each city assisted in implementing the field demonstration. The demonstration began in November 2015 and continued until September 2017. New condensing gas furnaces were installed in the 16 homes using the FasNSeal 80/90 venting system at different times during the field demonstration: March 2016 for the homes in Colorado Springs and Philadelphia, January 2017 for the homes in Minneapolis, and August 2017 for the homes in St. Louis. The performance of the venting systems was monitored both before and after retrofit in each house using periodic worst-case depressurization venting diagnostic tests and continuous monitoring equipment.

Barring any mechanical failures, a condensing furnace will always vent properly through the stainlesssteel inner pipe of the FasNSeal 80/90 venting system because it is connected directly to the condensing furnace and extends directly to the outdoors. Therefore, the performance evaluation of the FasNSeal 
80/90 venting system focused on when and for how long spillage occurred at the draft hood of the water heater in each home when the FasNSeal system was installed compared with the original venting system. Spillage (also commonly referred to as backdrafting) occurs when flue gases enter a home rather than being captured by a draft hood and exhausted through the chimney to the outdoors. The venting of the natural-draft water with the FasNSeal 80/90 venting system is still susceptible to spillage because it relies on hot flue gases rising naturally through the annular space between the pipes to the outdoors due to buoyancy. As with any venting system, spillage can occur with the FasNSeal system at startup for the short period of time required to establish the draft up the flue or chimney or after the draft has been established. This can occur for various reasons, including low or negative temperature differential between the house and the outside, wind, and depressurization within the house. Spillage can also occur due to the FasNSeal 80/90 design if the annular space between the inner liner and B Vent is not big enough to establish or maintain draft or if flow through the annular space is restricted by the inner pipe.

The field demonstration found that the FasNSeal 80/90 venting system successfully vented the naturaldraft water heater in each of the 16 demonstration homes following the replacement of the noncondensing furnace with a condensing unit as outlined below:

- Worst-case depressurization venting tests performed per the ANSI/BPI-1200-S-2015 Standard immediately after the installation of the condensing furnace in each house and several additional times during each house's post-retrofit monitoring period measured no spillage times at the water heater that exceeded the 2 minute (120 second) spillage limit for a water heater except for one measurement in one house. Three other measurements in this one house were less than the 120 second spillage limit. For comparison, two measurements taken on the existing water heaters before the condensing furnaces and FasNSeal 80/90 venting systems were installed exceeded the 120 second spillage limit.

- Instrumentation that continuously monitored the venting performance of each water heater measured water heater spillage cycles that exceeded 120 seconds in four houses following the installation of the FasNSeal 80/90 venting system. However, only one or two such cycles were measured in two of these houses, and just seven such cycles were measured in a third house over a year-long post-retrofit monitoring period. A leak in the return side of the furnace/air-conditioner air distribution system introduced when the condensing furnace was installed likely caused the spillage events measured in the fourth house. For comparison, one spillage cycle that exceeded 120 seconds was measured in three houses before retrofit, and 40 such cycles were measured in a fourth house during the preretrofit period.

- The frequency of spillage and average spillage time with non-zero spillage were about the same or better before and after retrofit for thirteen houses. For these houses, the average spillage times with non-zero spillage were less than 25 seconds before and after retrofit $(75$ seconds for one house before retrofit). The fractions of water heater cycles with spillage were generally less than 0.1 before and after retrofit, although they were 0.2 for one house and greater than 0.5 in three houses (although for these three houses the average spillage times were extremely short, on the order of 1 second). For these latter three houses, the high frequency of spillage was probably because the outdoor temperature range used for the houses to calculate these values was restricted to higher outdoor temperatures when it is more difficult to establish a draft. In the remaining three houses, anomalous post-retrofit venting performance could be explained by long or short venting runs and a duct leak introduced during the installation of the new condensing furnace.

- The patterns of the fraction of water heater cycles with spillage as a function of outdoor temperature were the same before and after retrofit in all houses except one. The fraction of water heater cycles with spillage was generally less than 0.2 at lower outdoor temperatures and became more frequent at 
higher outdoor temperatures in 11 houses, although the fraction of water heater cycles with spillage was always less than 0.2 in three houses while it was always greater than 0.2 in one house. The average spillage time for water heater cycles with non-zero spillage were generally less than 20 seconds at colder outdoor temperatures for all houses during the pre- and post-retrofit periods except for one house during each period (a different house each period). The spillage times were also usually less than 20 seconds at higher outdoor temperatures except for two houses during the pre-retrofit period and four houses during the post-retrofit period.

- As indicated above, the field demonstration found that the venting performance of the FasNSeal $80 / 90$ venting systems was generally comparable with the performance of the venting systems initially installed in the houses. Stated another way, minor spillage events, such as those described above for the FasNSeal 80/90 venting system, do not necessarily indicate unacceptable performance because comparable venting performance was observed before the FasNSeal 80/90 venting systems were installed, although not always in the same houses.

The venting field demonstration was also performed to determine installation times and costs associated with the FasNSeal 80/90 venting system, assess the installation process, and identify design improvements. Installation times were estimated to be 2-2.5 hours for a two-person crew, although agencies felt that this time could be reduced as crews gain experience with the new system. Material costs associated with the FasNSeal $80 / 90$ venting system were estimated to be about $\$ 678$, or about $\$ 200$ to $\$ 575$ more than the material costs estimated for more conventional venting systems.

The field demonstration found that the installation is best performed by a two-person crew, especially when the flexible inner liner is inserted into the existing B Vent. The field demonstration also found that crews had some difficulty in understanding the complete set of materials needed to install the FasNSeal venting system and that there was a short learning curve to becoming proficient in the installation of the system, especially in the use of the PolyPro piping to connect the condensing furnace to the flexible inner liner. Crews used to perform the installations for the field demonstration were not familiar with the availability of the system and felt that crews in general would need considerable exposure to the new system through demonstrations and training to become comfortable with using it.

Several possible design improvements to the FasNSeal 80/90 venting system were identified as the field demonstration was performed. The methods for clamping the flexible inner liner to the vent cap and connecting the PolyPro to the condensing furnace should be further investigated.

Based on these findings, the study concluded the following:

- The design of the FasNSeal 80/90 venting system provides adequate vent performance in the types of houses and climate conditions tested such that a condensing furnace and natural-draft water heater can be properly vented in the same vertical space using its pipe-within-a-pipe configuration (i.e., with the condensing furnace vented through the inner pipe and the natural-draft water heater vented through the annular space between the pipes).

- Trained crews can successfully install the FasNSeal 80/90 venting system, although literature and training materials could be improved.

- Higher cost associated with the FasNSeal 80/90 venting system should not preclude it from being a technically viable option for venting a condensing furnace and a natural-draft water heater. Although costs associated with the purchase and installation of the FasNSeal 80/90 venting system were estimated to be higher compared to a typical side-wall venting installation, they were estimated to be comparable or even less in those applications where side-wall venting installation is difficult, (e.g., if 
the condensing furnace is not adjacent to an exterior wall or the exterior wall is brick) or a second vertical vent would be required. In instances where side-wall venting or installing a second vertical vent are not possible, the FasNSeal venting system may be the only option available.

The following are recommended based on the results of the field demonstration:

- Research on the FasNSeal 80/90 venting system and other similar systems should continue to further establish its performance through increased sample size; investigate its performance in additional climates, especially cooling climates because this climate was not included in the current study and spillage is more likely to occur at higher outdoor temperatures; study the installation and performance of the venting system in homes in which the existing B Vent has bends in it; and compare the venting performance of the FasNSeal 80/90 venting system with alternative venting systems, if any, that could be employed when a non-condensing furnace is replaced by a condensing furnace in an existing home; and provide the additional data needed for model validation as described below.

- A model of the venting system should be developed to extrapolate results to other climates and variations in house and chimney configurations and perform a sensitivity analysis to better understand venting performance and anomalies regarding climate, chimney characteristics, equipment locations within the house, and other factors.

- Changes should be made to the FasNSeal 80/90 venting system literature and system design to make it easier to install and more acceptable to installers and to address the design issues identified during the field demonstration.

- Marketing, trainings, and continued field demonstrations may be needed to better move the product into the market. More training of DuraVent representatives may be needed so they can better assist new installers with ordering and provide installation guidance. 


\section{INTRODUCTION}

\subsection{BACKGROUND}

In 1987, the National Appliance Energy Conservation Act prescribed the first federal minimum energy conservation standard for natural gas and propane furnaces at an annual fuel utilization efficiency of $78 \%$, effective January 1, 1992. Per current minimum efficiency regulations in the Code of Federal Regulations (10 CFR 430.32), non-weatherized residential furnaces using natural gas and propane and manufactured after November 19, 2015 must have an AFUE of 80\%. One of the techno-economic issues highlighted by stakeholders while analyzing potential higher efficiency standards for furnaces is the lack of safe and cost-effective solutions that enable natural gas and propane condensing furnaces and natural-draft combustion water heaters to vent through a common (i.e., same) chimney space. This topic is important because natural gas and propane consumption for residential space heating is estimated at 3.89 quadrillion BTU (quad) of primary energy for 2019 (EIA 2019) and natural gas and propane use can be reduced 10\% or more by using a condensing furnace rather than a non-condensing furnace.

Natural-draft (also termed atmospheric) water heaters, natural-draft furnaces, and fan-assisted, noncondensing furnaces are all Category I appliances. They have high flue gas temperatures that result in high buoyancy forces and negative pressure vent pipes. In both new and existing homes equipped with a natural-draft water heater and a natural-draft or fan-assisted non-condensing furnace, the water heater can be and frequently is commonly vented with the furnace (i.e., they share a common combustion exhaust vent). The single flue or chimney typically rises vertically through the house and terminates above the roofline, and it is a viable and economical venting solution for this combination of Category I appliances.

Condensing furnaces are Category IV appliances and have relatively low flue gas temperatures with high humidity. Moisture in the flue gas readily condenses on the surface of the vent, so it must be corrosion resistant. The lower temperature flue gas also requires the use of a combustion blower to properly vent; therefore, the vent pipe is under positive pressure. A condensing furnace is typically vented out of a side wall of a home with plastic or stainless-steel vent pipe.

The differences between a natural-draft water heater and condensing furnace require the two flue streams to be separated. In new construction, a condensing furnace and a natural-draft water heater would be installed with their own vent systems: the condensing furnace would usually be vented through the side wall and the natural-draft water heater would usually be vented using a flue or chimney that extends vertically out the roof. When a commonly vented non-condensing furnace is replaced with a condensing furnace in an existing home, the condensing furnace is typically installed with its own new vent system that vents through a side wall while the natural-draft water heater remains vented using the existing vertical flue or chimney, although this flue or chimney may need to be resized if it is too large for the single appliance to vent properly. Because the natural-draft water heater is left as the only appliance venting through the existing flue or chimney, it is often referred to as being orphaned.

However, side-wall venting is not always possible, especially in an existing home. Building and gas codes have requirements on the distance between furnace exhaust vents and sidewalks, windows, doors, ventilation intakes, common areas, etc. These requirements sometimes make it difficult or impossible to side-wall vent a condensing furnace. The location of the furnace within the home relative to its exterior walls also sometimes makes side-wall venting difficult; this can be especially true in row houses, townhouses, condominiums, and other homes with a zero lot line. Other reasons that prohibit the use of side-wall venting include aesthetics, prevailing winds that create operation issues, and side-wall plumes 
that create long-term building maintenance issues such as icing, moisture (mold and mildew), and acidic condensate.

When side-wall venting is not feasible in a home, a condensing furnace must be vented vertically through the roof with its own rooftop vent separately from the vertical vent used to vent a natural-draft water heater also installed in the home. A condensing furnace may not be a viable option in such situations if the separate vertical vent cannot be installed or installed economically. It is typically more expensive to vent a condensing furnace vertically than through a side wall. This is especially pertinent in an existing home when an existing, non-condensing furnace is replaced with a condensing furnace. In this case, the existing vertical chase may not be big enough to accommodate a second vent. If a second chase cannot be created, which is often the case, then the condensing furnace cannot be installed. Even if a new vertical chase can be created and concealed within the living space of the home, this is usually a very high cost solution that may make the condensing furnace an uneconomical choice and can result in the loss of habitable space in the home.

M\&G DuraVent introduced the FasNSeal 80/90 venting system in 2015 that enables a condensing furnace and a natural-draft water heater to be vented in the same vertical space using a pipe-within-a-pipe configuration: the condensing furnace is vented through the inner pipe while the natural-draft water heater is vented through the annular space between the pipes. In an existing home where the existing noncondensing furnace is being replaced with a condensing unit, the existing B Vent pipe can be used. B Vent is a metal vent of double-wall construction with the inner wall typically being aluminum and the outer wall being galvanized steel, and commonly used to vent non-condensing furnaces and/or naturaldraft water heaters. The FasNSeal venting system can expand the feasibility and cost-effectiveness of condensing furnaces, especially in existing homes, by enabling installations where the condensing furnace could not otherwise be vented or where it was too expensive to do so. As a result, the energy savings potential and other benefits of condensing furnaces can be realized in more homes.

Barring any mechanical failures, a condensing furnace will always vent properly through the inner pipe because it is connected directly to the furnace and extends directly to the outdoors. However, the venting of the natural-draft water is still susceptible to spillage (also commonly referred to as backdrafting) because it relies on hot flue gases rising naturally through the annular space between the pipes to the outdoors due to buoyancy. Spillage occurs when flue gases enter a home rather than being captured by a draft hood and exhausted through the chimney to the outdoors. As with any venting system, spillage can occur with the FasNSeal system at startup for the short period of time required to establish the draft up the flue or chimney or after the draft has been established. This can occur for various reasons, including low or negative temperature differential between the house and the outside, wind, and depressurization within the house. Spillage can also occur due to the FasNSeal 80/90 design if the annular space between the inner liner and B Vent is not big enough to establish or maintain draft or if flow through the annular space is restricted by the inner pipe. Consequently, the FasNSeal 80/90 venting system was initially tested in a laboratory setting by the Oak Ridge National Laboratory (ORNL). Laboratory test results suggested that the new venting system would provide adequate vent performance in actual installations (Momen, Munk and Hughes 2015).

\subsection{PROJECT OBJECTIVES}

The purpose of this project was to further verify the applicability and performance of the FasNSeal 80/90 venting system by performing a field demonstration using actual houses. This included evaluating the venting performance of the system, particularly of the natural-draft water heater with the FasNSeal 80/90 venting system compared with the current venting system. It also included assessing the installation process, identifying design improvements, and determining installation time and costs. 


\subsection{REPORT ORGANIZATION}

This report documents the design and implementation of the field demonstration, the analyses performed, and the ensuing results. Section 2 provides an overview of the FasNSeal 80/90 venting system, and Sect. 3 presents details on the field test's design and implementation. Section 4 presents a short description of each of the houses used in the field demonstration. Section 5 discusses the results obtained from an analysis of the worst-case depressurization venting diagnostic tests taken periodically throughout the field demonstration and the performance of the venting systems as measured by instrumentation that provided continuous data throughout the field demonstration. Section 6 discusses costs, installation times, design improvements, and other installation-related information on the FasNSeal 80/90 venting systems based on feedback obtained from the installers. Conclusions and recommendations are presented in Sect. 7. 


\section{DURAVENT FASNSEAL 80/90 VENTING SYSTEM}

For an existing home, the DuraVent FasNSeal 80/90 venting system is applicable if the existing chimney venting both the natural-draft water heater and non-condensing furnace is a metal, double-wall B Vent. As depicted in Figure 2.1, the existing Category 1 water heater (i.e., natural-draft) and Category 1 furnace (e.g., natural-draft furnace, fan-assisted non-condensing furnace) are vented vertically through a common flue. The FasNSeal 80/90 venting system involves replacing the existing vent cap with a new one that supports a flexible stainless steel inner liner inserted down the existing B Vent to serve as the flue for the new Category IV condensing furnace. ${ }^{1}$ The annular space between the flexible liner and the wall of the original B Vent serves as the flue for the natural-draft water heater. The two flue streams remain separated and are exhausted individually to the atmosphere. The new vent cap is used to keep the flue gases separate at the vent termination. An animated video is available that demonstrates the installation and operation of the system (http://duravent.com/Product.aspx?hProduct=49).

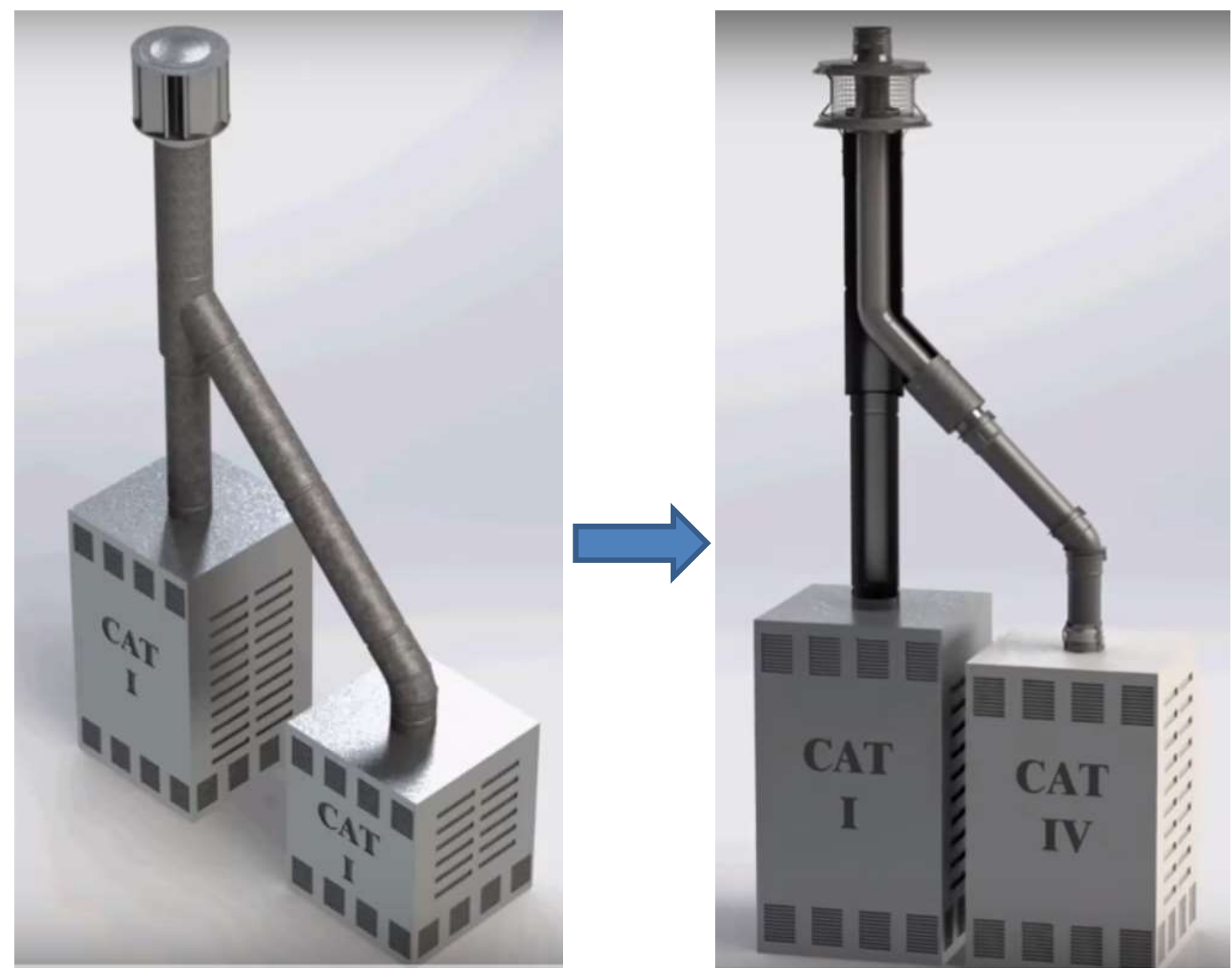

Figure 2.1. DuraVent FasNSeal 80/90 venting system before and after installation diagrams. (M\&G DuraVent 2015)

\footnotetext{
${ }^{1}$ Figure 2.1 shows the stainless steel liner inserted down the existing B Vent and exiting at a $45^{\circ}$ angle to the Category IV condensing furnace. The contractors for the field demonstration found that it was generally easier to exit the B Vent at the bottom and to connect the water heater to the B Vent at a $45^{\circ}$ or $90^{\circ}$ angle.
} 
Ordering catalogs, installation instructions, and other support material for the FasNSeal 80/90 venting system are provided by DuraVent at the above web site under the Literature tab. The more pertinent materials specific to the FasNSeal 80/90 venting system are identified below. DuraVent's general product catalog may also be needed in identifying needed B Vent transition pieces (as discussed in Item \#3 below).

- FasNSeal 80/90 Sales Sheet

- FasNSeal 80/90 Section 2016 (only)

- FasNSeal 80/90 Installation Instructions

A typical installation process is presented below:

1. The flexible stainless steel liner is pre-cut to its approximate length (leaving excess to be trimmed more precisely later) and then inserted down the existing B Vent (see Figure 2.2a). Arrows stamped on the flexible liner (not shown) indicate the correct orientation of the liner (arrows point in the direction of the exhaust flow). DuraVent installation instructions discuss the process for selecting the correct diameter of the liner given the diameter of the existing B Vent to ensure proper venting for both the condensing furnace through the liner and the natural-draft water heater through the annular space.

2. A vent cap is installed to support the flexible liner and keep the water heater and condensing furnace flue gases separate at the vent termination (see Figure 2.2b). The flue gases from the condensing furnace travel through the liner and exit the vent cap at the top (i.e., the termination cap). The water heater flue gases travel between the annular space formed by the liner and the existing B Vent and exit between the two round horizontal plates of the vent cap. A worm-drive hose clamp secures the liner to the termination cap, high-temperature silicone seals the liner to the termination cap, and a screen is installed at the top of the termination cap for bird and rodent protection (these are not shown in Figure 2.2b). As shown in Figure 2.2b, a screen between the two round horizontal plates provides bird and rodent protection for the annual space.

3. As shown in Figure 2.2c, a double-wall wye or tee (a wye is shown) is attached to the end of the existing B Vent, the flexible liner is brought out the bottom of the wye or tee (the water heater flue will be connected to the other opening), and the liner is cut to size if it was not already done so before being inserted down the existing B Vent. The liner could be brought out the wye's $45^{\circ}$ opening, although contractors used in the field demonstration generally found it easier to bring the liner out at the bottom of the wye. If a tee is used, the liner must be brought out the bottom of the tee to ensure that at least a $45^{\circ}$ downward slope is maintained to drain condensate back to the furnace. Although the existing wye or tee could be used, in the field test demonstration houses it was always replaced. In this case, an adaptor may be needed, depending on the brand of existing B Vent and the brand of wye or tee being purchased.

4. An adaptor is attached to the end of the flexible liner to allow connection to polypropylene (PolyPro) pipe (Figure 2.2d). A worm-drive hose clamp is used to secure the liner to the adaptor, and hightemperature silicone is used to seal the connection (not shown).

5. A firestop is attached onto/over the adaptor and then fastened to the wye or tee using provided hardware (Figure 2.2e).

6. The connection of the flexible liner to the condensing furnace is completed using PolyPro pipe run from the adaptor to the furnace's vent connection (Figure 2.2f). PolyPro is a polypropylene vent pipe 
used with condensing furnaces and is an engineered alternative to polyvinyl chloride (PVC) pipe. Locking bands are used at all joint connections. An appliance adapter and an adapter connector are used to connect the PolyPro to the furnace vent connection (not shown; an alternative connection is shown in Figure 2.2f).

7. The water heater vent is connected to the wye or tee using standard venting materials (Figure 2.2f).

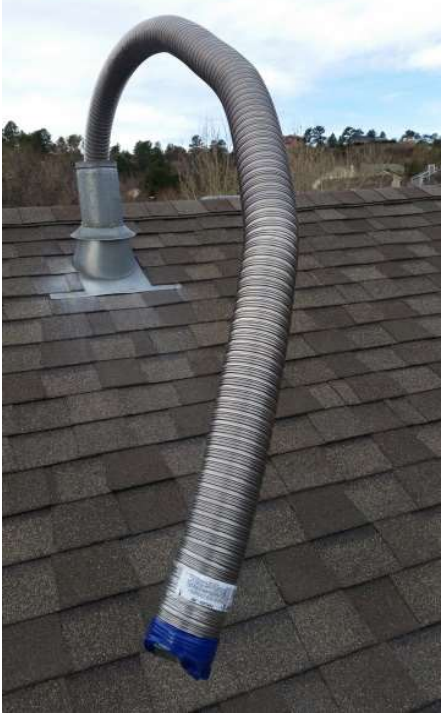

(a)

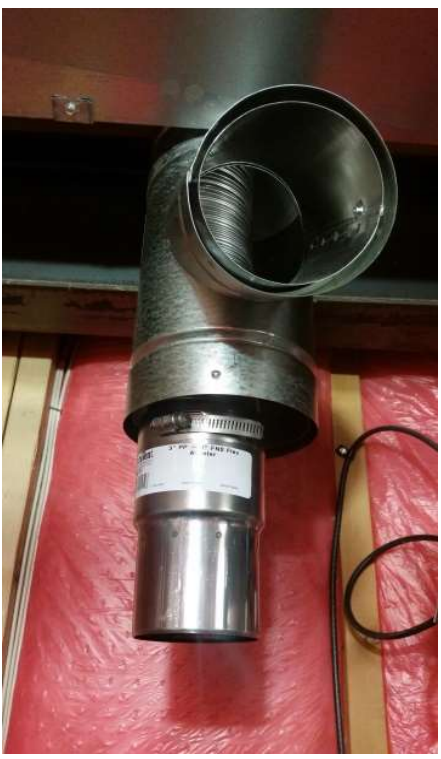

(d)

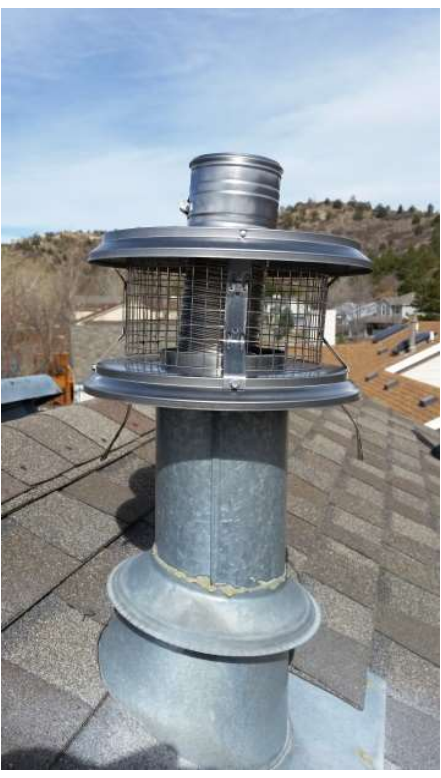

(b)

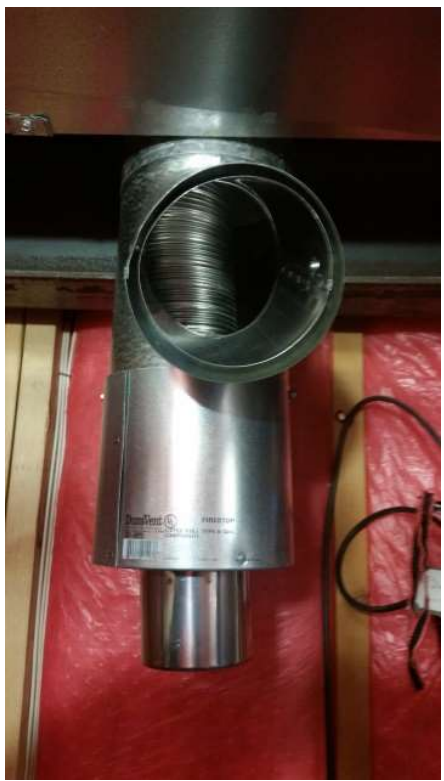

(e)

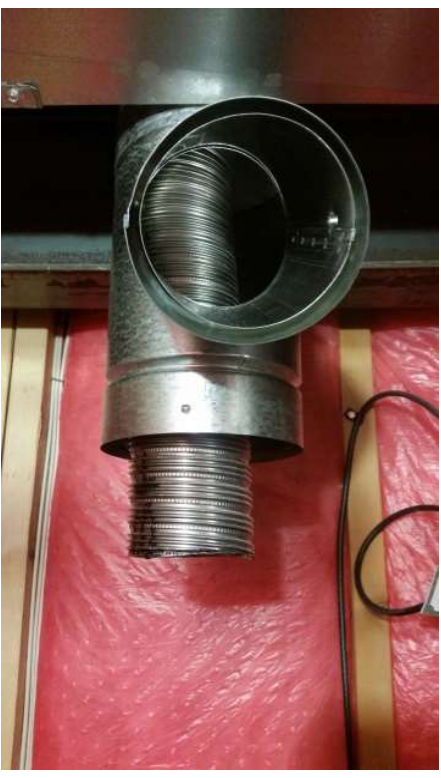

(c)

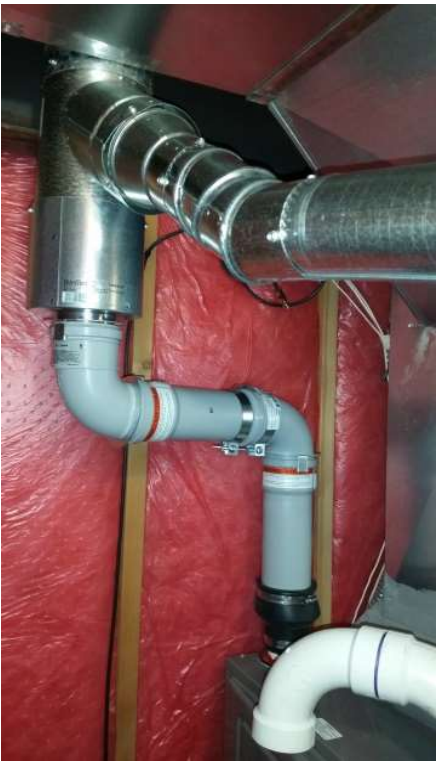

(f)

Figure 2.2. M\&G DuraVent FasNSeal 80/90 venting system installation process. 



\section{FIELD DEMONSTRATION DESIGN AND IMPLEMENTATION}

The field demonstration of the FasNSeal 80/90 venting system was performed in 16 houses located in four cities (four houses per city): Colorado Springs, CO; Philadelphia, PA; Minneapolis, MN; and St. Louis, MO (Figure 3.1). Local community action agencies located in each city assisted in implementing the field demonstration. The demonstration began in November 2015 and continued until September 2017. New condensing gas furnaces were installed in the 16 homes using the FasNSeal 80/90 venting system at different times during the field demonstration: March 2016 for the homes in Colorado Springs and Philadelphia, January 2017 for the homes in Minneapolis, and August 2017 for the homes in St. Louis. The performance of the venting systems was monitored both before and after retrofit in each house using periodic worst-case depressurization venting diagnostic tests and continuous monitoring equipment. Details of the field demonstration design are presented in this section.

\subsection{FIELD DEMONSTRATION DESIGN}

ORNL subcontracted with four local community action agencies that implement the US Department of Energy (DOE) Weatherization Assistance Program to assist in the field demonstration:

- $\quad$ Energy Resource Center (ERC), Colorado Springs, CO

- Energy Coordinating Agency of Philadelphia (ECA), Philadelphia, PA

- Community Action Agency, St. Louis County (CAASTLC), St. Louis, MO

- Sustainable Resources Center (SRC), Minneapolis, MN

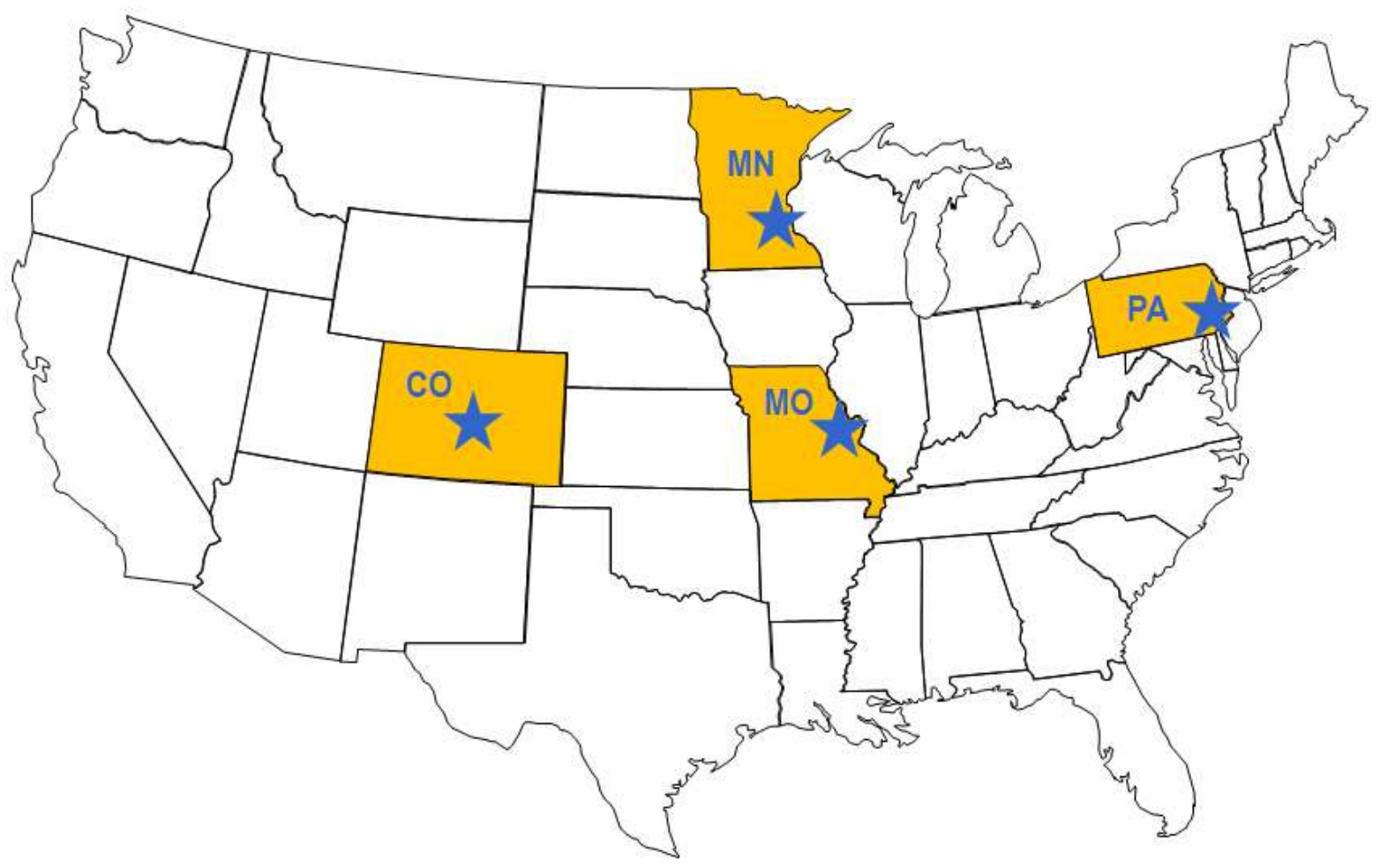

Figure 3.1. Locations of the homes used in the field demonstration. 
These agencies were selected for the demonstration because they

- weatherized the types of houses desired for the field demonstration (e.g., row houses, townhouses, condominiums, or other homes where side-wall venting a condensing furnace can be difficult and/or expensive to perform);

- had established capabilities for identifying homes, contacting and communicating with clients, performing combustion system diagnostics, and installing condensing furnaces;

- represented a diversity of housing types and characteristics;

- represented a diversity of climates and elevations; and

- were interested in participating in the project.

Each agency identified four houses for the demonstration so that a total of 16 homes were included in the demonstration. Selection criteria included the following:

- The occupants were willing to participate in the field demonstration and allow access to their home and were not planning any extended stays away from the house during the monitoring period.

- The house had a non-condensing gas furnace and natural-draft gas water heater vented through a common B Vent that was 5-8 inches in diameter. Boilers and oil-fired furnaces were not included in the demonstration.

- There were no known safety issues with the existing furnace and water heater. If the house had been previously weatherized by the agency, the existing furnace and water heater must have passed all final safety tests performed by the agency.

- The existing furnace and water heater installations were code compliant (especially regarding makeup air requirements because the new condensing furnaces were non-direct vent installations). The existing furnace and water heater were not enclosed in an airtight room or sealed behind solid doors. They had to have adequate airflow for efficient combustion and proper ventilation.

- There were no plans to weatherize the house or install any energy efficiency measures during the demonstration period.

- Preferably, the combustion air supply for the furnace and water heater did not come from laundry rooms or garages (where chemicals in the combustion air supply for the new condensing gas furnace generate higher concentrations of acids in the condensate that can reduce the lifespan of the heat exchangers).

- Preferably, a condensing furnace could not be easily installed in the home because of venting issues. Although this was desired, this was not always the case.

Pictures and a discussion of the houses selected for the field demonstration are provided in Sect. 4. In the end, houses selected represented a mix of desired characteristics:

- Nine houses were single-family detached homes and seven were single-family attached homes (i.e., townhouses, row houses, or duplexes). 
- Eight houses were one story and eight were two stories.

- Eleven homes were initially heated with a fan-assisted furnace and five were heated by natural-draft furnaces.

- The CAZ was a closet in the living area in eleven homes, an open basement in four homes, and an equipment room in a basement in two homes.

Continuous monitoring equipment as described in Sect. 3.2 was installed in each house once all the homes were selected within a city to monitor the performance of the venting systems throughout the demonstration period. The instrumentation was installed by ORNL personnel with assistance from agency staff. The dates that instrumentation was installed in the houses, signifying the start of the pre-retrofit monitoring period, are shown in Table 3.1. Pre-retrofit data were then collected on the existing furnace, water heater, and vent system (i.e., baseline data) in each home until the condensing furnaces were installed using the FasNSeal 80/90 venting system.

Table 3.1. Dates defining the pre- and post-retrofit periods for the houses

\begin{tabular}{|l|c|c|c|}
\hline House location & Instrumentation installed & $\begin{array}{c}\text { Condensing furnaces } \\
\text { installed using the FasNSeal } \\
\text { 80/90 venting system }\end{array}$ & Instrumentation removed \\
\hline Colorado Springs & November $16-19,2015$ & March $14-21,2016$ & March 29,2017 \\
\hline Philadelphia & December $17-18,2015$ & March $16-23,2016$ & March $30-$ April 1,2017 \\
\hline Minneapolis & August $17-18,2016^{a}$ & January $17-20,2017$ & September $22-27,2017^{c}$ \\
\hline St. Louis & December $8-9,2015$ & August $14-17,2017^{b}$ & September $20,2017^{c}$ \\
\hline
\end{tabular}

${ }^{a}$ Minneapolis was chosen as the fourth field demonstration site after it was determined that an agency in another city would not be able to participate in the demonstration, hence the late start in getting instrumentation installed in the four houses in Minneapolis.

${ }^{b}$ Contract complexities delayed the installation of the condensing furnaces in St. Louis.

${ }^{c}$ The field demonstration was extended from March to September 2017 in St. Louis and Minneapolis to provide additional time for post-retrofit data collection, particularly during the summer months.

The dates that the non-condensing furnace and associated venting system in each of the 16 demonstration houses were replaced by a new condensing gas furnace using the FasNSeal 80/90 venting system are shown in Table 3.1. These dates signify the end of the pre-retrofit monitoring period and the start of the post-retrofit monitoring period. This work was performed by staff at two agencies (i.e., agency staff were licensed contractors at two agencies) and by heating contractors hired by the agencies at the other two agencies. The new condensing gas furnaces were all non-direct vent installations (i.e., air adjacent to the condensing furnace was used for combustion). This approach assumed that a dedicated pipe allowing outside air to be drawn directly into the condensing furnace for combustion could not be installed in houses in which a condensing furnace could not be installed because of venting issues (e.g., could not be side-wall vented).

Post-retrofit data were collected on the existing water heater and the newly installed condensing furnace and FasNSeal 80/90 venting system until the instrumentation was removed. The dates that the instrumentation was removed from the field demonstration houses are shown in Table 3.1. Figure 3.2 shows the pre- and post-retrofit monitoring periods for the demonstration houses and how these periods varied among the agencies. 


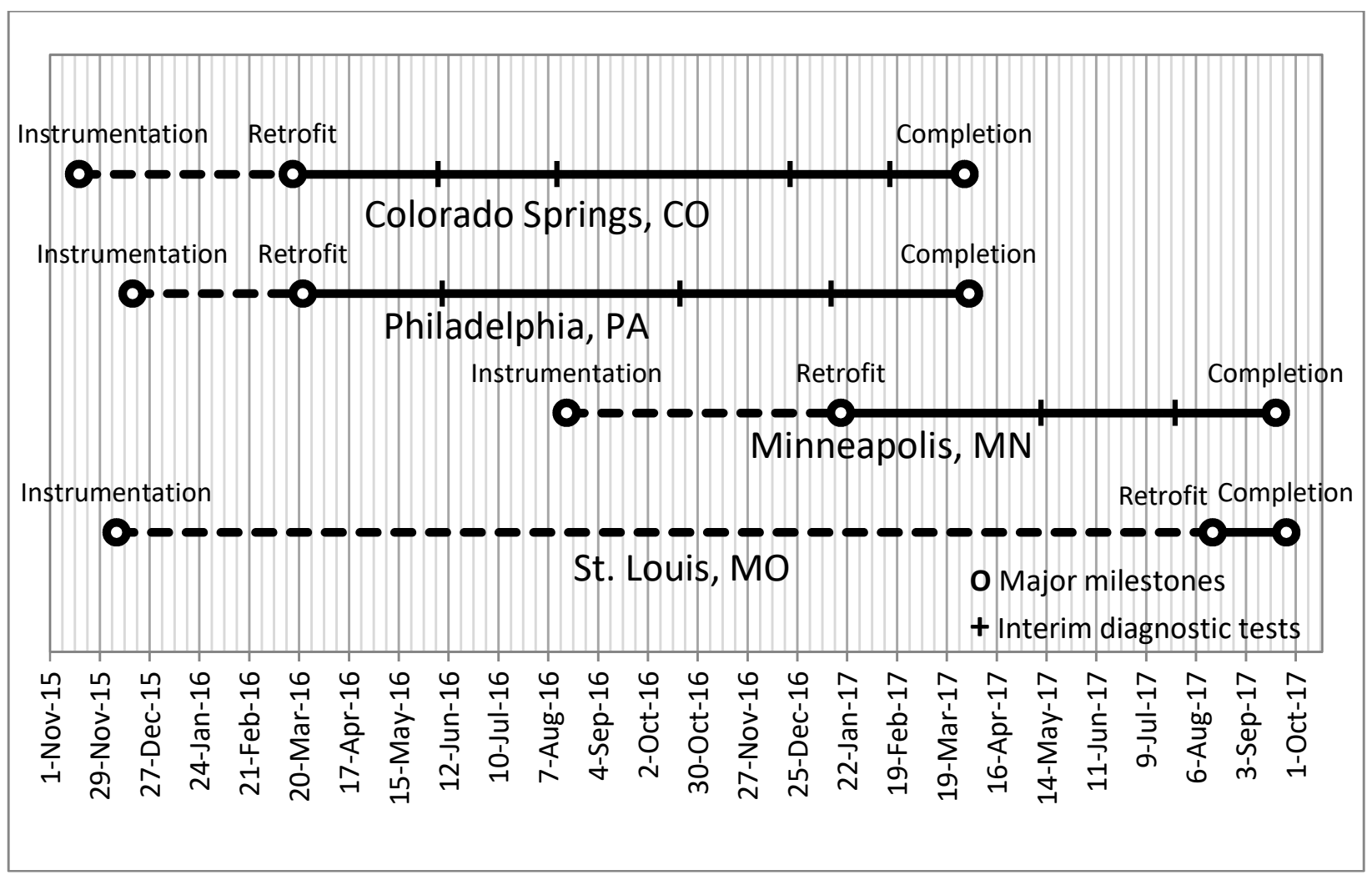

Figure 3.2. Pre- and post-retrofit monitoring periods for the demonstration houses.

A worst-case depressurization venting diagnostic test as outlined in Sect. 3.3 was performed repeatedly in each house, as indicated in Table 3.2 and as shown in Figure 3.2. The test was performed at the time monitoring instrumentation was installed, just before and after the furnaces and venting systems were replaced, and when the instrumentation was removed. The test was also performed periodically at other times during the post-retrofit monitoring period. This diagnostic test was generally performed by agency staff.

Table 3.2. Dates when the worst-case depressurization venting diagnostic test was performed in each house

\begin{tabular}{|l|l|l|}
\hline \multicolumn{1}{|c|}{ House location } & \multicolumn{1}{|c|}{ Pre-retrofit monitoring period } & \multicolumn{1}{c|}{ Post-retrofit monitoring period } \\
\hline Colorado Springs & November 2015 and March 2016 & $\begin{array}{l}\text { March 2016, June 2016, August 2016, } \\
\text { December 2016, February 2017, and March 2017 }\end{array}$ \\
\hline Philadelphia & December 2015 & $\begin{array}{l}\text { March 2016, June 2016, October 2016, } \\
\text { January 2017, and March 2017 }\end{array}$ \\
\hline Minneapolis & August 2016 and January 2017 & $\begin{array}{l}\text { January 2017, May 2017, July 2017, and } \\
\text { September 2017 }\end{array}$ \\
\hline St. Louis & December 2015 and August 2017 & August 2017 and September 2017 \\
\hline
\end{tabular}

\subsection{CONTINUOUS MONITORING}

A data acquisition system was installed in each house to continuously measure the performance of the existing venting system (i.e., the baseline vent system and appliances) and the performance of the newly installed FasNSeal 80/90 venting system. Continuous monitoring provides venting performance data over 
long periods of time that capture how the venting system performs under various conditions that occur throughout the course of a year.

The analysis presented in Sect. 5 focuses on determining and comparing the occurrence and duration of only water heater spillage for the existing (i.e., baseline) venting system and the new FasNSeal 80/90 venting system. Barring any mechanical failures, a condensing furnace will always vent properly through the flexible, stainless-steel inner liner of the FasNSeal 80/90 venting system because it is connected directly to the condensing furnace and extends directly to the outdoors. Therefore, the monitoring equipment was designed to identify when venting was occurring in the water heater and/or furnace, detect the presence of spillage at the water heater draft hood when the water heater was firing (i.e., when the fuel mixture was being burned by the burner, producing heat and combustion by-products), and determine the duration of both normal and spillage venting events.

The operating status of the water heater (i.e., when the water heater was firing) was determined based on the temperature measured by a thermocouple inserted into the outlet of the water heater flue. The start of a water heater firing cycle was indicated by a sharp increase in the water heater flue temperature when the water heater was previously determined to be off, and the end of the water heater cycle was indicated by a sharp decrease in the water heater flue temperature when the water heater was previously determined to be on.

The furnace operating status (i.e., when the furnace was firing) was determined by sensing the presence of current at the furnace's gas valve as measured via a current switch. The furnace was determined to be on when the gas valve was energized and off when the gas valve was de-energized.

The primary method used to detect the presence and duration of spillage at the water heater draft hood was to measure the pressure difference between the water heater vent connector and the combustion appliance zone (CAZ) using a differential pressure transducer. A CAZ is the room or immediate vicinity in which a combustion appliance is installed. This method is referred to as the differential pressure or DP method. The pressure tap into the water heater vent connector was generally made $1-2 \mathrm{ft}$ above the draft hood. This method captured both full and partial spilling. A positive pressure in the vent connector relative to the CAZ when the water heater was firing indicated full spillage of flue gases into the CAZ. A negative pressure in the vent connector relative to the CAZ when the water heater was firing that was greater than a set pressure/spillage limit indicated partial spillage of flue gases into the CAZ. Proper venting (i.e., airflow from the CAZ into the water heater draft hood) was indicated by a negative pressure in the vent connector relative to the CAZ when the water heater was firing that was less than the set pressure/spillage limit. The pressure/spillage limit reflects the pressure required for drafting all the water heater flue gas and was unique to each house because of variations in sensor placement, vent configuration, and other factors. The limit was determined by examining the monitored data for the house and adjusting it based on comparisons with the second and third detection methods described below.

A second method used to detect the presence and duration of spillage was to measure the difference between the ambient temperature surrounding the water heater (i.e., the temperature of the CAZ) and the dilution air temperature surrounding the draft hood of the water heater. This method is referred to as the differential temperature or DT method. The dilution air temperature was monitored by averaging the temperatures from four thermocouples equally spaced around the circumference of the water heater draft hood (Figure 3.3), while the CAZ temperature was monitored using a fifth thermocouple. In general, the dilution air temperature is very close to that of the ambient air under normal draft conditions and much greater than the ambient air temperature when spillage occurs because of the hot flue gases passing the outer perimeter of the draft hood. A sharp increase in the temperature differential between the dilution and ambient air when the water heater was on indicated the start of spillage of flue gases into the CAZ. A 
sharp decrease in this temperature differential when the water heater was on indicated the end of the spillage event.

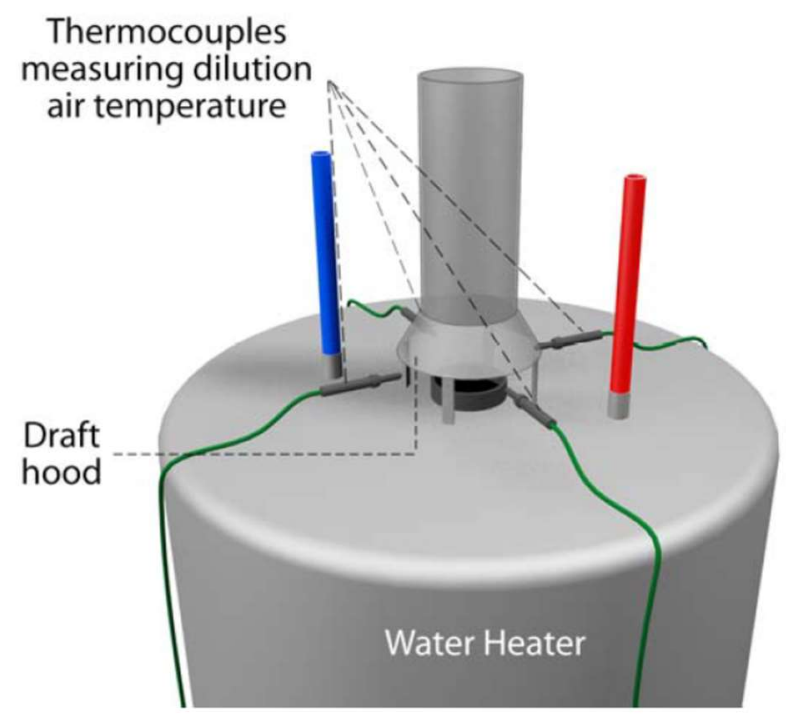

Figure 3.3. Thermocouple array to measure the dilution air temperature surrounding the water heater draft hood.

A third method used to detect the presence of spillage but not its duration was to measure the carbon dioxide $\left(\mathrm{CO}_{2}\right)$ level both in the $\mathrm{CAZ}$ and above the water heater draft hood using $\mathrm{CO}_{2}$ sensors. The $\mathrm{CO}_{2}$ sensor located above the water heater draft hood was installed about $1-2 \mathrm{ft}$ from the draft hood and was close enough to the draft hood for accurate detection of spillage, even if spillage occurred unevenly around the draft hood. During spillage, the $\mathrm{CO}_{2}$ sensor located above the water heater draft hood detected increased $\mathrm{CO}_{2}$ levels relative to the $\mathrm{CAZ}$ sensor due to the presence of flue gas. A sharp increase in the $\mathrm{CO}_{2}$ level above the water heater draft hood relative to the $\mathrm{CAZ}$ indicated the start of spillage.

In addition to the measurements described above, the following measurements were also made:

- The outdoor air temperature was monitored using a thermocouple. This allowed the venting performance to be analyzed as a function of outdoor air temperature.

- The pressure difference between the CAZ and the outdoors was measured using a differential pressure transducer to allow the CAZ depressurization level to be monitored. This allowed the CAZ depressurization levels that occurred when a non-condensing furnace was installed to be compared with that when a condensing furnace was installed. In addition, spillage events or spillage duration can be plotted against CAZ depressurization levels to determine if there is a direct correlation.

- Carbon monoxide (CO) was measured in the $\mathrm{CAZ}$ using a $\mathrm{CO}$ sensor to determine if any significant levels of $\mathrm{CO}$ were reached if appliance spilling occurred.

All measurements were collected at a 1 second interval to ensure proper resolution for identifying even brief spillage events. The major components of the data acquisition system were the data logger, a cellular modem for transmitting data, and the individual sensors. An enclosure was used to house the data logger and modem; it was mounted near the combustion appliances or placed on the floor. Wiring from the enclosure connected the sensors to the data logger. Table 3.3 provides the specifications for the sensors used to make the measurements previously described. 
Table 3.3. Instrumentation and data acquisition system specifications

\begin{tabular}{|l|l|}
\hline \multicolumn{1}{|c|}{ Measurement/Task } & \multicolumn{1}{c|}{ Model } \\
\hline Data acquisition system & Campbell Scientific CR1000 \\
\hline Data acquisition system communication & RAVENXTV Cellular Modem \\
\hline $\begin{array}{l}\text { CAZ (i.e., ambient) temperature and outdoor air } \\
\text { temperature }\end{array}$ & Type T thermocouples \\
\hline $\begin{array}{l}\text { Dilution air temperature and water heater flue outlet } \\
\text { temperature }\end{array}$ & Type K thermocouples \\
\hline CO & Dwyer CMT200 range: $0-200 \mathrm{ppm}$ \\
\hline Carbon dioxide & Dwyer CDT-2N40 range $0-2000 \mathrm{ppm}$ \\
\hline $\begin{array}{l}\text { Pressure differential between the water heater vent } \\
\text { connector and the CAZ }\end{array}$ & Setra 265 range: \pm 0.1 in. w.c. $( \pm 25 \mathrm{~Pa})$ \\
\hline Pressure differential between the CAZ and the outdoors & Setra 264 range: \pm 0.05 in. w.c. $( \pm 12.5 \mathrm{~Pa})$ \\
\hline Furnace status & Current switch on gas valve \\
\hline
\end{tabular}

A template website was created utilizing software from Campbell Scientific and hosted internally on ORNL's network that captured pertinent information from each site for quality control. Expected operating ranges for all sensors were established, and deviations from these ranges caused an email alert to be sent to the principal investigators. In addition, data were plotted and visually checked each week. This allowed for prompt identification of sensor issues and helped ensure that the data being collected were of the highest quality possible.

\subsection{WORST-CASE DEPRESSURIZATION VENTING DIAGNOSTIC TEST}

Worst-case depressurization venting diagnostic tests have been used routinely for years when evaluating the safety of combustion appliances and their venting systems. Such venting diagnostic tests are shortterm tests that offer a snapshot of venting system performance and are commonly performed by home energy auditors and inspectors as part of their combustion safety protocol. These tests generally place the home under conditions that try to produce the highest level of depressurization relative to the outdoors by operating exhaust fans and air handlers and opening or closing doors. Once worst-case depressurization is achieved, appliances are fired to see if they can establish draft in a prescribed amount of time and flue $\mathrm{CO}$ levels are measured.

A comparison of five worst-case depressurization venting diagnostic tests from different organizations was performed in 2015 at the beginning of the project. This comparison is shown in APPENDIX A. All procedures included the same basic steps for determining the house configuration (e.g., exhaust fans, door positions) that results in the worst-case depressurization of the CAZ, starting the appliances that will be tested, and observing the draft and measuring the $\mathrm{CO}$ content of the flue gas at a set time after the appliance's burner is lit. For this project, the newly proposed Building Performance Institute (BPI) procedure ANSI/BPI-1200-S-2015 (BPI 2015) was followed because it was the latest standard meant to correct deficiencies with earlier standards and required the shortest water heater spillage time.

The worst-case depressurization venting diagnostic test used in the field demonstration is presented in APPENDIX B. The time required to establish a draft was monitored when only the water heater was firing, the water heater and furnace were firing simultaneously, and only the furnace was firing. Instead of only evaluating the draft at a prescribed time, the draft was monitored from the moment the appliance started until the draft was established and the elapsed time to establish a draft after firing was recorded. 
This allowed the time required to establish a draft to be compared with the BPI criterion as would be typically done and the results from tests performed throughout the field demonstration to be compared with one another quantitatively.

As discussed in Sect. 3.1, the worst-case depressurization venting diagnostic test was performed in each house at the time monitoring instrumentation was installed, just before and after the new condensing furnace and venting system were replaced, and when the instrumentation was removed. The test was also performed periodically at other times during the post-retrofit monitoring period, as indicated in Table 3.2. The multiplicity of tests will help capture any variations in the test results that occur due to outdoor weather conditions.

\subsection{SURVEY INFORMATION}

Information pertinent to the field demonstration on the house, existing heating and water heating equipment, and existing venting system were collected in each house at the beginning of the field demonstration, generally at the time the continuous monitoring instrumentation was installed. The data collection form provided in APPENDIX $\mathrm{C}$ was used to collect the information identified below:

\section{House Characteristics}

- House type

- If the house had been previously weatherized

- Blower door reading

- Number of floors

- Conditioned floor area

- House height

- Presence of a basement

- Number of kitchen exhaust fans

- Presence of a clothes dryer, fireplace, whole-house fan, or continuous ventilation

- Safety inspection items

\section{CAZ}

- Location

- Area

- Height

- Area of the fresh air supply opening

- Safety inspection items

\section{Furnace and Water Heater}

- Model number

- Serial number

- Fuel type

- Input and output ratings

- Orientation

- Type of draft

- If it had been previously weatherized

- Safety inspection items 


\section{Chimney}

- Size

- Height in the CAZ

- Height above the roof

- Location

- Vent chase construction

- Vent connector characteristics

- Safety inspection items

Furnace and Water Heater Vent Connectors

- Type

- Rise and run

- Number of 45 and 90 degree elbows

- Outer diameter

- Safety inspection items

The contractors and/or agency staff that installed the FasNSeal 80/90 venting system in each of the homes were asked to provide their feedback on the system following completion of the installations. This feedback was open ended, but the questionnaire provided in APPENDIX D was used to promote and initiate the discussion. Information was sought on the training provided by ORNL on how to install the venting system (Sect. 3.5), ease of installation, installation issues, time required to install the venting system, time and cost difference between installing the FasNSeal 80/90 venting system and a more conventional side-wall venting approach, and possible future use of the FasNSeal 80/90 venting system.

\subsection{TRAINING AND INSTALLATION ASSISTANCE}

ORNL provided training via a webinar on the use and installation of the FasNSeal 80/90 venting system to each of the agencies and heating contractors assisting in the implementation of the field demonstration. These trainings were provided before the agencies performed the actual installations:

- The agencies in Colorado Springs and Philadelphia were trained on February 29, 2016.

- The agency in Minnesota and its heating subcontractor were trained on September 2, 2016.

- The agency in St. Louis and its heating subcontractor were trained on January 26, 2017.

The following materials available from DuraVent (http://duravent.com/Product.aspx?hProduct=49) were used in the trainings:

- Installation Video: FasNSeal 80/90

- FasNSeal 80/90 Installation Instructions

- FasNSeal 80/90 Sales Sheet

- FasNSeal 80/90 Frequently Asked Questions (no longer available on the web site)

The training showed the animated video (also mentioned in Sect. 2) that demonstrates the installation and operation of the system. This was reinforced using the installation diagrams of what a typical installation looks like that are included in the sales sheet and, for the two later trainings, pictures such as those shown in Figure 2.2 taken of the venting system being installed in one of the Colorado Springs or Philadelphia homes. The installation instructions were then reviewed. Highlighted was the process outlined in the installation instructions on sizing the vent required for the furnace and water heater and determining the correct combination of B Vent and flexible liner size to meet these sizing requirements. Use of the gas vent sizing tables in the National Fuel Gas Code (NFPA54 2015) in this process was demonstrated during 
the discussion. For the two later trainings, lessons learned from the earlier installations were also highlighted. The sales sheet was then reviewed to point out the materials that would need to be ordered to perform the installations. In the later trainings, DuraVent's general product catalog was also referenced to discuss the ordering of PolyPro materials and B Vent transition pieces that might be needed.

DuraVent representatives participated in the first training and answered questions from the two agencies. DuraVent representatives were on-site at the first house installed at each agency to provide additional oversight and assistance as needed. 


\section{HOUSE CHARACTERISTICS}

A short description of each of the 16 houses participating in the field demonstration is provided in this section. The houses include a mix of heights (one and two story), foundations (basement, crawlspace, and slab), and furnace and water heater locations (conditioned space or non-conditioned space). House CO1 is the house that required the longest vent run because the furnace and water heater were in the basement of the house and the house was two stories.

\subsection{COLORADO SPRINGS HOUSES}

\section{CO1}

This is a two-story, single-family detached house with an open (i.e., no interior partitions or rooms) basement (Figure 4.1). The water heater and original fan-assisted furnace $(100,000 \mathrm{Btu} / \mathrm{h}$ input) were in the open basement. This house required the longest flue run of the 16 houses participating in the field demonstration.

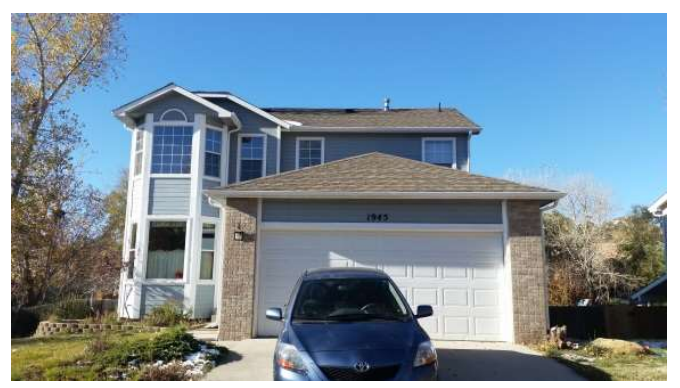

Figure 4.1. House CO1.

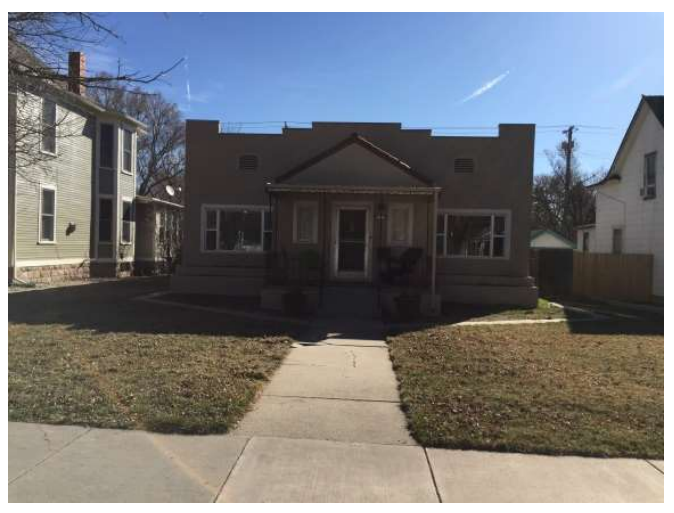

Figure 4.2. House CO2.

\section{$\mathrm{CO} 2$}

This is a one-story, single-family detached house with an open (i.e., no interior partitions or rooms) basement (Figure 4.2). The water heater and original fan-assisted furnace $(100,000 \mathrm{Btu} / \mathrm{h}$ input) were in the open basement.

\section{$\mathrm{CO3}$}

This is a one-story, single-family detached house built on a slab (i.e., no basement) (Figure 4.3). The water heater and original fan-assisted furnace $(56,000 \mathrm{Btu} / \mathrm{h}$ input) were in a small equipment closet inside the home. The equipment closet is about $12 \mathrm{sq}$. $\mathrm{ft}$ and has louvered doors for combustion air.

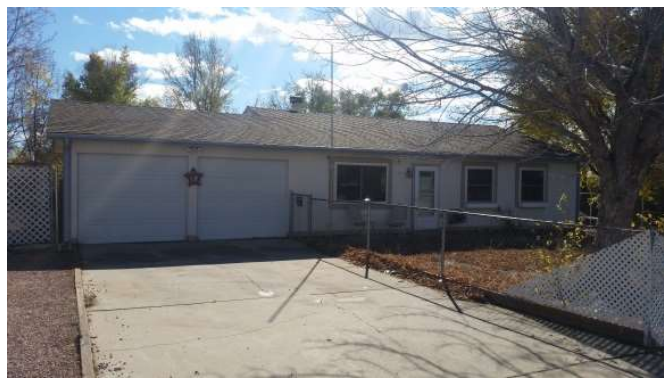

Figure 4.3. House CO3. 


\section{CO4}

This is a two-story, tri-level, single-family detached house (Figure 4.4). All spaces are living areas; there is no basement. The living area on the bottom right is partially below grade and built on a slab. The middle left living area adjacent to the garage is built above a crawl space. The water heater and original fan-assisted furnace $(75,000 \mathrm{Btu} / \mathrm{h}$ input $)$ were in a small equipment closet inside the bottom right living area. The closet is about $15 \mathrm{sq} . \mathrm{ft}$, has a louvered door, but is also open to the crawl space.

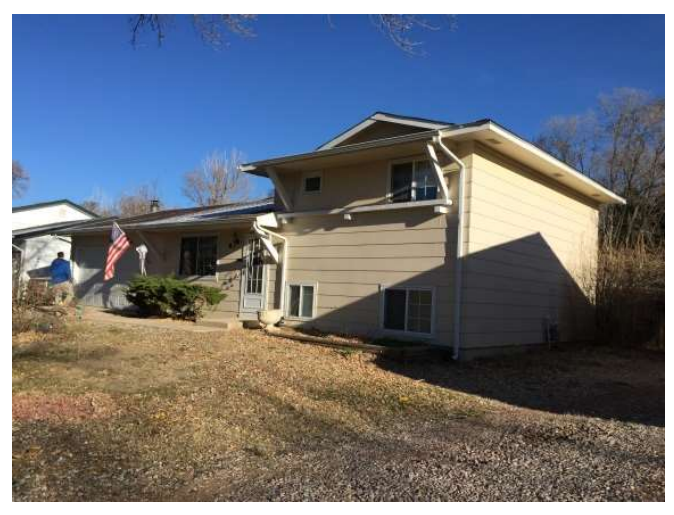

Figure 4.4. House CO4.

\subsection{PHILADELPHIA HOUSES}

\section{PA1}

This is a one-story, single-family detached house built on a crawl space (Figure 4.5). The water heater and original fanassisted furnace $(75,000 \mathrm{Btu} / \mathrm{h}$ input) were in a large laundry/equipment room inside the house. The laundry/equipment room is about $70 \mathrm{sq}$. $\mathrm{ft}$ and has a louvered door for combustion air. A dryer is also present in the laundry/equipment room.

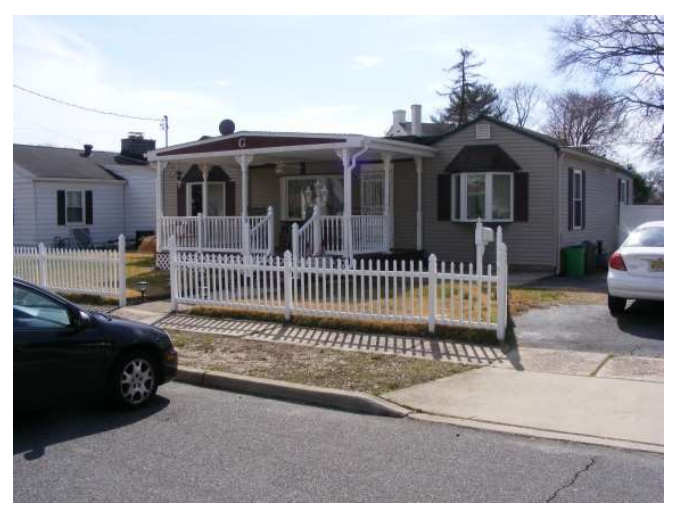

Figure 4.5. House PA1.

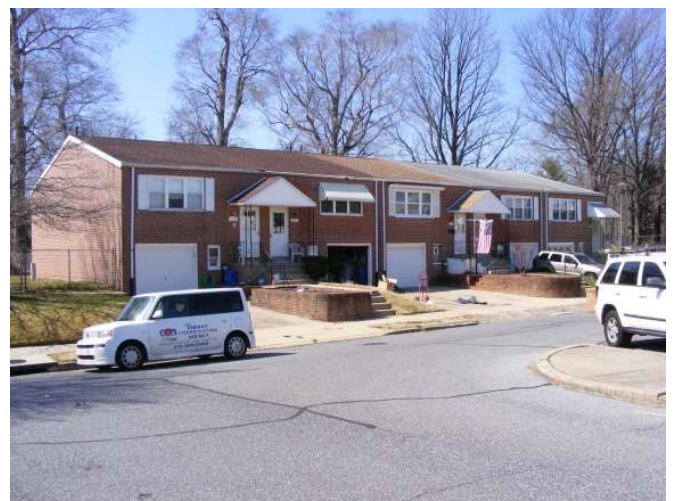

Figure 4.6. House PA2.

\section{PA2}

This is a two-story, single-family attached house (i.e., townhouse) built on a slab (i.e., no basement) (Figure 4.6). Both floors are used as living space, with the lower floor being a recreation room and an office. The unit participating in the field demonstration is the second unit from the left with the open garage door. The water heater and original natural-draft furnace $(65,000 \mathrm{Btu} / \mathrm{h}$ input $)$ were in a small equipment closet inside the home on the lower floor. The equipment closet is about 24 sq. $\mathrm{ft}$ and has louvered doors for combustion air. A dryer is present in a separate laundry room (no door) that is also on the lower floor. There is a door at the top of the stairs connecting the lower and upper floors. 


\section{PA3}

This house closely resembles PA4. This house can perhaps best be described as a two-story, single-family attached house (i.e., row house) with a split-foyer design (Figure 4.7). Upon entering the front door, one may go up a half a flight of stairs to the top floor (three bedrooms and bathroom) or down a half a flight of stairs to the main living area (living room, dining area, and kitchen). The bottom floor, whether best described as a basement or not, is $50 \%$ below grade and $50 \%$ above grade. The water heater and original natural-draft furnace $(55,000 \mathrm{Btu} / \mathrm{h}$ input) were in a small laundry/equipment room on the bottom floor off the kitchen. The laundry/equipment room is about 40 sq. $\mathrm{ft}$ and is

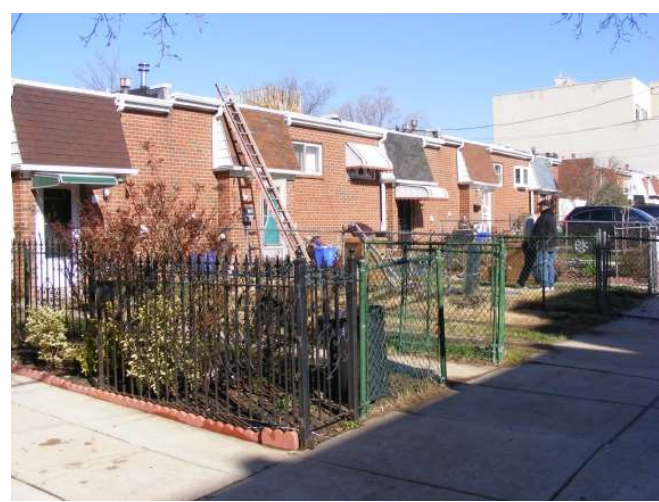

Figure 4.7. House PA3. partially tucked under the stairs leading from the front door to the bottom floor. An approximately 6 in. by 10 in. louvered opening connecting the laundry/equipment room to the main living area on the bottom floor provides combustion air. A dryer is also present in the laundry/equipment room.

\section{PA4}

This house closely resembles PA3. This house can perhaps best be described as a two-story, single-family attached house (i.e., row house) with a split-foyer design (Figure 4.8). Upon entering the front door, one may go up a half a flight of stairs to the top floor (three bedrooms and bathroom) or down a half a flight of stairs to the main living area (living room, dining area, and kitchen). The bottom floor, whether best described as a basement or not, is $50 \%$ below grade and $50 \%$ above grade. The water heater and original natural-draft furnace $(55,000 \mathrm{Btu} / \mathrm{h}$ input) were in a small laundry/equipment room on the bottom floor off the kitchen. The laundry/equipment room is about 20 sq. $\mathrm{ft}$ and has a

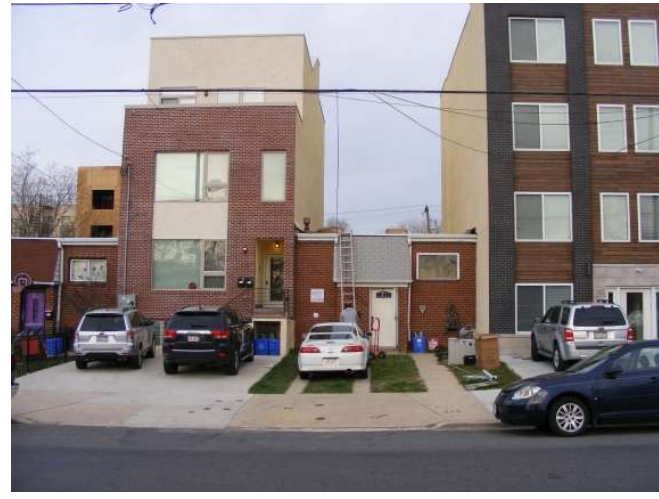

Figure 4.8. House PA4. louvered door for combustion air. A dryer is also present in the laundry/equipment room.

\subsection{MINNEAPOLIS HOUSES}

\section{MN1}

This house closely resembles MN2. This is a one-story, single-family attached house (i.e., townhouse or duplex) with a crawlspace (Figure 4.9). The water heater and original natural-draft furnace $(75,000 \mathrm{Btu} / \mathrm{h}$ input) were in the living space in a 15 sq. $\mathrm{ft}$ closet with folding doors.

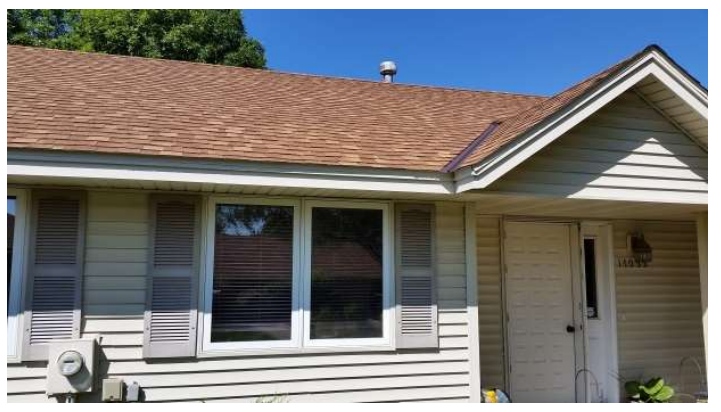

Figure 4.9. House MN1. 


\section{MN2}

This house closely resembles MN1. This is a one-story, singlefamily attached house (i.e., townhouse or duplex) with a crawlspace (Figure 4.10). The water heater and original natural-draft furnace $(75,000 \mathrm{Btu} / \mathrm{h}$ input) were in the living space in a $15 \mathrm{sq}$. $\mathrm{ft}$ closet with folding doors.

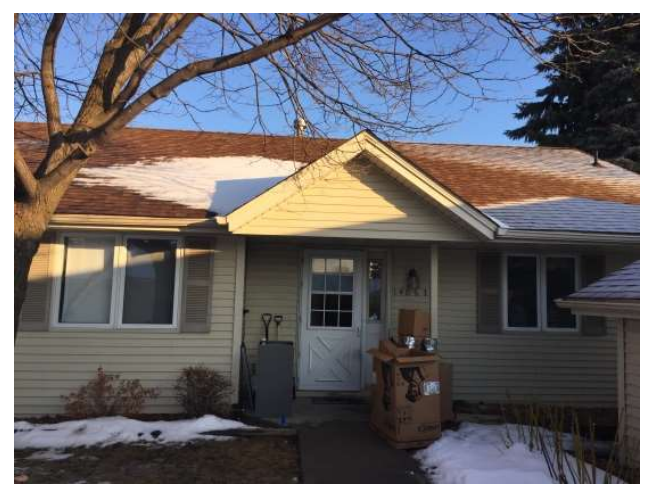

Figure 4.10. House MN2.

\section{MN3}

This house closely resembles MN 4. This is a two-story, single-family attached house (i.e., townhouse or duplex) (Figure 4.11). The water heater and original fan-assisted furnace $(75,000 \mathrm{Btu} / \mathrm{h}$ input) were in a small $(80 \mathrm{sq} . \mathrm{ft})$ equipment room off an open basement. A dryer is also present in the basement.

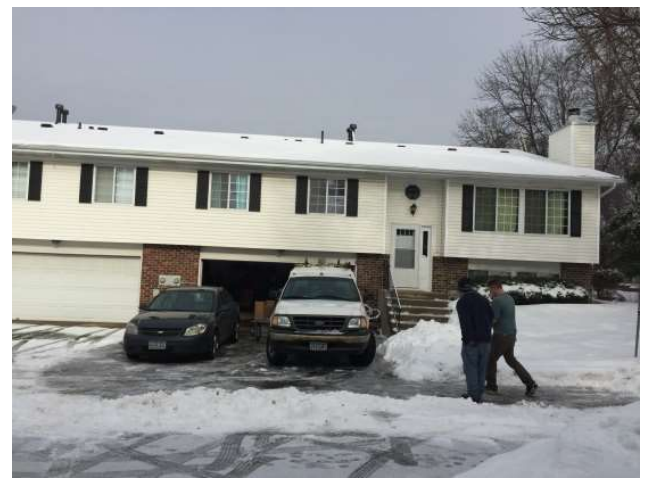

Figure 4.11. House MN3.

\section{MN4}

This house closely resembles MN 3. This is a two-story, single-family attached house (i.e., townhouse or duplex) (Figure 4.12). The water heater and original fan-assisted furnace $(75,000 \mathrm{Btu} / \mathrm{h}$ input) were in a small ( $80 \mathrm{sq} . \mathrm{ft})$ equipment room off an open basement. A dryer is also present in the basement.

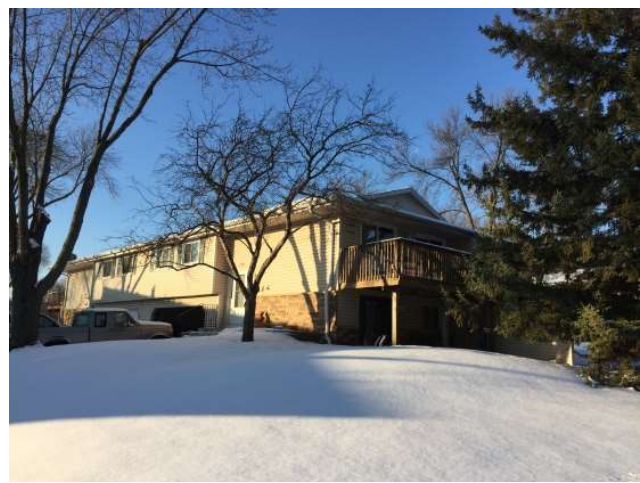

Figure 4.12. House MN4. 


\subsection{ST. LOUIS HOUSES}

\section{MO1}

This is a one-story, single-family detached house with a basement (Figure 4.13). The water heater and original fanassisted furnace $(80,000 \mathrm{Btu} / \mathrm{h}$ input) were in a large laundry/equipment room in the basement. A dryer is also present in the laundry/equipment room. Because the double doors to the laundry/equipment room were removed, the laundry/equipment room is essentially open to the rest of the basement.

\section{MO2}

This is a one-story, single-family detached house with an open (i.e., no interior partitions or rooms) basement (Figure 4.14). The water heater and original fan-assisted furnace $(80,000 \mathrm{Btu} / \mathrm{h}$ input) were in the open basement. A dryer is also present in the open basement.

\section{MO3}

This is a one-and-a-half story, single-family detached house (Figure 4.15). A basement is present beneath the main living area on the right that is conditioned and used as living space. The living area to the left is built above the garage but is not conditioned. The original fan-assisted furnace $(75,000 \mathrm{Btu} / \mathrm{h}$ input) was in a small equipment room in the basement. The water heater is in a separate equipment/storage room adjacent to the furnace equipment room. Because doors are present on both equipment rooms, passive grills were installed at the beginning of the field demonstration into the equipment rooms and above the basement door leading to the equipment rooms to ensure adequate combustion air supply. A dryer is also present in the basement.

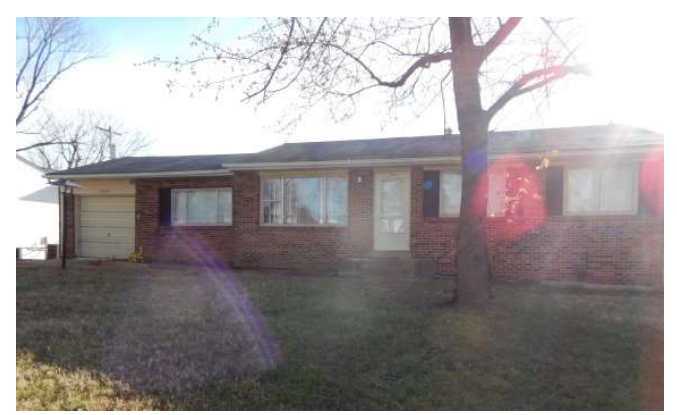

Figure 4.13. House MO1.

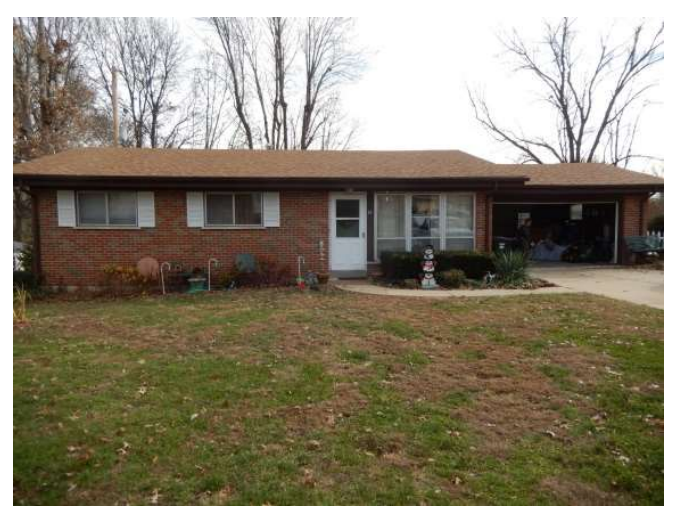

Figure 4.14. House MO2.

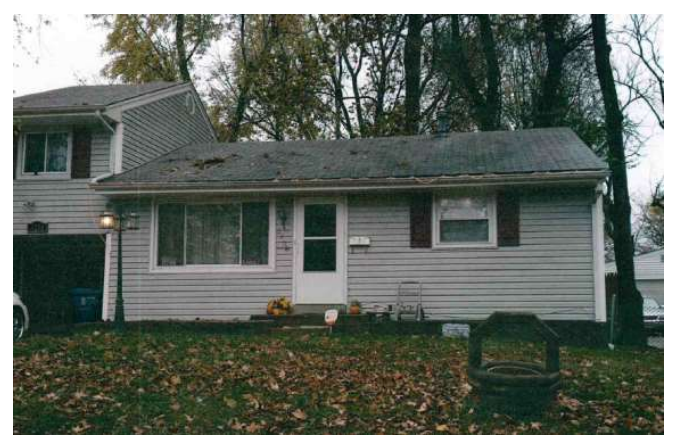

Figure 4.15. House MO3. 


\section{MO4}

This is a one-story, single-family detached house with an open (i.e., no interior partitions or rooms) basement (Figure 4.16). The water heater and original fan-assisted furnace $(80,000 \mathrm{Btu} / \mathrm{h}$ input) were in the open basement.

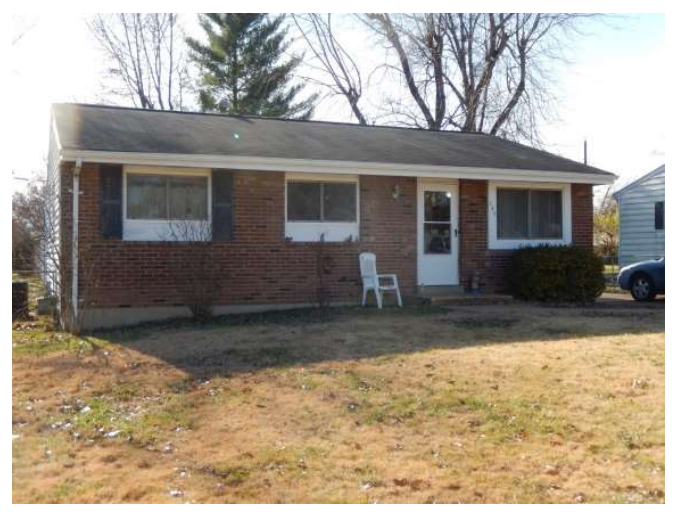

Figure 4.16. House MO4. 


\section{ANALYSES AND RESULTS}

Spillage of a natural-draft water heater occurs when flue gases enter a home rather than being captured by a draft hood and exhausted through the chimney to the outdoors. The venting of a natural-draft water is susceptible to spillage because there is no fan to assist in the venting process; rather, the venting process relies on hot flue gases rising naturally through the venting system to the outdoors due to buoyancy.

Spillage can occur with a conventional venting system at startup for the short period of time required to establish the draft up the flue or chimney or after the draft has been established. This can occur for various reasons, including low or negative temperature differential between the house and the outside, wind, and depressurization within the house.

Barring any mechanical failures, a condensing furnace will always vent properly through the flexible, stainless-steel inner liner of the FasNSeal 80/90 venting system because it is connected directly to the condensing furnace and extends directly to the outdoors. Therefore, the venting performance of the FasNSeal 80/90 venting system essentially depends on its ability to properly vent the water heater through the annular space around the flexible inner liner. The venting of the natural-draft water is susceptible to spillage with the FasNSeal system for the same reasons as for a conventional venting system: there is no fan and the system still relies on hot flue gases rising naturally through the annular space between the inner liner and the B vent pipe to the outdoors due to buoyancy. As with a conventional venting system, spillage can occur with the FasNSeal system at startup or after the draft has been established for the same reasons identified for a conventional system. With the FasNSeal 80/90 system, spillage can also occur due to its design if the annular space between the inner liner and B Vent is not big enough to establish or maintain draft or if flow through the annular space is restricted by the inner pipe.

As a result, the analyses presented in this section are focused on determining and comparing the occurrence and duration of spillage associated with the water heater only before and after the installation of the FasNSeal venting system; spillage associated with the existing non-condensing furnaces is not analyzed. The primary objective of the analysis is to ascertain the performance of the FasNSeal 80/90 venting systems used to vent the existing natural-draft water heaters, which are no longer commonly vented with the furnaces. A secondary objective is to compare the performance of the FasNSeal 80/90 venting systems (i.e., the post-retrofit systems) with the pre-retrofit venting systems originally installed in the homes (i.e., a conventional venting system commonly venting a non-condensing furnace and a natural-draft water heater).

\subsection{PRE- AND POST-RETROFIT WATER HEATER OPERATION}

The pre- and post-retrofit operation of the water heaters is presented in this section. For this, the trend of water heater runtime per day was plotted for each house throughout the monitoring period. Also, the average runtime per day, average number of water heater cycles per day, and average runtime per cycle were calculated for the pre- and post-retrofit periods for each house. This information is provided to provide context for the measured spillage times and percentage of cycles with spillage discussed in the remaining parts of Sect. 5 .

Figure 5.1(a) through (d) show the trend of water heater runtime per day during the monitoring period for each house in the four cities. The water heater runtimes per day were determined from 1 second data of the water heater flue outlet temperature. The lines showing the trends in these figures are 14 day moving averages of water heater runtime per day; 14 day moving averages were used to avoid the high variability 


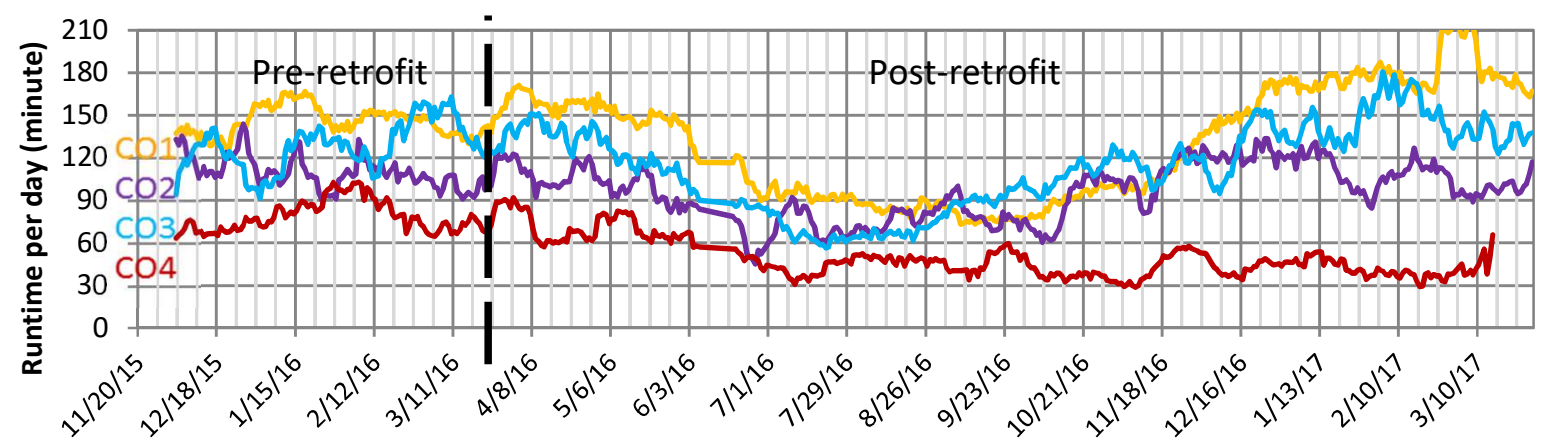

(a) Colorado Spring houses.

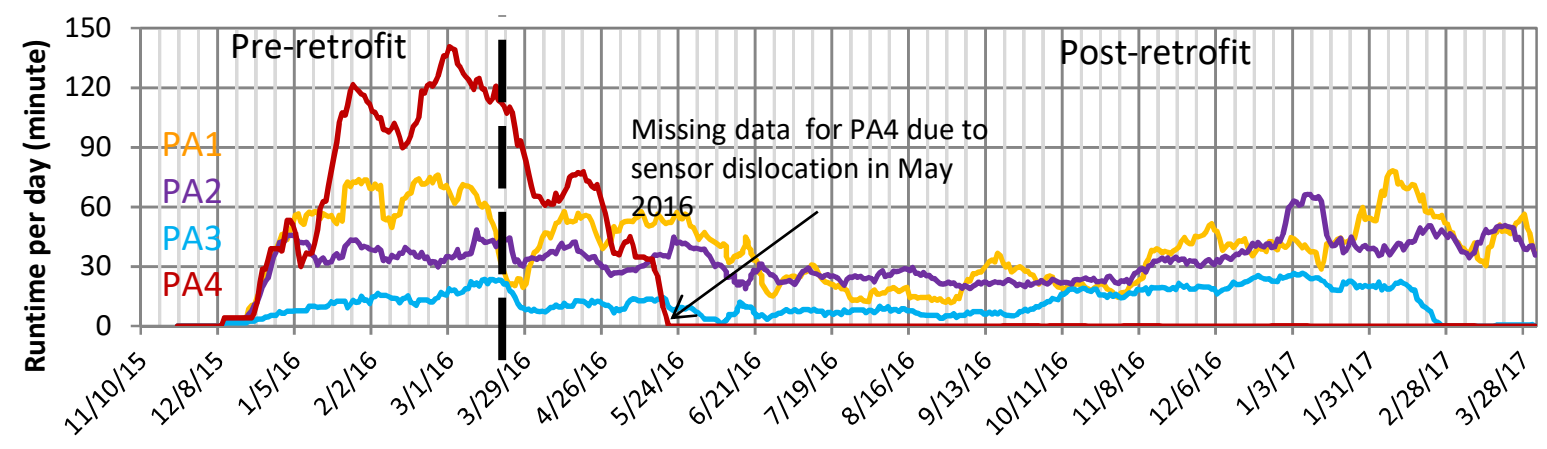

(b) Philadelphia houses.

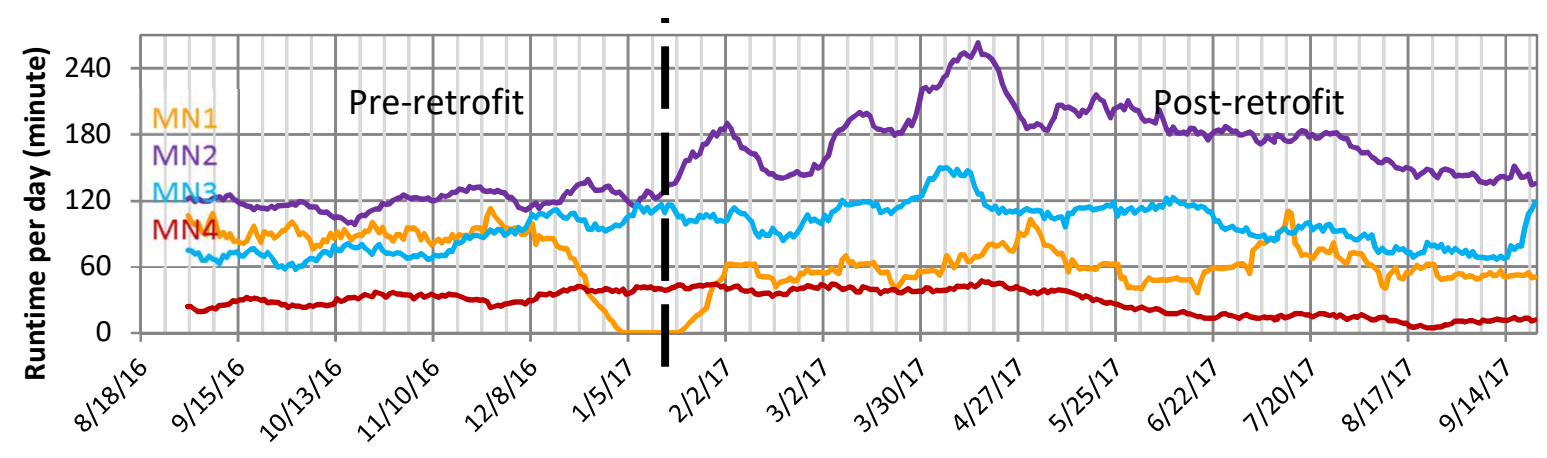

(c) Minneapolis houses.

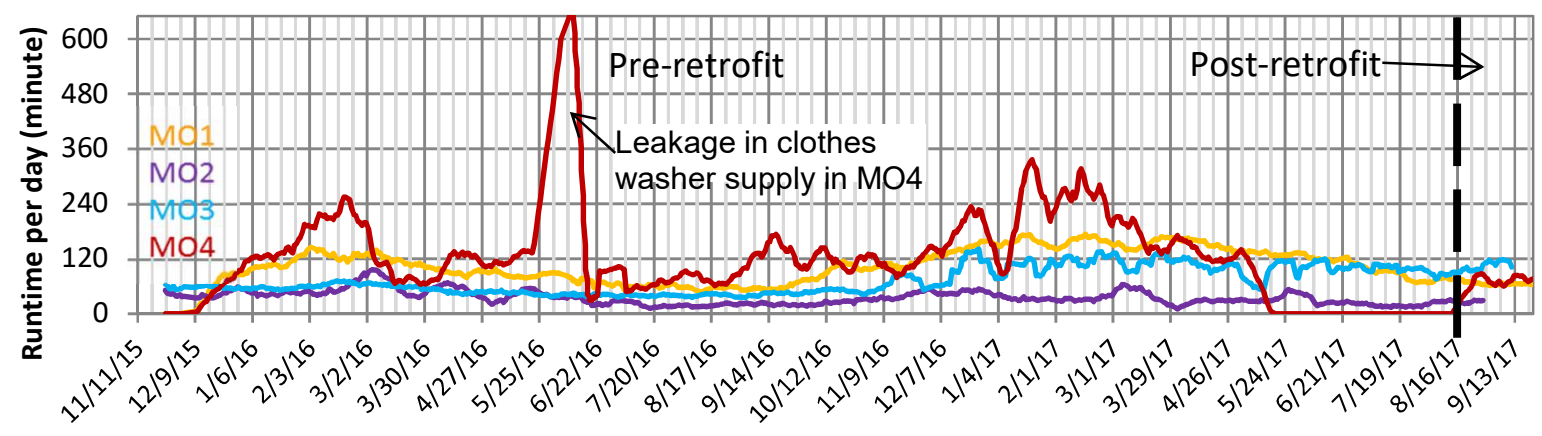

(d) St. Louis houses.

Figure 5.1. Trend of water heater runtime per day during the monitoring period. 


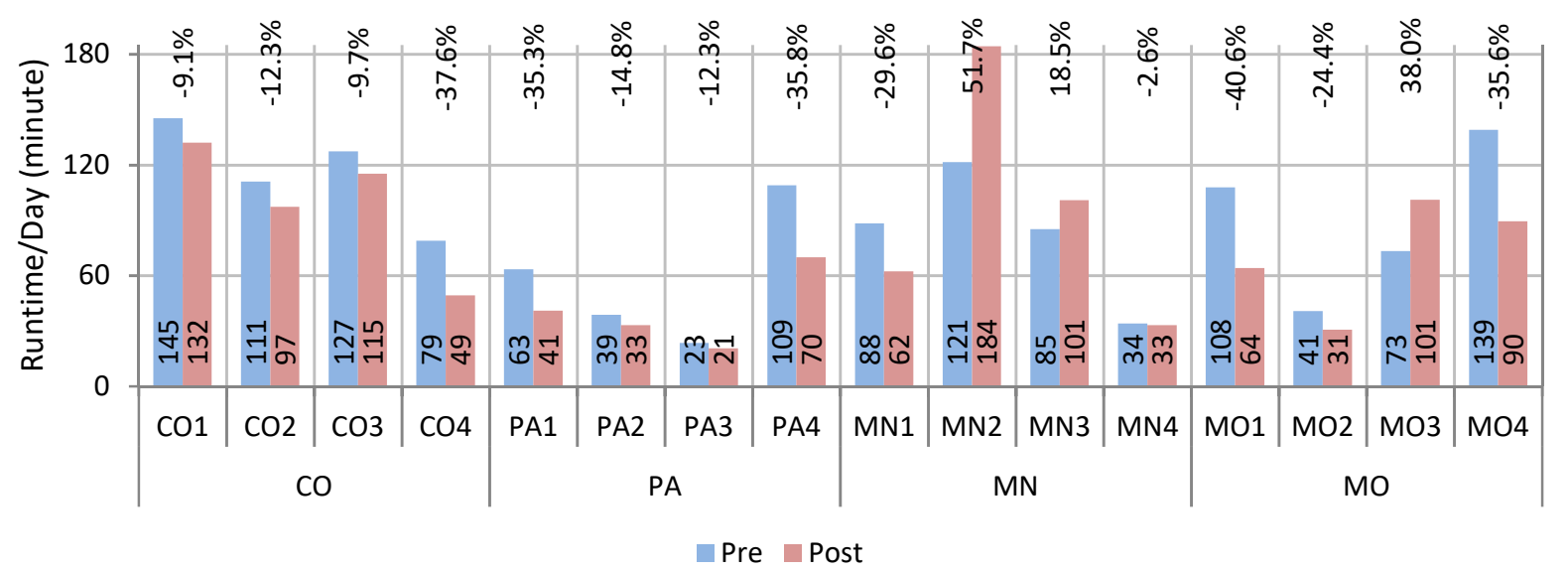

(a) Average runtime per day.

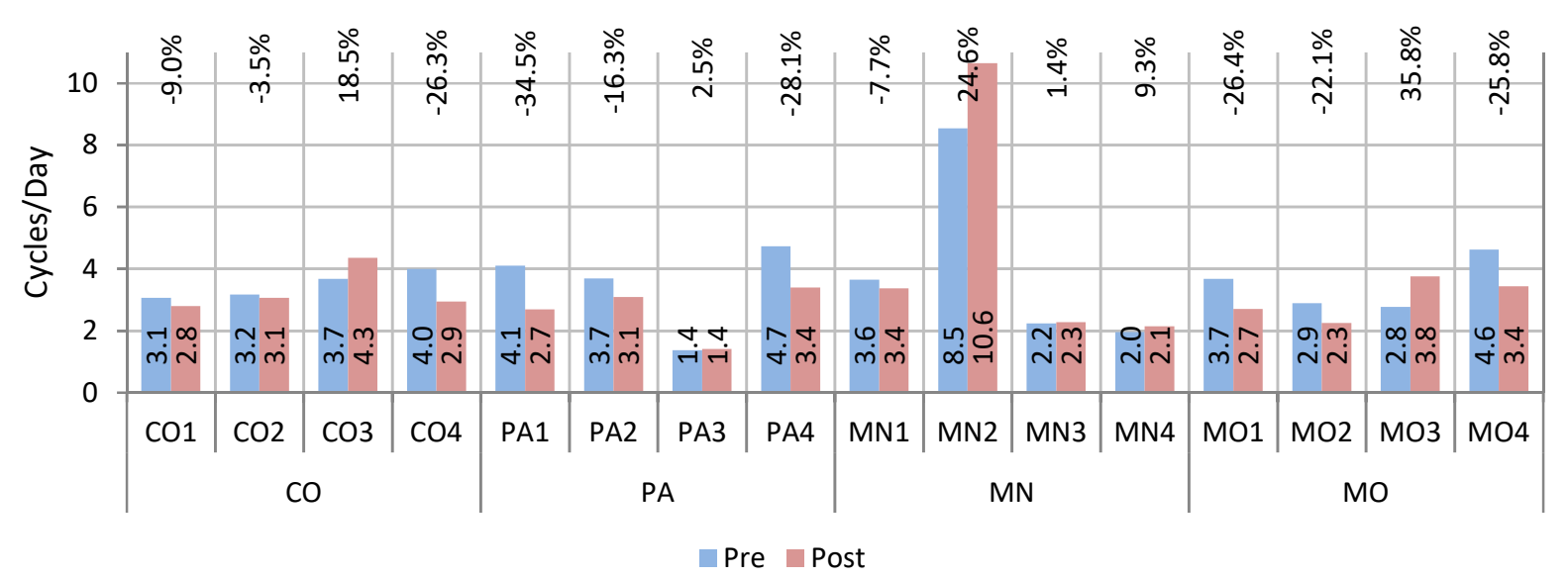

(b) Average number of cycles per day.

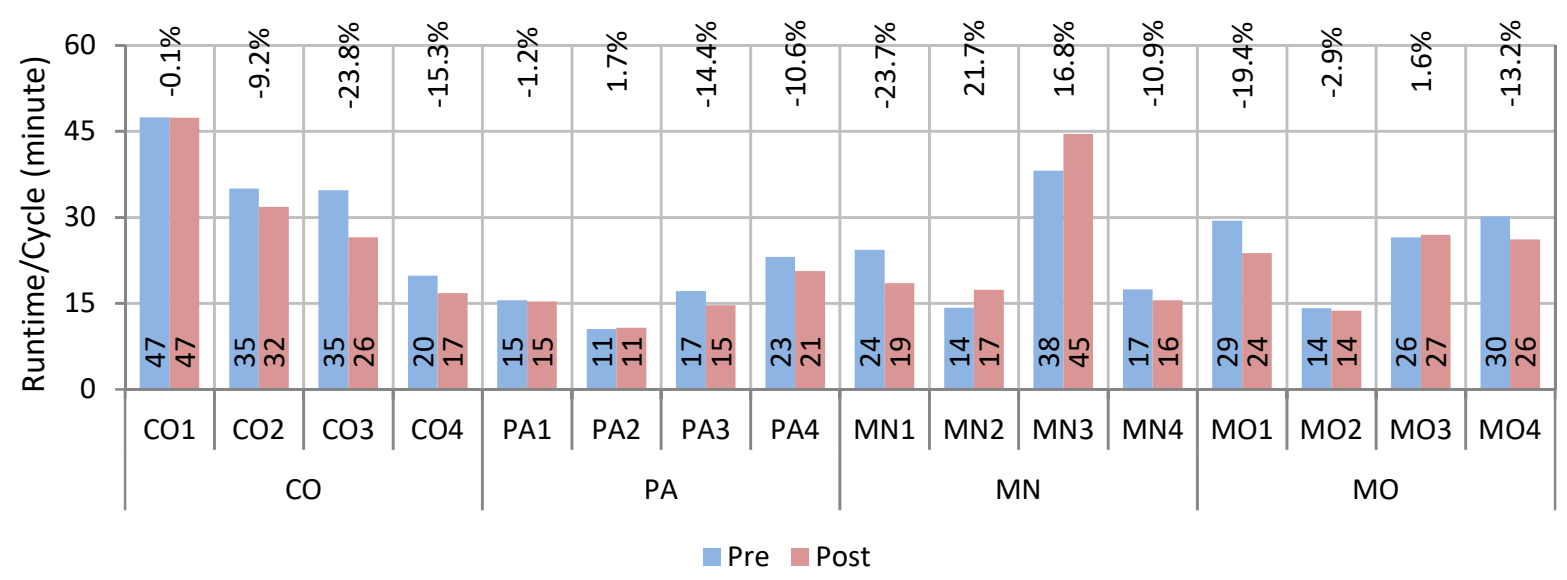

(c) Average runtime per cycle.

Figure 5.2. Comparison of water heater operation during the pre- and post-retrofit periods. 
that would be shown if daily averages were used. The pre- and post-retrofit periods for each city are marked on the figures.

These figures, and especially Figure 5.1(a) and (b) for the Colorado Springs and Philadelphia houses, respectively, show the seasonal fluctuation that can occur in the average daily runtime of water heaters due to seasonal variations in inlet cold water temperature, seasonal variations in water use due to occupant behavior, and other factors. Considering the seasonal variation in runtime, the pre- and postretrofit runtime patterns were similar in most of the houses because the water heaters were not replaced during the monitoring periods (only the furnaces were replaced) and the same occupants lived in the houses. $^{2}$

Figure 5.2(a) through (c) show the average runtime per day, average number of cycles per day, and average runtime per cycle, respectively, for the pre- and post-retrofit periods for each house. The water heater runtime per day and number of water heater cycles per day were determined for each house from 1 second data of the water heater flue outlet temperature and averaged over days when water heater operation was detected. The average runtime per cycle was calculated as the ratio of total runtime and total number of cycles. In all three figures, the two columns for each house represent the pre- and postretrofit periods. The percent change in these averages after retrofit is also indicated on these figures.

Figure 5.2(b) shows that the water heaters fired, on average, 2-5 times per day in all the houses during both the pre- and post-retrofit periods with the exceptions of Houses PA3 and MN2. Figure 5.2(c) shows that the average duration of each firing cycle in both the pre- and post-retrofit periods was commonly about $15-30$ minutes.

\subsection{WORST-CASE DEPRESSURIZATION VENTING DIAGNOSTIC TEST RESULTS}

As discussed in Sect. 3.3, a worst-case depressurization venting diagnostic test was performed in all the houses periodically throughout the monitoring period to measure the time it took to establish a draft after firing when only the water heater was firing, both the water heating and furnace were firing, and only the furnace was firing. The diagnostic test used in the field demonstration is presented in APPENDIX B. These tests were performed at the time monitoring instrumentation was installed, just before and after the new condensing furnaces and venting systems were replaced, and when the instrumentation was removed. Additional tests were performed depending on the length of the post-retrofit monitoring period in each state (Figure 3.2). Dates when the tests were performed varied among the states (Table 3.2).

Staff from the agencies that assisted in the implementation of the field demonstration generally performed the tests. The same person at each agency performed the tests except in the Pennsylvania houses where multiple staff performed the tests.

Results from these diagnostic tests are shown in Table 5.1. The following observations are made:

- Pre-retrofit measurements - Two measurements taken on the existing water heaters before the condensing furnaces and FasNSeal 80/90 venting systems were installed exceeded the BPI 2015 spillage limit of 2 minutes (i.e., 120 seconds). These measurements occurred in Houses MN2 and MO3. The anomalies with these houses are discussed in Sect. 5.5.

\footnotetext{
${ }^{2}$ It was confirmed that the occupancy in House CO4 changed from two to one during the monitoring period.
} 
Table 5.1. Time required to establish a draft after appliance firing (seconds) ${ }^{a, b, c}$

\begin{tabular}{|c|c|c|c|c|c|c|c|c|}
\hline \multirow{3}{*}{ House } & \multicolumn{2}{|c|}{ Pre-retrofit } & \multicolumn{6}{|c|}{ Post-retrofit $^{d}$} \\
\hline & \multirow{2}{*}{$\begin{array}{l}\text { Instrumentation } \\
\text { installation }\end{array}$} & \multirow{2}{*}{$\begin{array}{c}\text { Before } \\
\text { furnace } \\
\text { installation }\end{array}$} & \multirow{2}{*}{$\begin{array}{c}\text { After } \\
\text { furnace } \\
\text { installation }\end{array}$} & \multicolumn{4}{|c|}{ Additional measurements $^{e}$} & \multirow{2}{*}{$\begin{array}{l}\text { Instrumentation } \\
\text { removal }\end{array}$} \\
\hline & & & & 1 & 2 & 3 & 4 & \\
\hline $\mathrm{CO} 1$ & $\begin{array}{c}30 / 26 / 10 \\
28^{\circ} \mathrm{F}\end{array}$ & $\begin{array}{c}20 / 10 / 13 \\
49^{\circ} \mathrm{F}\end{array}$ & $\begin{array}{l}90 / 0 \\
67^{\circ} \mathrm{F} \\
\end{array}$ & $\begin{array}{l}30 / 0 \\
80^{\circ} \mathrm{F}\end{array}$ & $\begin{array}{l}50 / 0 \\
82^{\circ} \mathrm{F}\end{array}$ & $\begin{array}{l}45 / 0 \\
28^{\circ} \mathrm{F}\end{array}$ & $\begin{array}{l}20 / 0 \\
38^{\circ} \mathrm{F}\end{array}$ & $\begin{array}{l}22 / 0 \\
41^{\circ} \mathrm{F}\end{array}$ \\
\hline $\mathrm{CO} 2$ & $\begin{array}{c}36 / 20 / 15 \\
30^{\circ} \mathrm{F} \\
\end{array}$ & $\begin{array}{l}1 / 1 / 8 \\
39^{\circ} \mathrm{F} \\
\end{array}$ & $\begin{array}{c}8 / 0 \\
65^{\circ} \mathrm{F} \\
\end{array}$ & $\begin{array}{c}5 / 0 \\
70^{\circ} \mathrm{F} \\
\end{array}$ & $\begin{array}{c}2 / 0 \\
62^{\circ} \mathrm{F} \\
\end{array}$ & $\begin{array}{c}5 / 0 \\
48^{\circ} \mathrm{F} \\
\end{array}$ & $\begin{array}{c}4 / 3 \\
35^{\circ} \mathrm{F} \\
\end{array}$ & $\begin{array}{c}5 / 0 \\
37^{\circ} \mathrm{F} \\
\end{array}$ \\
\hline $\mathrm{CO} 3$ & $\begin{array}{c}20 / 5 / 5 \\
49^{\circ} \mathrm{F} \\
\end{array}$ & $\begin{array}{c}20 / 1 / 10 \\
32^{\circ} \mathrm{F} \\
\end{array}$ & $\begin{array}{c}5 / 0 \\
49^{\circ} \mathrm{F} \\
\end{array}$ & $\begin{array}{l}5 / 0 \\
68^{\circ} \mathrm{F} \\
\end{array}$ & $\begin{array}{c}5 / 0 \\
55^{\circ} \mathrm{F} \\
\end{array}$ & $\begin{array}{c}3 / 0 \\
42^{\circ} \mathrm{F} \\
\end{array}$ & $\begin{array}{c}0 / 0 \\
33^{\circ} \mathrm{F} \\
\end{array}$ & $\begin{array}{c}2 / 0 \\
54^{\circ} \mathrm{F} \\
\end{array}$ \\
\hline $\mathrm{CO} 4$ & $\begin{array}{c}23 / 15 / 5 \\
49^{\circ} \mathrm{F} \\
\end{array}$ & $\begin{array}{c}10 / 10 / 13 \\
27^{\circ} \mathrm{F} \\
\end{array}$ & $\begin{array}{c}0 / 0 \\
45^{\circ} \mathrm{F} \\
\end{array}$ & $\begin{array}{l}2 / 0 \\
69^{\circ} \mathrm{F} \\
\end{array}$ & $\begin{array}{l}10 / 0 \\
70^{\circ} \mathrm{F} \\
\end{array}$ & $\begin{array}{c}4 / 0 \\
27^{\circ} \mathrm{F}\end{array}$ & $\begin{array}{c}3 / 0 \\
45^{\circ} \mathrm{F} \\
\end{array}$ & $\begin{array}{c}5 / 0 \\
44^{\circ} \mathrm{F} \\
\end{array}$ \\
\hline PA1 & $\begin{array}{c}<30 /<30 /<30 \\
41^{\circ} \mathrm{F}\end{array}$ & $\begin{array}{c}\text { Not } \\
\text { available }\end{array}$ & $\begin{array}{c}<30 / \mathrm{NA} \\
78^{\circ} \mathrm{F}\end{array}$ & $\begin{array}{c}<15 / \mathrm{NA} \\
69^{\circ} \mathrm{F}\end{array}$ & $\begin{array}{c}60 / \mathrm{NA} \\
70^{\circ} \mathrm{F}\end{array}$ & & & $\begin{array}{c}300 / \mathrm{NA} \\
66^{\circ} \mathrm{F}\end{array}$ \\
\hline PA2 & $\begin{array}{c}<30 / 0 /<30 \\
61^{\circ} \mathrm{F} \\
\end{array}$ & $\begin{array}{c}\text { Not } \\
\text { available } f\end{array}$ & $\begin{array}{c}<30 / \mathrm{NA} \\
56^{\circ} \mathrm{F}\end{array}$ & $\begin{array}{c}25 / \mathrm{NA} \\
65^{\circ} \mathrm{F} \\
\end{array}$ & $\begin{array}{c}90 / \mathrm{NA} \\
76^{\circ} \mathrm{F} \\
\end{array}$ & & & Not available ${ }^{g}$ \\
\hline PA3 & $\begin{array}{c}<30 /<30 /<30 \\
44^{\circ} \mathrm{F}\end{array}$ & $\begin{array}{c}\text { Not } \\
\text { available }^{f}\end{array}$ & $\begin{array}{c}<30 / \mathrm{NA} \\
50^{\circ} \mathrm{F}\end{array}$ & $\begin{array}{c}<30 / \mathrm{NA} \\
80^{\circ} \mathrm{F}\end{array}$ & $\begin{array}{c}\text { Not } \\
\text { available }^{g}\end{array}$ & & & Not available ${ }^{g}$ \\
\hline PA4 & $\begin{array}{c}<30 /<30 /<30 \\
42^{\circ} \mathrm{F} \\
\end{array}$ & $\begin{array}{c}\text { Not } \\
\text { available }\end{array}$ & $\begin{array}{c}<30 / \mathrm{NA} \\
72^{\circ} \mathrm{F} \\
\end{array}$ & $\begin{array}{c}<30 / \mathrm{NA} \\
75^{\circ} \mathrm{F} \\
\end{array}$ & $\begin{array}{c}<30 / \mathrm{NA} \\
40^{\circ} \mathrm{F} \\
\end{array}$ & & & Not available ${ }^{g}$ \\
\hline MN1 & $\begin{array}{c}\text { 90/NA/NA } \\
73^{\circ} \mathrm{F} \\
\end{array}$ & $\begin{array}{c}\text { Not } \\
\text { available }\end{array}$ & $\begin{array}{c}0 / 0 \\
36^{\circ} \mathrm{F} \\
\end{array}$ & $\begin{array}{c}0 / 0 \\
70^{\circ} \mathrm{F} \\
\end{array}$ & $\begin{array}{c}0 / 0 \\
78^{\circ} \mathrm{F} \\
\end{array}$ & & & $\begin{array}{c}0 / 0 \\
75^{\circ} \mathrm{F} \\
\end{array}$ \\
\hline MN2 & $\begin{array}{c}210 / 5 / \mathrm{NA} \\
82^{\circ} \mathrm{F}\end{array}$ & $\begin{array}{c}0 / 0 / 0 \\
9^{\circ} \mathrm{F}\end{array}$ & $\begin{array}{c}0 / 0 \\
37^{\circ} \mathrm{F}\end{array}$ & $\begin{array}{c}0 / 0 \\
70^{\circ} \mathrm{F}\end{array}$ & $\begin{array}{c}0 / 0 \\
78^{\circ} \mathrm{F}\end{array}$ & & & $\begin{array}{c}0 / 0 \\
75^{\circ} \mathrm{F}\end{array}$ \\
\hline MN3 & $\begin{array}{c}0 / 0 / \mathrm{NA} \\
81^{\circ} \mathrm{F} \\
\end{array}$ & $\begin{array}{l}0 / 0 / 0 \\
27^{\circ} \mathrm{F} \\
\end{array}$ & $\begin{array}{c}0 / 0 \\
37^{\circ} \mathrm{F} \\
\end{array}$ & $\begin{array}{l}0 / 0 \\
60^{\circ} \mathrm{F} \\
\end{array}$ & $\begin{array}{l}0 / 0 \\
75^{\circ} \mathrm{F} \\
\end{array}$ & & & $\begin{array}{l}0 / 0 \\
71^{\circ} \mathrm{F} \\
\end{array}$ \\
\hline MN4 & $\begin{array}{l}/ 0 / \mathrm{NA} \\
84^{\circ} \mathrm{F} \\
\end{array}$ & $\begin{array}{l}0 / 0 / 0 \\
27^{\circ} \mathrm{F} \\
\end{array}$ & $\begin{array}{c}0 / 0 \\
40^{\circ} \mathrm{F} \\
\end{array}$ & $\begin{array}{c}0 / 0 \\
62^{\circ} \mathrm{F} \\
\end{array}$ & $\begin{array}{l}0 / 0 \\
70^{\circ} \mathrm{F} \\
\end{array}$ & & & $\begin{array}{c}0 / 0 \\
71^{\circ} \mathrm{F} \\
\end{array}$ \\
\hline MO1 & $\begin{array}{l}2 / 0 / 0 \\
35^{\circ} \mathrm{F} \\
\end{array}$ & $\begin{array}{l}0 / 0 / 0 \\
78^{\circ} \mathrm{F} \\
\end{array}$ & $\begin{array}{c}3 / 0 \\
90^{\circ} \mathrm{F} \\
\end{array}$ & & & & & $\begin{array}{c}6 / 0 \\
79^{\circ} \mathrm{F} \\
\end{array}$ \\
\hline MO2 & $\begin{array}{c}0 / 20 / 10 \\
62^{\circ} \mathrm{F} \\
\end{array}$ & $\begin{array}{l}4 / 2 / 0 \\
78^{\circ} \mathrm{F} \\
\end{array}$ & $\begin{array}{r}45 / 0 \\
91^{\circ} \mathrm{F} \\
\end{array}$ & & & & & $\begin{array}{c}5 / 0 \\
70^{\circ} \mathrm{F} \\
\end{array}$ \\
\hline MO3 & $\begin{array}{c}124 / 0 / 0 \\
48^{\circ} \mathrm{F} \\
\\
10 / 0 / 0 \\
45^{\circ} \mathrm{F} \\
\end{array}$ & $\begin{array}{c}>120 \\
76^{\circ} \mathrm{F} \\
\\
58 / 0 / 0 \\
76^{\circ} \mathrm{F} \\
\end{array}$ & $\begin{array}{l}60 / 0 \\
90^{\circ} \mathrm{F}\end{array}$ & & & & & $\begin{array}{c}0 / 0 \\
71^{\circ} \mathrm{F}\end{array}$ \\
\hline MO4 & $\begin{array}{l}0 / 0 / 0 \\
52^{\circ} \mathrm{F}\end{array}$ & $\begin{array}{l}0 / 5 / 5 \\
72^{\circ} \mathrm{F}\end{array}$ & $\begin{array}{c}5 / 0 \\
83^{\circ} \mathrm{F}\end{array}$ & & & & & $\begin{array}{c}0 / 0 \\
70^{\circ} \mathrm{F}\end{array}$ \\
\hline
\end{tabular}

${ }^{a}$ Dates when the tests were performed varied by state (Table 3.2 ).

${ }^{b}$ The first number is when only the water heater was firing, the second number when the water heater and furnace were firing, and the third number when only the furnace was firing. The temperature is the outdoor temperature at the time of the test.

${ }^{c}$ Cells highlighted in yellow had spillage times that exceeded the BPI 2015 spillage limit of 2 minutes (i.e., 120 seconds) or, for

House CO1, were consistently high across the pre- and post-retrofit periods.

${ }^{d}$ For the post-retrofit period, the furnace-only draft was not monitored because the furnaces were condensing units and vented directly to the outdoors with no possibility of spillage.

${ }^{e}$ The length of the post-retrofit monitoring period varied among the states (Figure 3.2), so the number of additional worst-case depressurization venting diagnostic tests that could be performed on each house varied by state.

$f$ In Pennsylvania, the existing furnaces were removed before the diagnostic measurements could be made. In Minnesota house $\mathrm{MN1}$, the existing furnace stopped working before the diagnostic measurement could be made.

gThese measurements were made incorrectly by a new technician.

$\mathrm{NA}$ - not available. 
- Post-retrofit "after-furnace-installation" measurements - All of the measurements taken on the water heaters immediately after the installation of the condensing furnaces and the FasNSeal 80/90 venting system passed (i.e., were less than) the 120 seconds spillage limit for a water heater.

- Other post-retrofit measurements - All of the other post-retrofit measurements (i.e., the additional measurements and the measurements taken at the time of instrumentation removal) taken on the water heaters after the condensing furnaces and FasNSeal 80/90 venting systems were installed (i.e., the post-retrofit period) were less than the 120 seconds spillage limit for a water heater except for the measurement of 300 seconds taken for House PA1 at the end of field demonstration when instrumentation was removed. The anomaly with this house is discussed in Sect. 5.5

- House CO1 measurements - Although spillage times for House CO1 were always less than the 120 second spillage limit, they were consistently high across the pre- and post-retrofit periods. The anomaly with this house is discussed in Sect. 5.5

\subsection{DETERMINATION OF SPILLAGE EVENTS AND THEIR DURATION}

As described in Sect. 3.2, three methods were used to determine when spillage at the water heater occurred and the duration of the spillage events:

- DP method - By measuring the pressure difference between the water heater vent connector and the CAZ. A pressure in the vent connector relative to the CAZ greater than the DP pressure/spillage limit indicated full or partial spillage of flue gases into the CAZ, and the duration that the pressure was greater than the DP pressure/spillage limit indicated the duration of a spillage event.

- DT method - By calculating the temperature difference between the CAZ and the dilution air surrounding the draft hood of the water heater. A sharp increase in the dilution air temperature relative to the CAZ air temperature indicated the start of a spillage event, and a sharp decrease in this temperature difference indicated the end of the spillage event.

- $\mathrm{CO}_{2}$ method - By calculating the difference in the $\mathrm{CO}_{2}$ level in the $\mathrm{CAZ}$ and above the water heater draft hood. $\mathrm{A} \mathrm{CO}_{2}$ level above the water heater draft hood that was greater than the $\mathrm{CO}_{2}$ level in the $\mathrm{CAZ}$ indicated the start of a spillage event. Due to the slower response time of the $\mathrm{CO}_{2}$ sensors, this method was only used to verify occurrences of spillage and when spillage started; it was not used to determine the duration of a spillage event.

Figure 5.3 shows an example of how the three methods detect spillage at the beginning of a water heater cycle. Each plot shows the same 20 minute snapshot of 1 second data for house PA3. A 12 minute long water heater cycle (from $\sim 3.09$ to $\sim 3.21$ ) is shown as a red line labeled WHOn in each plot. The increase in the DP measurement at the start of the water heater cycle (as indicated by the blue line labeled Measured DP in the top plot) and the subsequent drop about 3 minutes later at 3:12 define a 180 second spillage event. Analysis software generates the black line in the top plot labeled DP Spill to clearly identify the spillage event based on the logic described above. The increase and subsequent decrease in the calculated DT (as indicated by the blue line labeled Measured DT in the middle plot) corresponds to the measured DP almost exactly, defining the same 180 second spillage event. The black line generated by the analysis software and labeled DT Spill in the middle plot defines the same spillage event as the blank line in the top plot. The increase in the $\mathrm{CO}_{2}$ level measured at the draft hood (as indicated by the blue line labeled $\mathrm{CO}_{2}$ Draft Hood in the bottom plot) at the beginning of the water heater cycle confirms the occurrence of the spillage event defined by the DP and DT measurements. 
FV_PA3_TestTable-b071016.csv
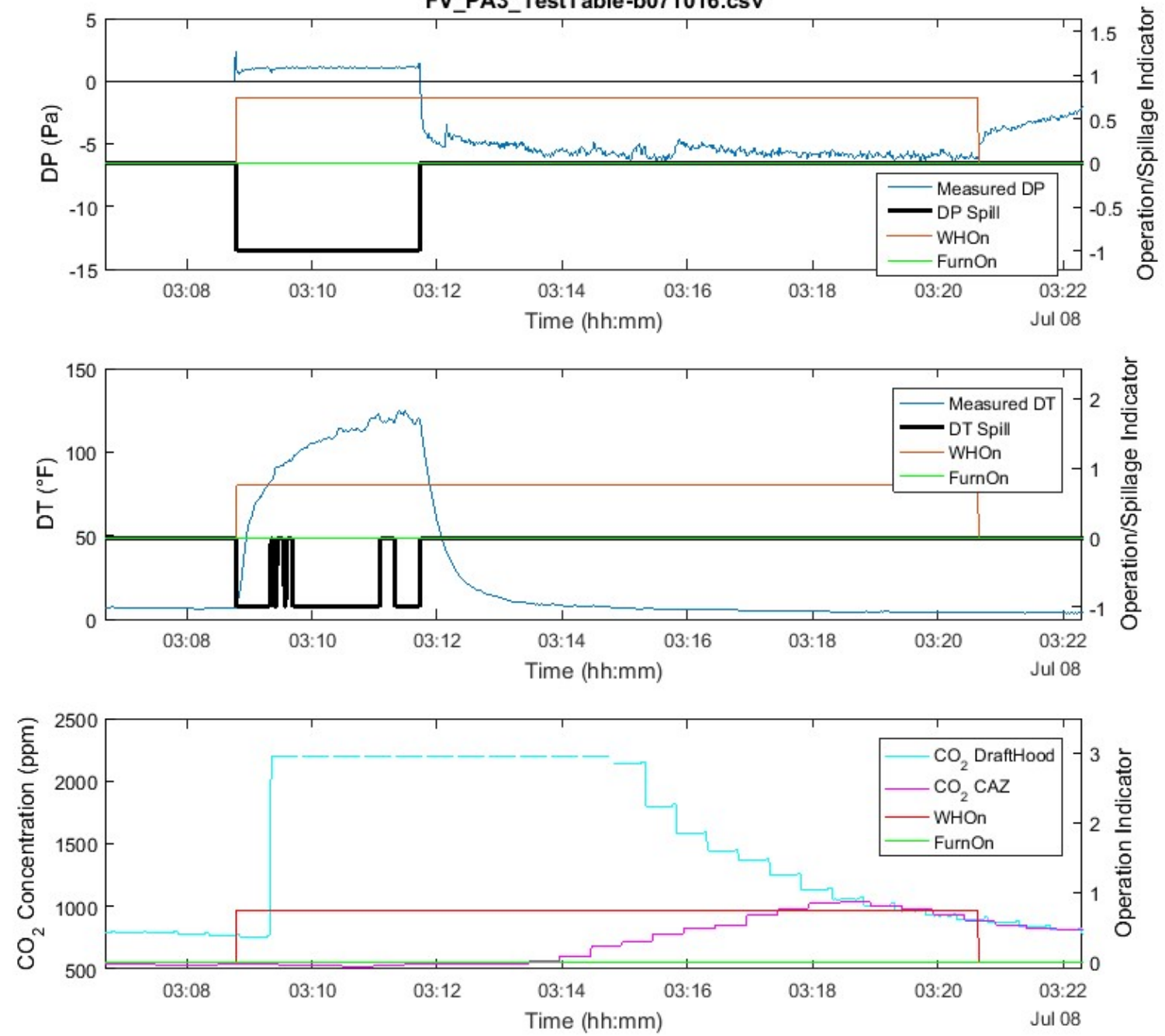

Figure 5.3. Spillage detected by DP, DT, and $\mathrm{CO}_{2}$ at the start of one 12 minute water heater cycle.

Spillage does not necessarily occur just at the beginning of a water heater cycle. Although it may occur most frequently at the start of a water heater cycle, spillage can occur at any time during a cycle. As shown in Figure 5.4, spillage occurred twice during this $\sim 11$ minute water heater cycle (from $\sim 12.36$ to 12.47) in the middle of the cycle rather than at the start, with each spillage event occurring for just a few seconds. The DP and DT methods both detected these events and detected the same duration for the events (see the black lines generated by the analysis software in the top and middle plots that indicate that these spillage events occurred at $\sim 12.38$ and $\sim 12.40$ ). The $\mathrm{CO}_{2}$ measurement confirmed the occurrence of the first spillage event. 

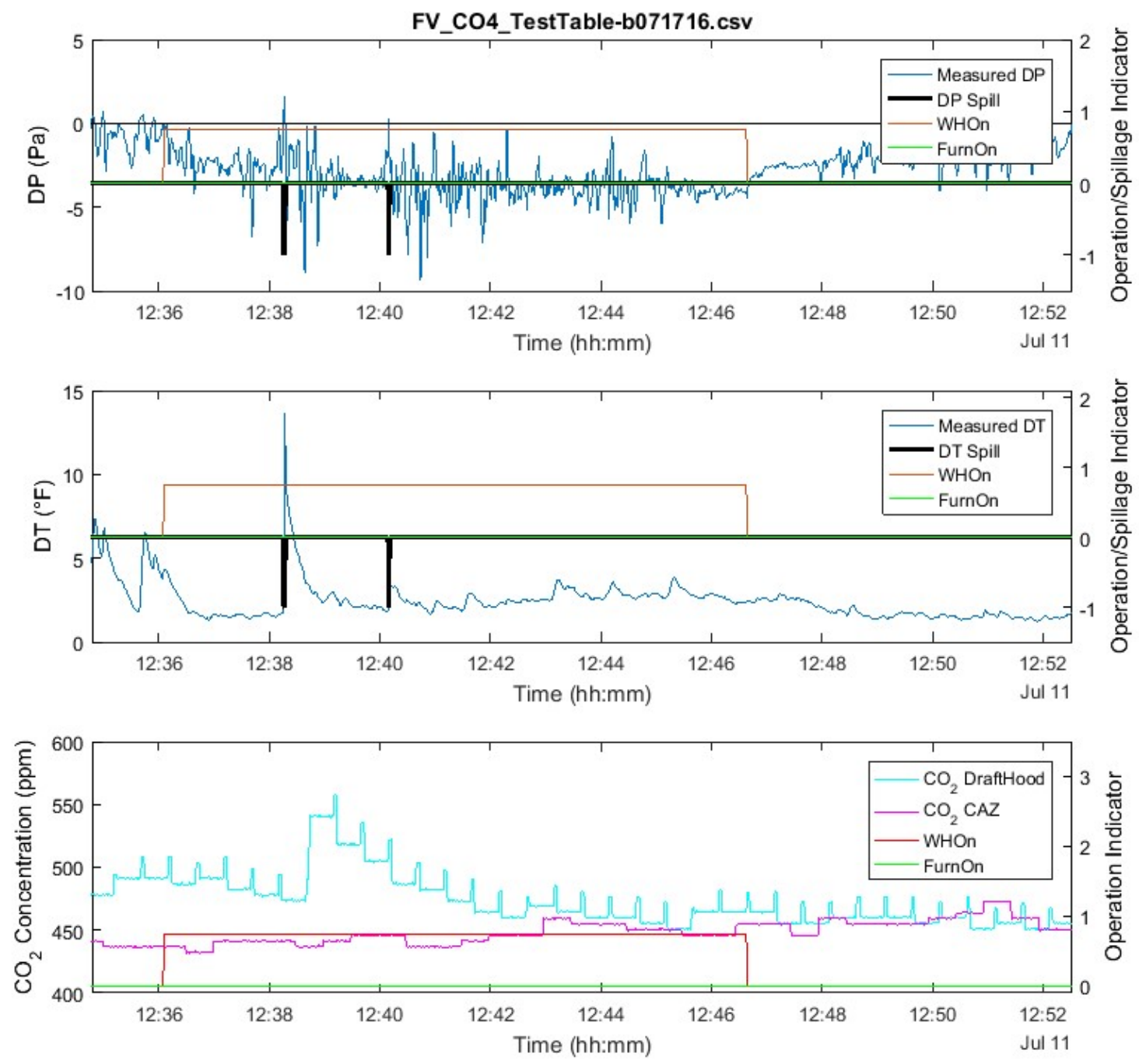

Figure 5.4. Two spillage events detected by DP, DT, and $\mathrm{CO}_{2}$ in the middle of a 10 minute water heater cycle.

In subsequent analyses, both the total spillage time for a water heater cycle and the spillage time at the beginning of a water heater cycle are examined. The total spillage time is the sum of the duration of all spillage events occurring during a given cycle, including at the start of the cycle and any other spillage events that occur during the cycle. The spillage time at the beginning of a water heater cycle excludes any spillage that may occur after the initial spillage event.

Figure 5.5 is another example demonstrating that the DP and DT methods are generally consistent in identifying spillage events at the water heater and determining their duration over an extended period. Figure 5.5 shows a week of monitoring (from July10 to July 17) that included 18 water heater cycles (see the red lines in the three plots labeled WHOn). Both the DP and DT plots show that spillage occurred during the second, third, and thirteenth water heater cycles, as marked by the black lines generated by the analysis software. Both methods determined that the total spillage time over this week was 23 seconds, as labeled on the plots. The spikes on the $\mathrm{CO}_{2}$ plot during the second and thirteenth water heater cycles 
confirm these two spillage events. Spillage during the third water heater cycle was not detected by the $\mathrm{CO}_{2}$ method because of its proximity in time to the second water heater cycle.

The DP method is used to present the results in Section 5.4 because it is the more direct measurement of when a spillage event occurs and especially the duration of a spillage event. The DT and $\mathrm{CO}_{2}$ methods were used to verify the results of the DP method and determine the DP pressure/spillage limit. Using all three methods ensured that all spillage events during the water heater cycles were detected.
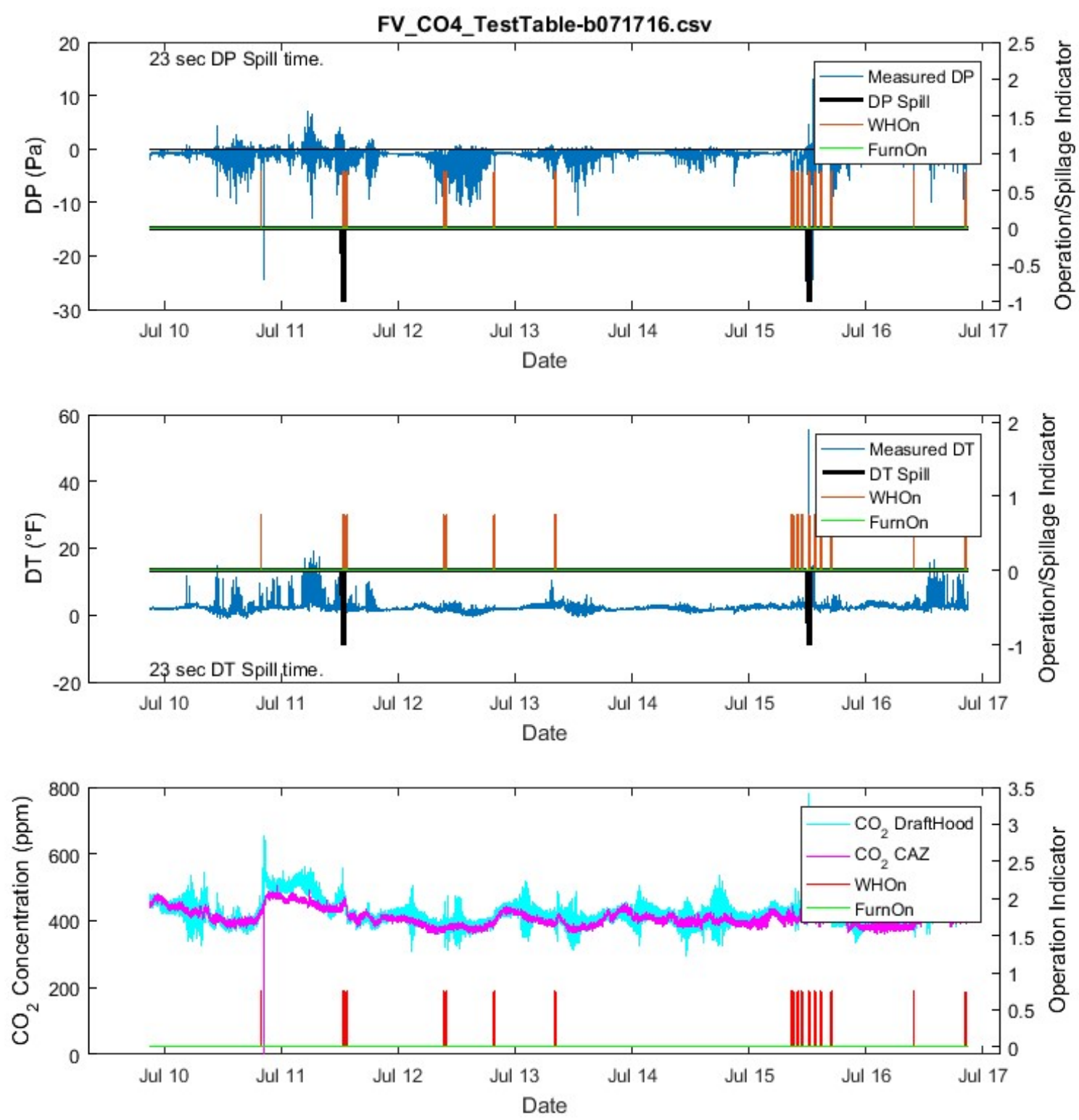

Figure 5.5. Alignment of the DT, DP, and $\mathrm{CO}_{2}$ methods for detecting spillage over a week. 


\subsection{PRE- AND POST-RETROFIT SPILLAGE PERFORMANCE}

Plots were developed for each house to analyze the pre- and post-retrofit performance of the venting systems installed in each house. In these plots, the duration and frequency of water heater spillage was plotted as a function of outdoor temperature because the pre- and post-retrofit monitoring periods spanned different seasons for all the houses. Outdoor temperature is an important variable that can impact spillage because the temperature differential between the house and the outside is low or negative at higher outdoor temperatures, which makes it more difficult for a natural-draft water heater to establish and maintain draft. It should be emphasized that the total spillage time for each water heater cycle was the variable used in these plots, not the spillage time that occurred just at the start of each water heater cycle. Figure 5.6 shows an example of the plots developed for one house (House CO4).

- The plots on the left are based on using the DP method to detect and measure spillage, and the plots on the right are based on using the DT method.

- The scatter plots at the top of the figure show the total spillage time that occurred in a house (in this example House $\mathrm{CO} 4$ ) for every water heater cycle during the pre- and post-retrofit periods as a function of the average outdoor temperature during the cycle. The data points identified by the circles represent water heater cycles when only the water heater was firing, and the data points identified by the plus sign represent water heater cycles when both the water heater and furnace were firing simultaneously. Blue data points represent water heater cycles during the pre-retrofit period, and red data points represent water heater cycles during the post-retrofit period.

- The plots in the middle of the figure show histograms of the average spillage time for all the water heater cycles during the pre- and post-retrofit periods in $5^{\circ} \mathrm{F}$ outdoor temperature bins. Also shown as lines in the plots in the middle of the figure are the number of water heater cycles (i.e., the number of data points) in the pre- and post-retrofit periods used to calculate the average spillage time in each temperature bin. In these plots, blue histograms and lines represent the pre-retrofit period, while red histograms and lines represent the post-retrofit period.

- The plots at the bottom of the figure show histograms of the average spillage time for water heater cycles with non-zero spillage during the pre- and post-retrofit periods in $5^{\circ} \mathrm{F}$ outdoor temperature bins. Also shown as lines in the plots at the bottom of the figure are the fraction of water heater cycles with spillage in each temperature bin. In these plots, blue histograms and lines represent the preretrofit period, while red histograms and lines represent the post-retrofit period

Figure 5.6 for House CO4 demonstrates that the DP method (left) and DT method (right) produce similar, if not identical, results when evaluating spillage events and durations. The two scatter plots in Figure 5.6 show that the DP and DT methods produce similar scatter of total water heater cycle spillage times at varying outdoor air temperatures for House CO4. The DP and DT methods also produce pre- and postretrofit histograms for House CO4 that are similar. All other homes exhibited similar agreement between the DP and DT methods; as a result, and as already discussed in Sect. 5.3, the DP method is used to present the results in the remainder of this section because it is the more direct measurement of when a spillage event occurs and especially the duration of a spillage event. 


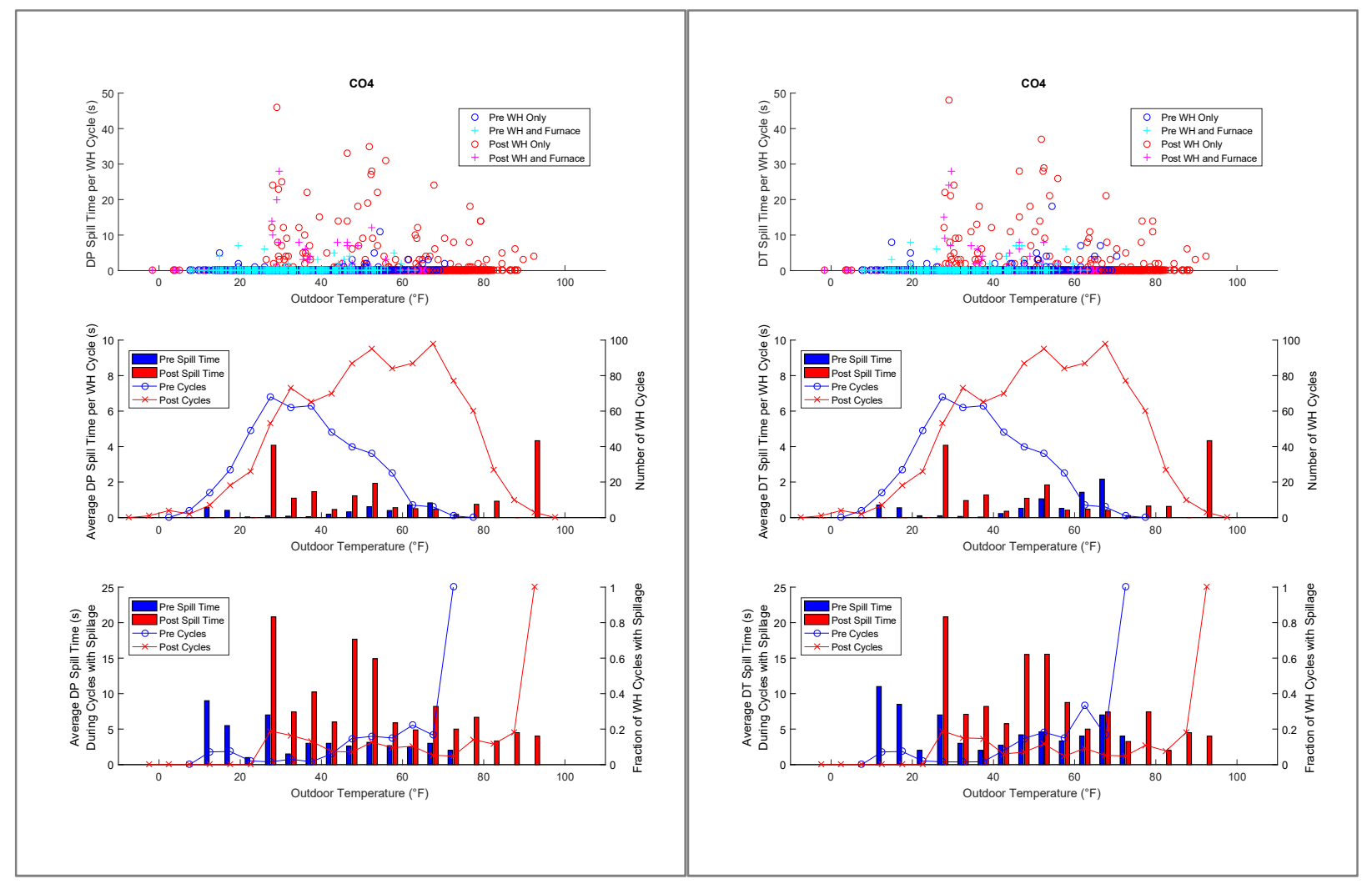

Figure 5.6. Spillage summary plots based on DP (left) and DT (right) methods for House CO4. (In the bottom plots, the left axis refers to the histogram and the right axis refers to the lines.)

The scatter plots are useful to visualize the performance of the venting systems before and after retrofit. For example, the total spillage time for a water heater cycle is often zero, which is evident by the large number of data points plotted on the x-axis of the scatter plots. Of course, a low fraction of water heater cycles with spillage shown in the bottom plots also conveys that the total spillage time for a water heater cycle may often be zero. The scatter plots begin to show how some houses exhibit several water heater cycles in which spillage occurred, as shown in Figure 5.6, while others exhibit very few water heater cycles with spillage (Figure 5.7)

Care should be taken in extracting information from the scatter plots. For example, the number of nonzero spillage events seen when viewing the scatter plots can be misleading because the length of the preand post-retrofit periods varied for a given house and among houses. Only a few cycles with spillage may be shown because the duration of the monitoring period was short, while many cycles with spillage may be shown because the monitoring period was long. Thus, the number of non-zero spillage events shown may be due to the length of the monitoring period as much as the performance of the venting system. For this example, the fraction of water heater cycles with spillage shown in the bottom plots normalize out the different lengths of the monitoring periods and is a better indicator of the frequency of spillage events.

The histograms in the middle and bottom plots reduce the scatter of data points on the scatter plots to quantifiable numbers. The average spillage time for all water cycles presented in the middle figure can be misleading because it is averaging over many water heater cycles with no spillage. For example, as shown in Figure 5.7, a 355 second total spillage time for one water heater cycle during the pre-retrofit period resulted in an average pre-retrofit spillage time of about 5 seconds for the $25-30^{\circ} \mathrm{F}$ temperature bin. Most of the spillage times for the other $\sim 80$ water heater cycles in this temperature bin were about zero. Thus, the average spillage time during cycles with spillage is provided in the bottom figure and used in most of 
the subsequent analyses. In fact, the plot of the fraction of water heater cycles with spillage, when examined with the plot of the average spillage time during cycles with spillage, provide a sense of how common spillage occurs and the severity of the spillage.

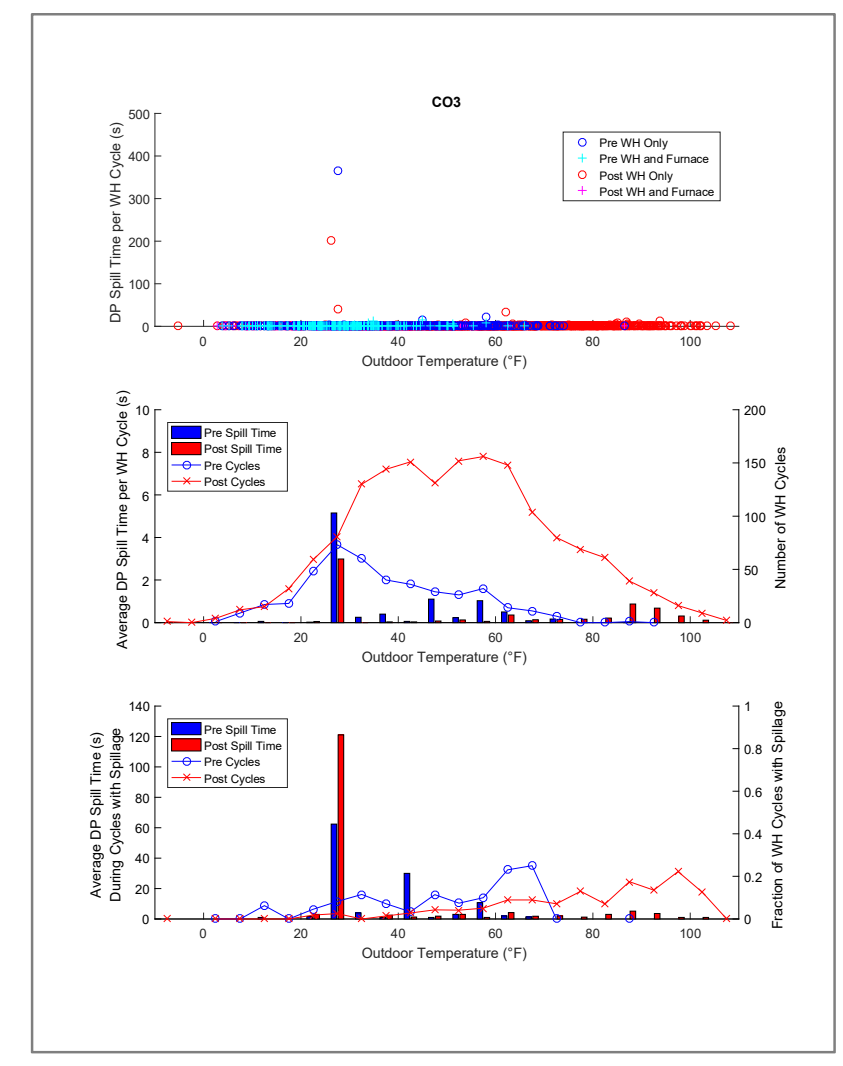

Figure 5.7. High average spillage time caused by one or two water heater cycles.

The plot of the number of water heater cycles in each temperature bin is useful to assess the significance of the bin-average values and the fraction of water heater cycles with spillage. There are no or a very small number of data points for some temperature bins (especially at the lower or higher outdoor temperatures) because the pre- and/or post-retrofit periods often spanned different seasons and less than a year. When there were no data points in a temperature bin, average spillage times and the fraction of water heater cycles with spillage could not be calculated. When there were few data points in a temperature bin, these values were calculated but they should be used with caution because they are based on just a few data points. For example, in Figure 5.6, the average spillage time and fraction of water heater cycles with spillage calculated for the post-retrofit $90-95^{\circ} \mathrm{F}$ temperature bin are based on only three water heater cycles.

Figures 5.8 to 5.11 show performance plots for the four houses in each city (full page plots for each house are shown in APPENDIX E). For all houses, a fixed temperature scale of -20 to $100^{\circ} \mathrm{F}$ is used for the $\mathrm{x}$-axis for both the scatter plots and histograms and a fixed y-axis scale of 0 to 1 is used for the fraction of water heater cycles with spillage. Care must be taken to note the y-axis scale used for the other plots when comparing houses because they varied. 


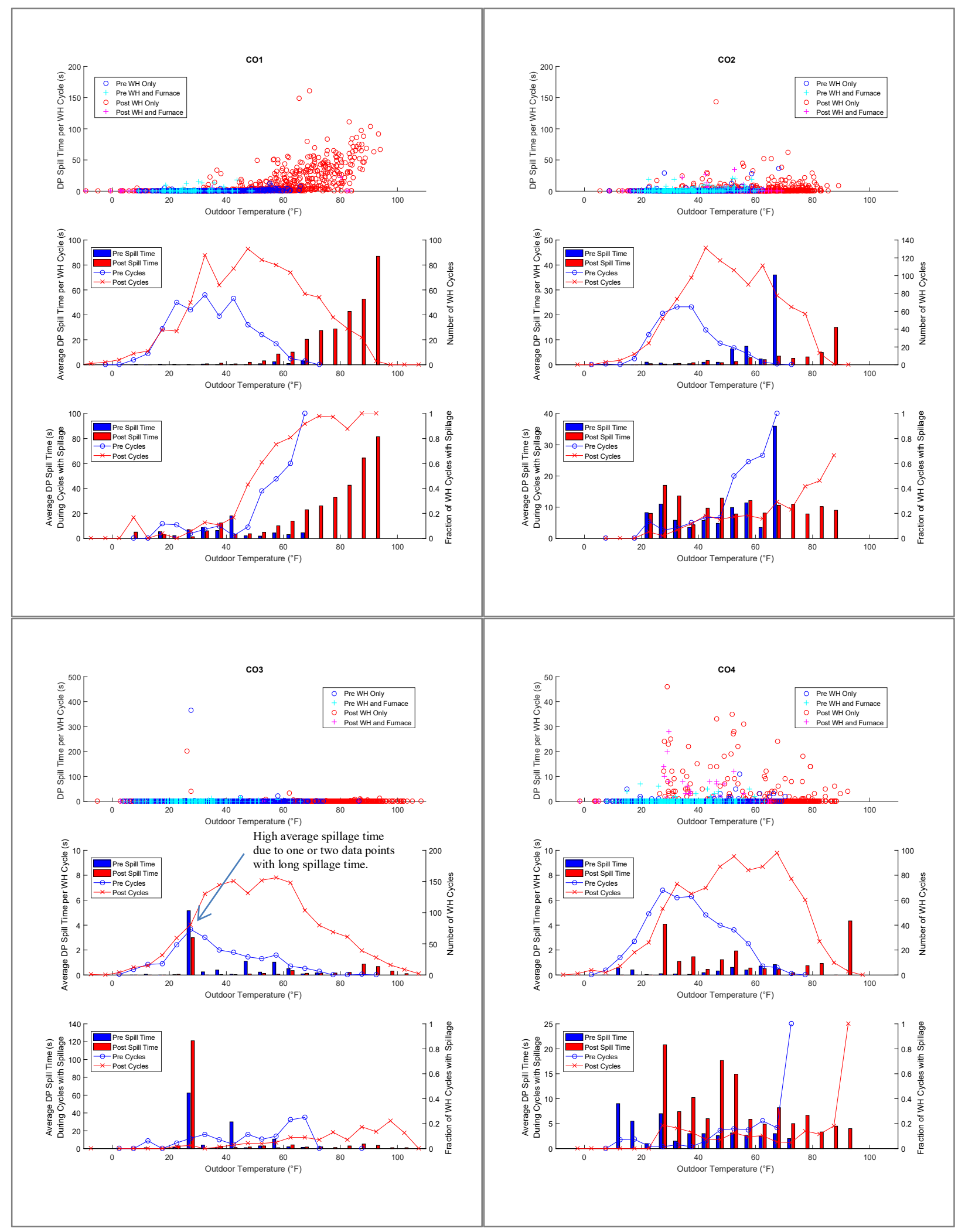

Figure 5.8. Spillage summary plots for the Colorado Springs houses. 


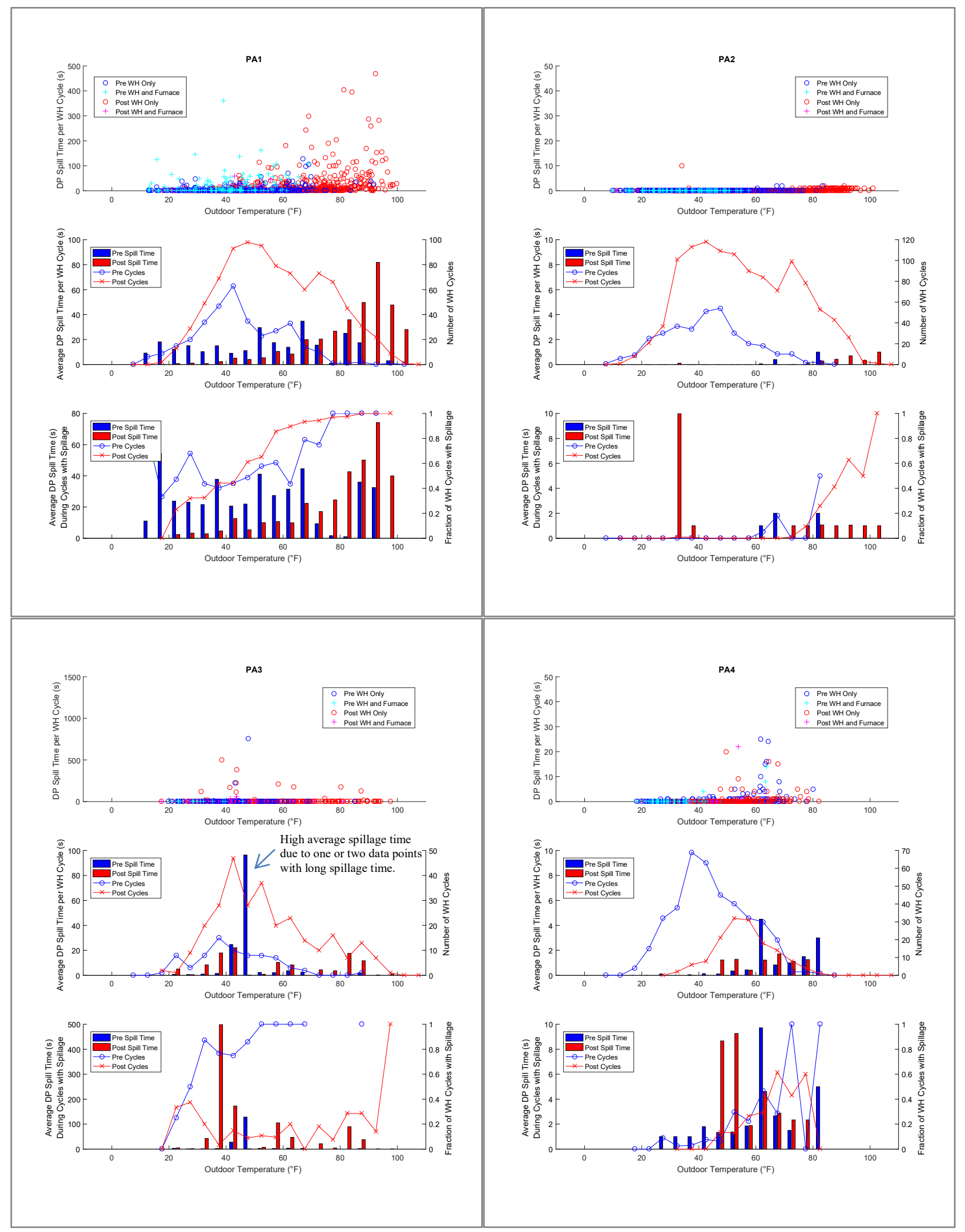

Figure 5.9. Spillage summary plots for the Philadelphia houses. 


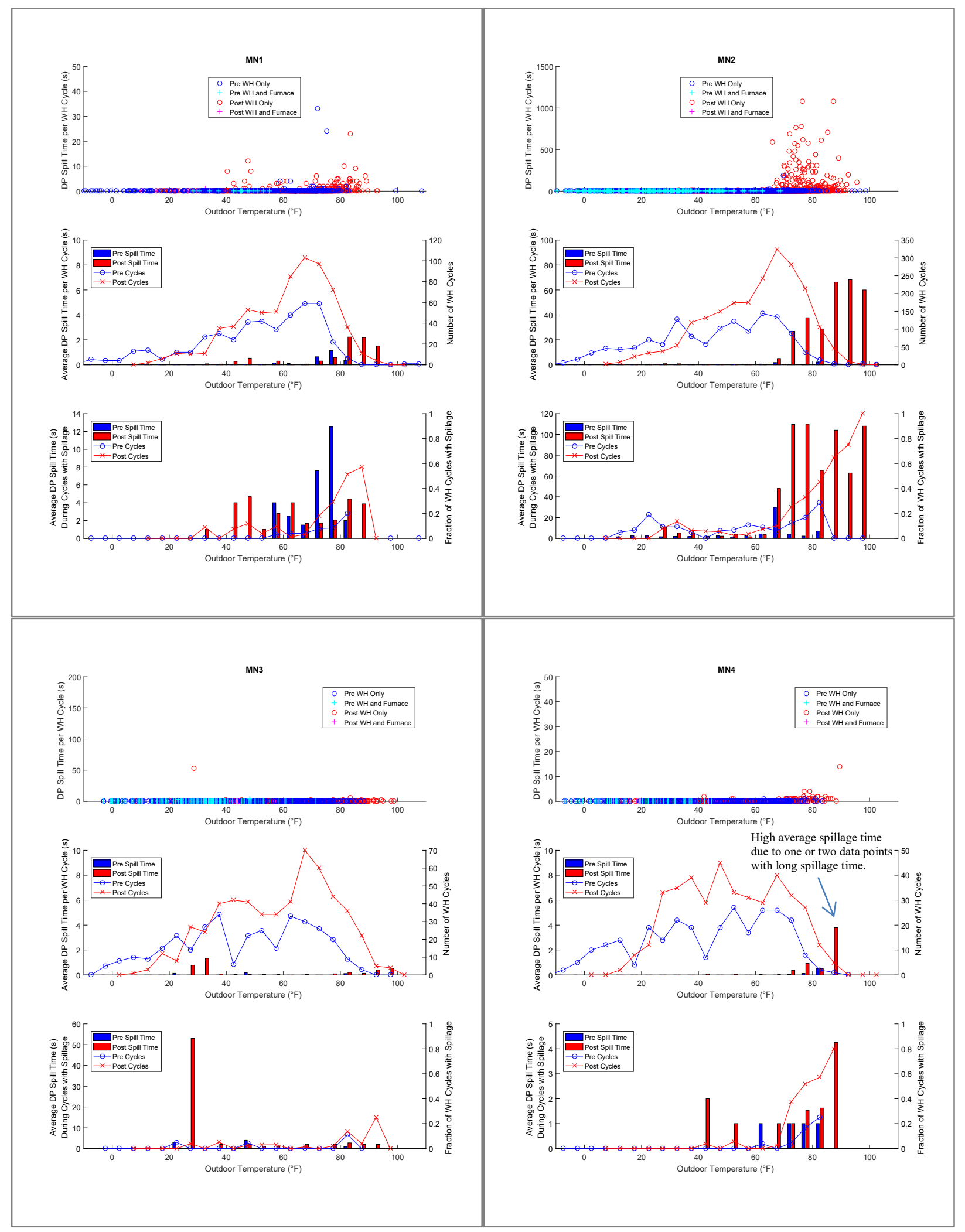

Figure 5.10. Spillage summary plots for the Minneapolis houses. 


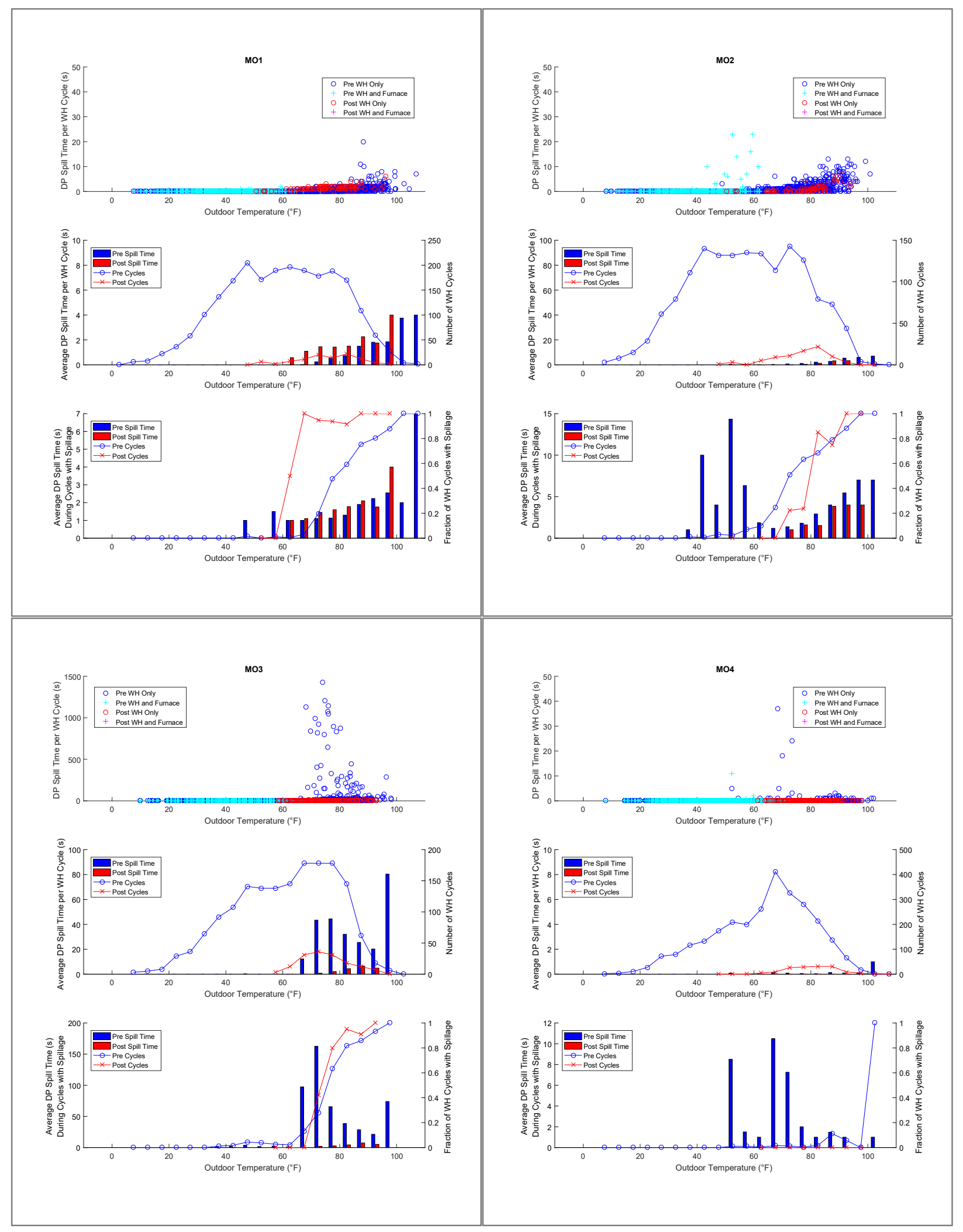

Figure 5.11. Spillage summary plots for the St. Louis houses. 
Examination of the scatter plots for the post-retrofit periods when the FasNSeal 80/90 venting system was installed show that water heater spillage occurred in all homes. It occurred infrequently during the monitoring periods for eight houses: CO3, PA2, MN3, MN4, MO1, MO2, MO3, and MO4. Although House CO3 only had three post-retrofit spillage events over a year-long post-retrofit monitoring period, one of these events was for about 200 seconds, or more than 3 minutes. Post-retrofit spillage occurred more frequently in three homes: PA3, PA4, and MN1. The spillage times were less than 20 seconds and generally less than 5 seconds in two of these homes (PA4 and MN1), while in House PA3 the infrequent spillages that did occur often totaled between 100 and 500 seconds per event. Five houses showed a moderate number of spillage events: $\mathrm{CO} 1, \mathrm{CO} 2, \mathrm{CO} 4, \mathrm{PA} 1$, and $\mathrm{MN} 2$. Although a moderate number of spillage events occurred in Houses $\mathrm{CO} 2$ and $\mathrm{CO} 4$, the duration of the events was generally less than 60 seconds, except for one event of about 140 seconds in House CO2. In House CO1, spillage events often lasted between 60 and 120 seconds, and in Houses PA1 and MN2, spillage events lasting longer than 120 seconds occurred.

Examination of the scatter plots for the pre-retrofit periods show that spillage also occurred in all the homes when the water heater was vented conventionally with the non-condensing furnace, indicating that spillage of a natural-draft water heating occurs with current venting systems and is not unique to the FasNSeal system. Water heater spillage occurred infrequently in eight houses (CO1, CO3, PA2, PA3, MN1, MN2, MN3, and MN4), although only four of these houses exhibited the same behavior after retrofit. As before, although Houses CO3 and PA3 showed infrequent spillage, one or two events per house were greater than 300 seconds. More frequent spillage occurred in five houses (CO2, CO4, PA4, MO1, and MO4), with spillage times being less than 40 seconds in all houses. A moderate number of spillage events occurred in the remaining three houses (PA1, MO2, and MO3). Houses PA1 and MO2 had durations that were mostly less than 150 seconds, while MO3 had durations that exceeded 500 seconds.

Examination of the histograms of the fraction of water heater cycles with spillage provides some general observations. The patterns observed were the same before and after retrofit in all houses except for House PA3. The fraction of water heater cycles with spillage was generally less than 0.2 at lower outdoor temperatures and became more frequent at higher outdoor temperatures in 11 houses. The transition occurred between outdoor temperatures of 40 to $60^{\circ} \mathrm{F}$ in three houses and above $60^{\circ} \mathrm{F}$ in eight houses. The fraction of water heater cycles with spillage was always less than 0.2 in three houses while it was always greater than 0.2 in one house (House PA1). In House PA3, the fraction was greater than 0.2 during the pre-retrofit period for all outdoor temperatures while it was greater than 0.2 in the post-retrofit period only at outdoor temperatures less than $35^{\circ} \mathrm{F}$ and above $80^{\circ} \mathrm{F}$. The anomalies with Houses PA1 and PA3 are discussed in Sect. 5.5.

Observations based on an examination of the histograms of the average spillage time for water heater cycles with non-zero spillage are harder to generalize, in part because spillage times for a given temperature bin were sometimes still based on just a few spillage events. Taking this into account, the average spillage time for water heater cycles with non-zero spillage were generally less than 20 seconds at colder outdoor temperatures for all houses during the pre-retrofit period except for House PA1 and for all houses during the post-retrofit period except for House PA3. The spillage times were also usually less than 20 seconds at higher outdoor temperatures except for Houses PA1 and MO3 during the pre-retrofit period and except for Houses CO1, PA1, PA3, and MN2 during the post-retrofit period.

To facilitate a comparison of the frequency of spillage and average spillage time with non-zero spillage between the pre- and post-retrofit periods in each a house, a single value was calculated for these for each house (Figure 5.12). These values were calculated using only those water heater cycles that occurred within an outdoor temperature range unique to each house. The outdoor temperature range was selected such that 20 or more water heater cycles occurred in each of the pre- and post-retrofit temperature bins within the selected range. This was done to make sure there were enough pre- and post-retrofit data to 
provide an accurate comparison. The temperature ranges used for each house are shown in Table 5.2. Note that the temperature ranges used for the MO houses spanned considerably higher outdoor temperatures than those used for the other houses.

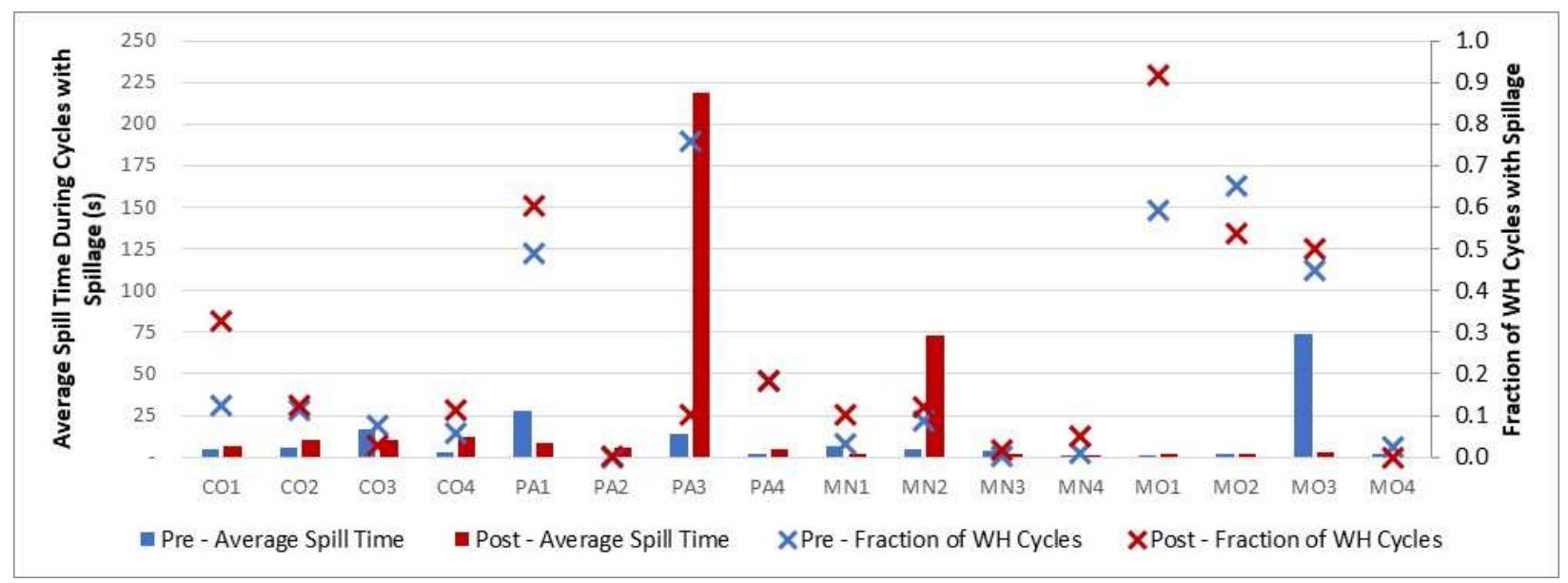

Figure 5.12. Average spillage for all houses.

Table 5.2. Outdoor temperature ranges used to calculate values in Figure 5.12.

\begin{tabular}{|c|c|}
\hline House & Outdoor temperature range \\
\hline CO1 & 15 to $60^{\circ} \mathrm{F}$ \\
\hline CO2 & 25 to $50^{\circ} \mathrm{F}$ \\
\hline CO3 & 15 to $60^{\circ} \mathrm{F}$ \\
\hline CO4 & 20 to $60^{\circ} \mathrm{F}$ \\
\hline PA1 & 25 to $65^{\circ} \mathrm{F}$ \\
\hline PA2 & 20 to $55^{\circ} \mathrm{F}$ \\
\hline PA3 & 35 to $45^{\circ} \mathrm{F}$ \\
\hline PA4 & 45 to $60^{\circ} \mathrm{F}$ \\
\hline MN1 & 35 to $80^{\circ} \mathrm{F}$ \\
\hline MN2 & 15 to $80^{\circ} \mathrm{F}$ \\
\hline MN3 & 30 to $80^{\circ} \mathrm{F}$ \\
\hline MN4 & 30 to $75^{\circ} \mathrm{F}$ \\
\hline MO1 & 80 to $85^{\circ} \mathrm{F}$ \\
\hline MO2 & 75 to $85^{\circ} \mathrm{F}$ \\
\hline MO3 & 65 to $85^{\circ} \mathrm{F}$ \\
\hline MO4 & 70 to $90^{\circ} \mathrm{F}$ \\
\hline
\end{tabular}

${ }^{\text {a }}$ The criteria was dropped to 10 or more water heater cycles for PA3 because of a lack of data.

${ }^{b}$ These houses had less than 20 water heater cycles in two or three temperature bins.

Figure 5.12 shows that the pre-and post-retrofit values calculated for the frequency of spillage and average spillage time with non-zero spillage were the same before and after retrofit for nine houses: $\mathrm{CO} 2$, $\mathrm{CO} 3, \mathrm{CO} 4, \mathrm{PA} 2, \mathrm{PA} 4, \mathrm{MN} 1, \mathrm{MN} 3, \mathrm{MN} 4$, and MO4. For these houses, the fractions of water heater cycles with spillage were less than 0.1 with one exception (the pre- and post-retrofit fractions were both just less than 0.2 for House PA4) and the average spillage times with non-zero spillage were less than 25 seconds (with the BPI 2015 spillage limit being 120 seconds as a source of reference). 
It can also be concluded that the pre- and post-retrofit performance of the conventional and FasNSeal venting systems are the same in Houses MO1 and MO2. The fraction of water heater cycles with spillage was high for both houses both before and after retrofit (the post-retrofit value was higher than the preretrofit value for House MO1 while this was reversed for House MO2); however, the average spillage times for these houses were extremely short (on the order of 1 second). This can be seen in the scatter plots for these two houses provided in Figure 5.11, where many spillage cycles of short duration are shown as evidenced by the number of data points just above the $\mathrm{x}$-axis. One possible explanation for the frequent spillage could be that the outdoor temperature range used for both houses was restricted to higher outdoor temperatures when it is more difficult to establish a draft; a similar high spillage frequency was measured in House MO3, but not MO4, under the same outdoor temperature conditions.

For the remaining five houses shown in Figure 5.12 (Houses CO1, PA1, PA3, MN2, and MO3) differences in the pre- and post-retrofit performance of the venting system is evident in individual houses and/or data indicating frequent spillage or long spillage times are observed. The anomalies with these five houses are discussed in Sect. 5.5.

The discussion in Sect. 5.4 to this point has focused on results based on the total spillage time per water heater cycle. As discussed in Sect. 5.3, spillage can occur at the beginning of the water heater cycle and intermittently anytime during the water heater cycle, with the total spillage time being the sum of all these spillages for a given water heater cycle. In some cases, a high total spillage time may have been due to intermittent spillage occurring during the water heater cycle (i.e., reoccurrence of spillage after the draft was successfully established at the beginning of the water heater cycle). To identify these instances, an analysis was performed to determine just the spillage time at the start of each water heater cycle and identify specifically the number of cycles where the continuous spillage time at the start of a water heater cycle was more than 120 seconds.

The 120 second time limit was selected to be consistent with the BPI 2015 spillage limit of 2 minutes (i.e., 120 seconds) for a water heater, which was also used in the analysis of the worst-case depressurization venting tests presented in Sect. 5.2. In some sense, this analysis can be thought of as performing a venting diagnostic test for every water heater cycle. Although the CAZ is not being brought to worst-case depressurization conditions, the analysis is determining if a draft can be established within 120 seconds of start-up every time the water heater fires.

The results from this analysis are tabulated in Table 5.3 for the pre- and post-retrofit periods for all 16 houses. Water heater cycles with total spillage times greater than 120 seconds occurred infrequently. Such events occurred at least once in just five houses before retrofit and six houses after retrofit and occurred more than 10 times in just one house before retrofit and two houses after retrofit. Restricting the focus to just spillage at startup further reduced the frequency of occurrences. Such events occurred at least once in just four houses before retrofit and four houses after retrofit and occurred more than 10 times in just one house (MO3) before retrofit and one house (MN2) after retrofit.

There was little change in the venting performance of the water heaters from the point of view of spillage being greater than 120 seconds due to the installation of the FasNSeal 80/90 venting system. Changes of more than 10 cycles occurred in just three houses:

- $\quad$ PA1 - The number of cycles with total spillage greater than 120 seconds increased from 6 to 20 . 
Table 5.3. Total and startup spillage times for the pre- and post-retrofit periods

\begin{tabular}{|c|c|c|c|c|}
\hline \multirow[b]{2}{*}{ House } & \multicolumn{2}{|c|}{ Pre-retrofit } & \multicolumn{2}{|c|}{ Post-retrofit } \\
\hline & $\begin{array}{l}\text { Cycles with more } \\
\text { than } 120 \text { seconds of } \\
\text { total spillage }\end{array}$ & $\begin{array}{l}\text { Cycles with more } \\
\text { than } 120 \text { seconds of } \\
\text { continuous spillage } \\
\text { at start-up }\end{array}$ & $\begin{array}{l}\text { Cycles with more } \\
\text { than } 120 \text { seconds of } \\
\text { total spillage }\end{array}$ & $\begin{array}{l}\text { Cycles with more } \\
\text { than } 120 \text { seconds of } \\
\text { continuous spillage } \\
\text { at start-up }\end{array}$ \\
\hline $\mathrm{CO} 1$ & 0 & 0 & 2 & 0 \\
\hline $\mathrm{CO} 2$ & 0 & 0 & 1 & 0 \\
\hline $\mathrm{CO} 3$ & 1 & 1 & 1 & 1 \\
\hline $\mathrm{CO} 4$ & 0 & 0 & 0 & 0 \\
\hline PA1 & 6 & 0 & 20 & 7 \\
\hline PA2 & 0 & 0 & 0 & 0 \\
\hline PA3 & 2 & 1 & 9 & 2 \\
\hline PA4 & 0 & 0 & 0 & 0 \\
\hline MN1 & 0 & 0 & 0 & 0 \\
\hline MN2 & 1 & 1 & 58 & 55 \\
\hline MN3 & 0 & 0 & 0 & 0 \\
\hline MN4 & 0 & 0 & 0 & 0 \\
\hline MO1 & 0 & 0 & 0 & 0 \\
\hline $\mathrm{MO} 2$ & 0 & 0 & 0 & 0 \\
\hline MO3 & 40 & 40 & 0 & 0 \\
\hline MO4 & 0 & 0 & 0 & 0 \\
\hline
\end{tabular}

- MN2 - Both the number of cycles with total spillage greater than 120 seconds and the number of cycles with continuous spillage at startup greater than 120 seconds increased from 1 to 58 and 55, respectively.

- MO3 - Both the number of cycles with total spillage greater than 120 seconds and the number of cycles with continuous spillage at start-up greater than 120 seconds decreased from 40 to 0 .

The venting system performance of these three houses (PA1, MN2, and MO3) is discussed in detail in Sect. 5.5.

\subsection{VENTING PERFORMANCE IN INDIVIDUAL HOMES}

The venting performance of houses CO1, PA1, PA3, MN2, and MO3 are discussed in this section because of anomalous results as discussed previously in Sects. 5.2 and 5.4. The anomalies are related to the worst-case depressurization venting tests (four houses); the fraction of water heater cycles with spillage as shown by the histograms (two houses); the pre-and post-retrofit values calculated for the frequency of spillage and average spillage time with non-zero spillage (five houses); and a change in the number of cycles with spillage greater than 120 seconds before and after retrofit (three houses). One of these houses had anomalies associated with all four of these analyses, and the remaining four houses had anomalies associated with two or three of these analyses. Information that was examined to explain the anomalous results included lengths of the venting systems, alterations made to the house and its ventilation systems, and CAZ pressures. 


\subsubsection{House CO1}

House $\mathrm{CO} 1$ exhibited anomalies with two of the analyses:

- Spillage times measured as part of the worst-case depressurization venting test were consistently high across the pre- and post-retrofit periods, although they were always less than the 120 second spillage limit.

- Spillage occurred more frequently at the water heater following the installation of the FasNSeal 80/90 venting system, as indicated by the average fraction of water heater cycles with spillage calculated for the outdoor temperature range of 15 to $60^{\circ} \mathrm{F}$ increasing from about 0.12 to 0.32 . However, the average spillage time during cycles with spillage remained relatively unchanged (pre- and postretrofit values were both less than 10 seconds) and spillages of greater than 120 seconds were not generally observed following the installation of the FasNSeal system.

The long length of the flue run in this house likely explains these anomalies. House CO1 is a two-story house above an open basement, where the water heater and furnace are located. This house required the longest flue run of the 16 houses participating in the field demonstration. Such a long flue run can require extra time to establish a draft upon initial firing of the water heater, especially under worst-case depressurization conditions.

The combination of a reduced venting area due to the inner liner in the vertical chimney and the long vertical rise put this installation near the limit of acceptable performance in the NFPA 54 vent tables and is likely why it is experiencing frequent spillage events following the installation of the FasNSeal 80/90 venting system. Significant spillage was seen after the initial installation of the FasNSeal system. For this reason, the interconnecting vent between the water heater and the vertical vent pipe was increased from a 3 in. to a 4 in. diameter, as shown in Figure 5.13, approximately one month after the FasNSeal system was installed. This improved the drafting based on spillage tests performed with a smoke stick. The continuous data monitoring still showed frequent spillage events, but of much shorter durations.
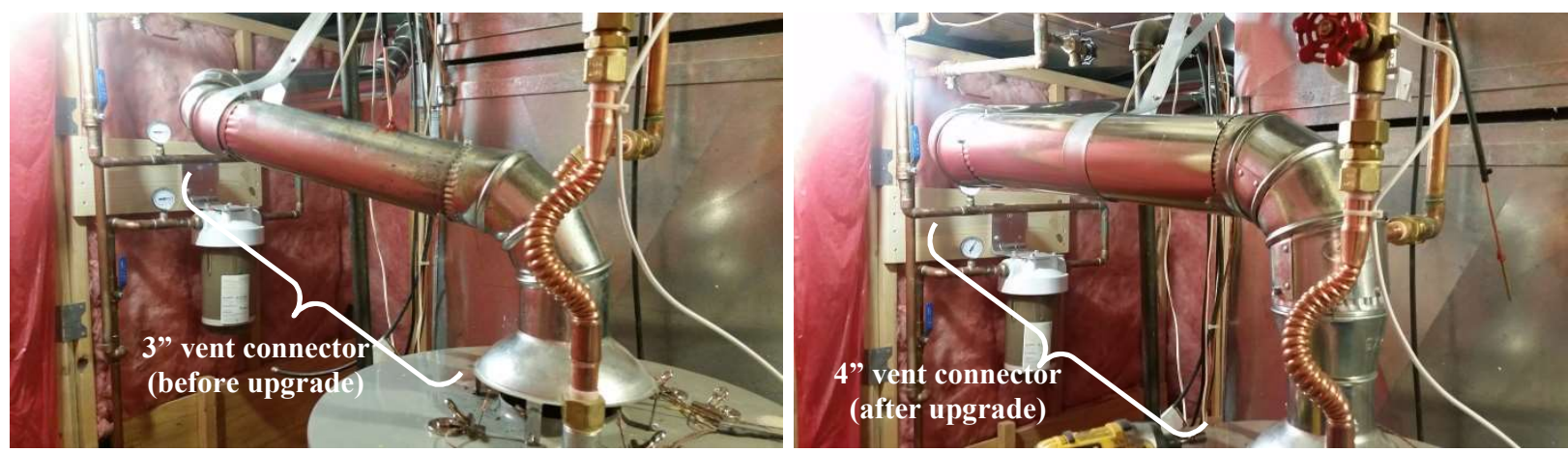

Figure 5.13. Three inch vent connector (left) upgraded to a 4 inch vent connector (right) in House CO1. 


\subsubsection{House PA1}

House PA1 exhibited anomalies with all four of the analyses:

- A spillage time measured as part of the worst-case depressurization venting test at the end of the field demonstration was 300 seconds, although three other post-retrofit tests measured spillage times of just 15,30 , and 60 seconds.

- Spillage occurred frequently at the water heater both before and after the installation of the FasNSeal $80 / 90$ venting system as indicated by two analyses. The fraction of water heater cycles with spillage was always greater than 0.2 in both the pre- and post-retrofit periods as shown in the histogram for this house of the fraction of water heater cycles with spillage (Figure 5.9). The average fractions of water heater cycles with spillage calculated for the outdoor temperature range of 25 to $65^{\circ} \mathrm{F}$ were about 0.5 and 0.6 for the pre- and post-retrofit periods, respectively.

- The number of total spillage times greater than 120 seconds increased from 6 to 20 after the retrofit, although no spillage at start-up was greater than 120 seconds for either period.

The short length of the flue run in this house may explain these anomalies. The length of the venting system in this house was the shortest of the 16 houses used in the field demonstration. As shown in Figure 5.14, the venting from the water heater to the vertical vent pipe was short and direct, and the vent rose just a few feet through essentially a flat roof. Examination of the NFPA 54 vent tables shows that the maximum allowable capacity for a naturally vented water heater decreases as the height of the flue decreases. For example, for a $3 \mathrm{in}$. vent diameter, a $6 \mathrm{ft}$ height, and a $2 \mathrm{ft}$ lateral run, the maximum capacity is $36,000 \mathrm{Btu} / \mathrm{h}$. The $34,000 \mathrm{Btu} / \mathrm{h}$ water heater that is installed should be well below the maximum capacity allowed for the 6 in. B Vent installed before retrofit, so this does not necessarily explain the frequent spillage observed before the installation of the FasNSeal venting system. However, following the retrofit, the water heater capacity may be closer to the acceptable limit with the 4 in. effective diameter of the annular space ( 2 in. inner liner installed in a 6 in. B Vent according to the DuraVent installation instructions).
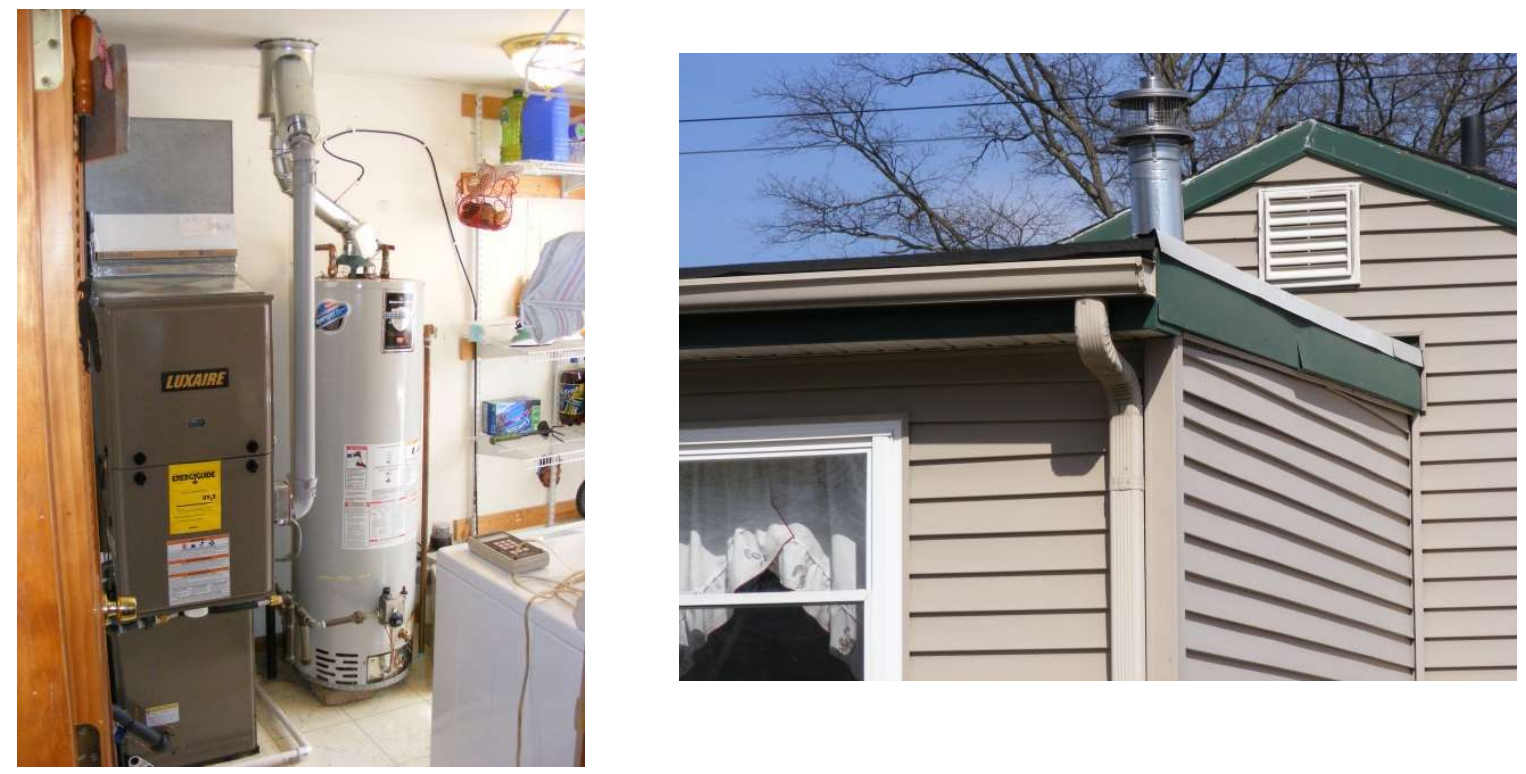

Figure 5.14. Short flue run found in House PA1. 
New 6 in. B Vent was installed as part of the new venting system, so obstruction of the flue is not an explanation for the anomalies. Measurements of the CAZ pressure during venting show that the pressure was typically between -2 and $0 \mathrm{~Pa}$, which should not have presented an issue.

Several possible explanations for the worst-case depressurization venting test measurement of 300 seconds made at the end of the field demonstration were also discounted. The outdoor temperature of $66^{\circ} \mathrm{F}$ at the time of the measurement is not an explanation because all the post-retrofit measurements were taken at about the same outdoor temperature. It was not a windy day. The worst-case pressure that was established in the CAZ for this final measurement was $-2.5 \mathrm{~Pa}$, which was less (more depressurization) than the worst-case CAZ pressure established for the other measurements, but not significantly (the other pressures ranged from -0.5 to $-1.9 \mathrm{~Pa}$ ).

\subsubsection{House PA3}

House PA3 exhibited an anomaly with two of the analyses:

- Spillage occurred frequently at the water heater before the installation of the FasNSeal 80/90 venting system as indicated by two analyses. The fraction of water heater cycles with spillage was greater than 0.2 during the pre-retrofit period for all outdoor temperatures while it was greater than 0.2 in the post-retrofit period only at outdoor temperatures less than $35^{\circ} \mathrm{F}$ and above $80^{\circ} \mathrm{F}$. This is shown in the histogram for this house of the fraction of water heater cycles with spillage (Figure 5.9). The average fraction of water heater cycles with spillage calculated for the outdoor temperature range of 35 to $45^{\circ} \mathrm{F}$ was about 0.75 for the pre-retrofit period while it was only 0.1 for the post-retrofit period.

- The average spillage time during cycles with spillage calculated for the outdoor temperature range of 35 to $45^{\circ} \mathrm{F}$ was over 200 seconds for the post-retrofit period, but less than 25 seconds for the preretrofit period.

The average fraction of water heater cycles with spillage and the average spillage time during cycles with spillage calculated for the pre- and post-retrofit periods for this house are probably misleading because they are based on just a few water heater cycles. The average number of water heater cycles that occurred per day in this house was the least of the 16 houses. As a result, the number of water heater cycles in each of the temperature bins in the pre-retrofit period was generally less than 10 . This limited the outdoor temperature range selected for this house to calculate and compare pre- and post-retrofit values to a very narrow range of 35 to $45^{\circ} \mathrm{F}$.

Closer examination of the scatter plot for this house (Figure 5.9) indicates that the pre- and post-retrofit spillage behavior was similar and did not effectively change following the installation of the FasNSeal $80 / 90$ venting system. The scatter plot shows that long total spillage times on the order of several hundred seconds and more occurred in this house in both the pre- and post-retrofit periods, with more such events being shown in the scatter plot for the post-retrofit period because it spanned a full year rather than only 3 months for the pre-retrofit period. As seen from Table 5.3, there was only one spillage event at startup before retrofit where the spillage lasted more than 120 seconds and only two such events after retrofit. The reason for the long spillage times occurring intermittently during the water heater cycles is not known. 


\subsubsection{House MN2}

House MN2 exhibited anomalies with three of the analyses:

- A spillage time measured as part of the worst-case depressurization venting test at the beginning of the field demonstration was 210 seconds, although a second pre-retrofit test measured no spillage, and no spillage was measured during any of the four post-retrofit tests.

- The average spillage time during cycles with spillage calculated for the outdoor temperature range of 15 to $85^{\circ} \mathrm{F}$ was about 75 seconds for the post-retrofit period, but less than 10 seconds for the preretrofit period.

- The number of total spillage times and spillage time at start-up greater than 120 seconds increased from 1 to 58 and 55, respectively, after the retrofit.

The change in spillage behavior following retrofit as indicated by the change in the average spillage time during cycles with spillage and the increase in spillage events greater than 120 seconds may be due, in part, to a leak in the return duct introduced during the installation of the new condensing furnace. The furnace and water heater were in a small $15 \mathrm{sq}$. $\mathrm{ft}$ closet with solid folding doors in the living space of the house (Figure 5.15). A leak introduced in the portion of the return duct located in the closet would pull air from the closet and effectively down the water heater flue when the furnace or air-conditioner were running, making it harder for the water heater to vent properly.

Figure 5.16 shows the daily average pressure difference between the CAZ and the outdoors (blue for the pre-retrofit period and gray for the post-retrofit period) and the daily average pressure difference between the CAZ and the outdoors only when the furnace, and therefore the supply air blower, was running (orange for the pre-retrofit period and yellow for the post-retrofit period). The average daily pressure difference between the CAZ and the outdoors was about the same before and after retrofit, but the pressure

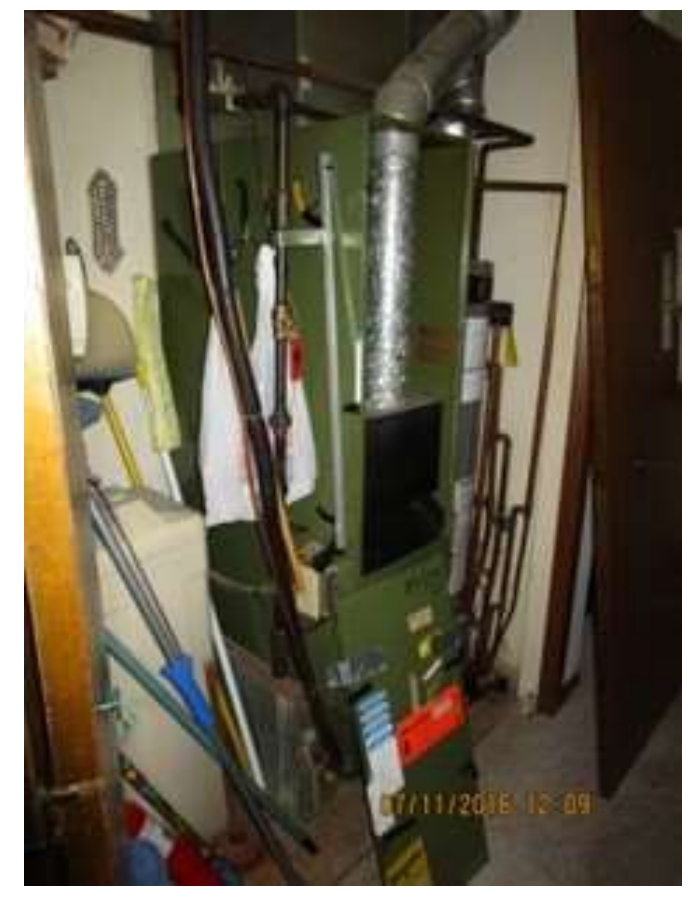

Figure 5.15. House MN2 furnace closet. difference when the supply air blower was running was noticeably different following retrofit. The CAZ became more depressurized relative to the outdoors in the post-retrofit period when the supply air blower was running compared with the average daily pressure in the CAZ; this behavior did not occur in the pre-retrofit period. 


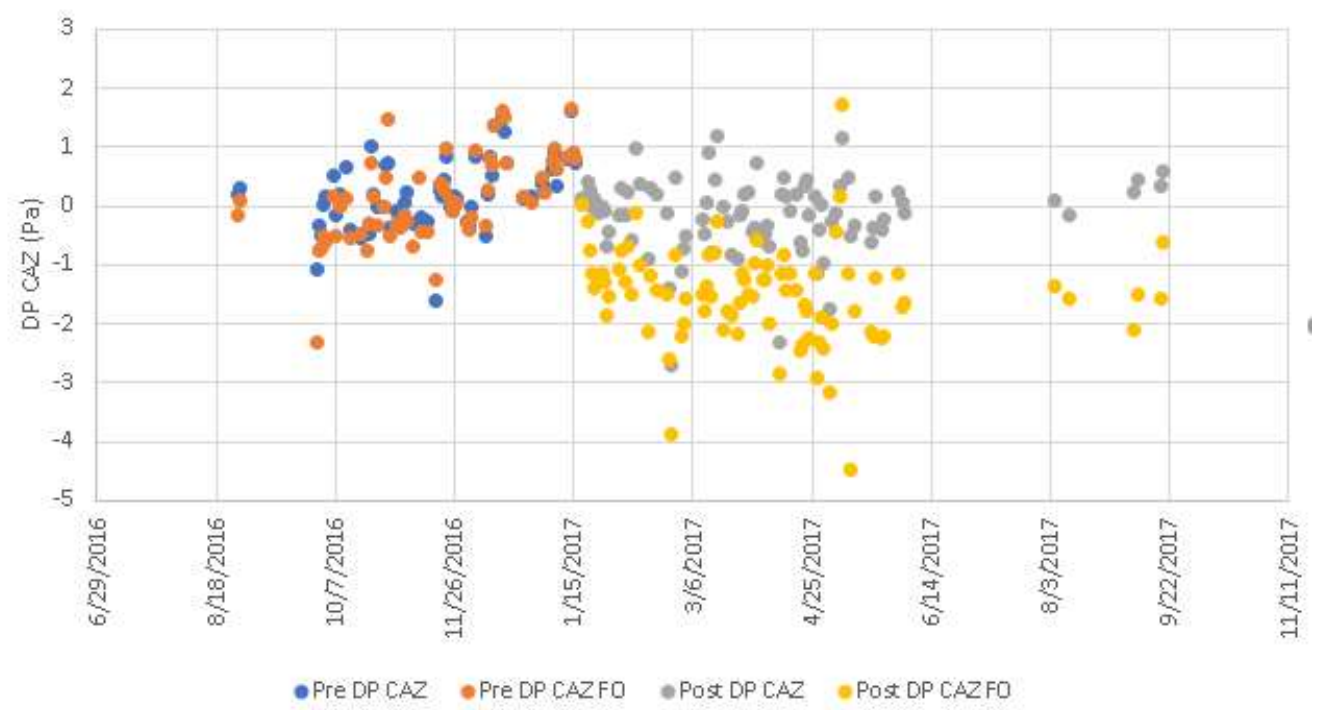

Figure 5.16. Daily average pressure differences between the CAZ and the outdoors in House MN2. (FO means furnace on)

The operational impact of the supply air blower on the CAZ pressure and the venting system is shown more directly in Figure 5.17. At the same time that the condensing furnace turns on (as shown by the blue bars in the plot on the left in Figure 5.17), the pressure difference between the CAZ and the outdoors (the black line labeled DP_CAZ) decreases noticeably and the pressure difference between the vent and the CAZ (the red line labeled DP Vent) increases, which indicates a downflow of air. A similar decrease in the CAZ pressure and an increase in the vent pressure can be seen in the plot on the right in Figure 5.17 when the air-conditioner turns on (as shown by the blue bars).

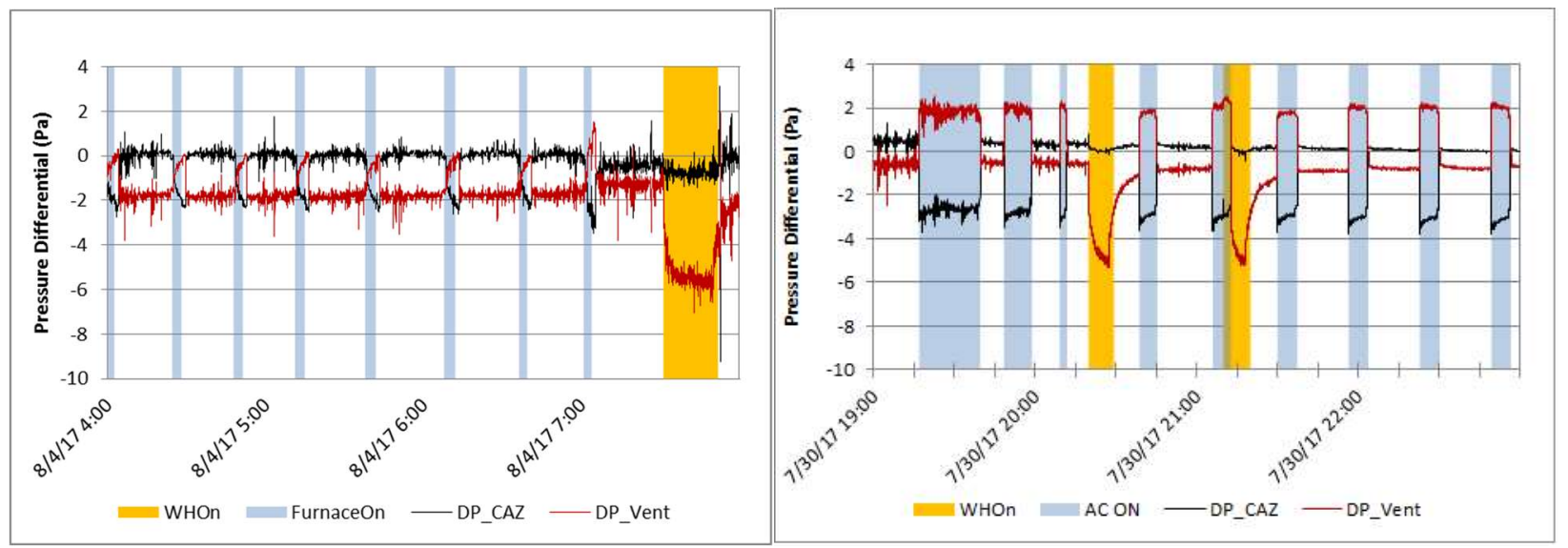

Figure 5.17. Post-retrofit $\mathrm{CAZ}$ and vent pressures during supply air blower operation during furnace operation (left) and air-conditioner operation (right) in House MN2.

A greater depressurized CAZ when the supply air blower is running presents more challenging conditions for the water heater to establish a draft when it is firing while the supply air blower is running. This would lead to increased spillage during the post-retrofit water heater cycles, but only for those cycles that coincided with times when the supply air blower was also running. Therefore, in Figure 5.10 for MN2, there were still water heater cycles where the spillage was zero during the post-retrofit period. Because the air-conditioner uses the furnace's supply air blower, CAZ depressurization would also occur when the 
air-conditioner ran. Therefore, in Figure 5.10 for MN2, spillage across all post-retrofit outdoor temperatures was observed.

A decrease in the CAZ pressure relative to the outdoors when a supply air blower runs is indicative of a leak in the return duct located in the CAZ. It is possible that a return leak was introduced when the condensing furnace was installed, perhaps where the return connects to the new furnace.

A furnace pulling combustion air from the CAZ would also cause the pressure in the CAZ to decrease when it was firing. This does not appear to be an explanation for the observed decrease in CAZ pressure when the furnace ran in the post-retrofit period for several reasons:

- This would only explain CAZ depressurization and hence spillage during colder outdoor temperatures when the furnace ran but not at warmer outdoor temperatures when it would not run.

- A condensing furnace requires less combustion air for the same input.

- The condensing furnace that was installed was a smaller capacity than the original, non-condensing furnace (44 kBtu/h versus $75 \mathrm{kBtu} / \mathrm{h}$, respectively), so it should pull less air from the CAZ.

- No changes were made to the closet doors or make-up air system.

The differences in spillage measured by the pre-retrofit worst-case depressurization venting tests may be due to the outdoor temperatures at the time the measurements were taken. The outdoor temperature for the first pre-retrofit test when the measured spillage time was 210 seconds was $82^{\circ} \mathrm{F}$, while it was $9^{\circ} \mathrm{F}$ for the second test when no spillage was observed. It is generally easier to establish a draft at start-up when the temperature is colder.

The reason that the post-retrofit venting tests did not observe any spillage when the water heater and furnace were firing at the same time may have been because the closet doors were open during the tests. There was not enough room in the small CAZ room for a person to stand to observe the spillage while the venting tests were performed. The open doors may have prevented the depressurization of the CAZ when the furnace ran.

\subsubsection{House MO3}

House MO3 exhibited anomalies with three of the analyses:

- Spillage times measured as part of the pre-retrofit worst-case depressurization venting tests were greater than 120 seconds, although they were 60 and 0 seconds for the two post-retrofit tests.

- The average fraction of water heater cycles with spillage calculated for the outdoor temperature range of 65 to $85^{\circ} \mathrm{F}$ was about 0.5 for both the pre- and post-retrofit periods. The average spillage time during cycles with spillage calculated for the same outdoor temperature range was about 75 seconds for the pre-retrofit period, but less than 5 seconds for the post-retrofit period.

- There were 40 instances before retrofit where the total spillage time and spillage time at start-up were greater than 120 seconds, but none after retrofit. 
The high frequency of spillage calculated for the outdoor temperature range of 65 to $85^{\circ} \mathrm{F}$ is likely because it is more difficult to establish a draft at high outdoor temperatures. This same behavior was observed for Houses MO1 and MO2. As seen in the scatter plots for these three houses provided in Figure 5.11, there are many spillage cycles of short duration as evidenced by the number of data points just above the x-axis.

The decrease in spillage times from the pre-retrofit period to the post-retrofit period was likely due to an upstairs ventilation fan and basement return grill that were reconfigured between the pre- and post-retrofit periods rather than the installation of the FasNSeal 80/90 venting system.

The water heater and furnace are installed in separate but adjacent equipment rooms located in the conditioned basement of House MO3. As shown in Figure 5.18, the white paneled door on the right opens into the furnace room, while the paneled door on the left opens into a large storage/laundry room where the water heater is installed.

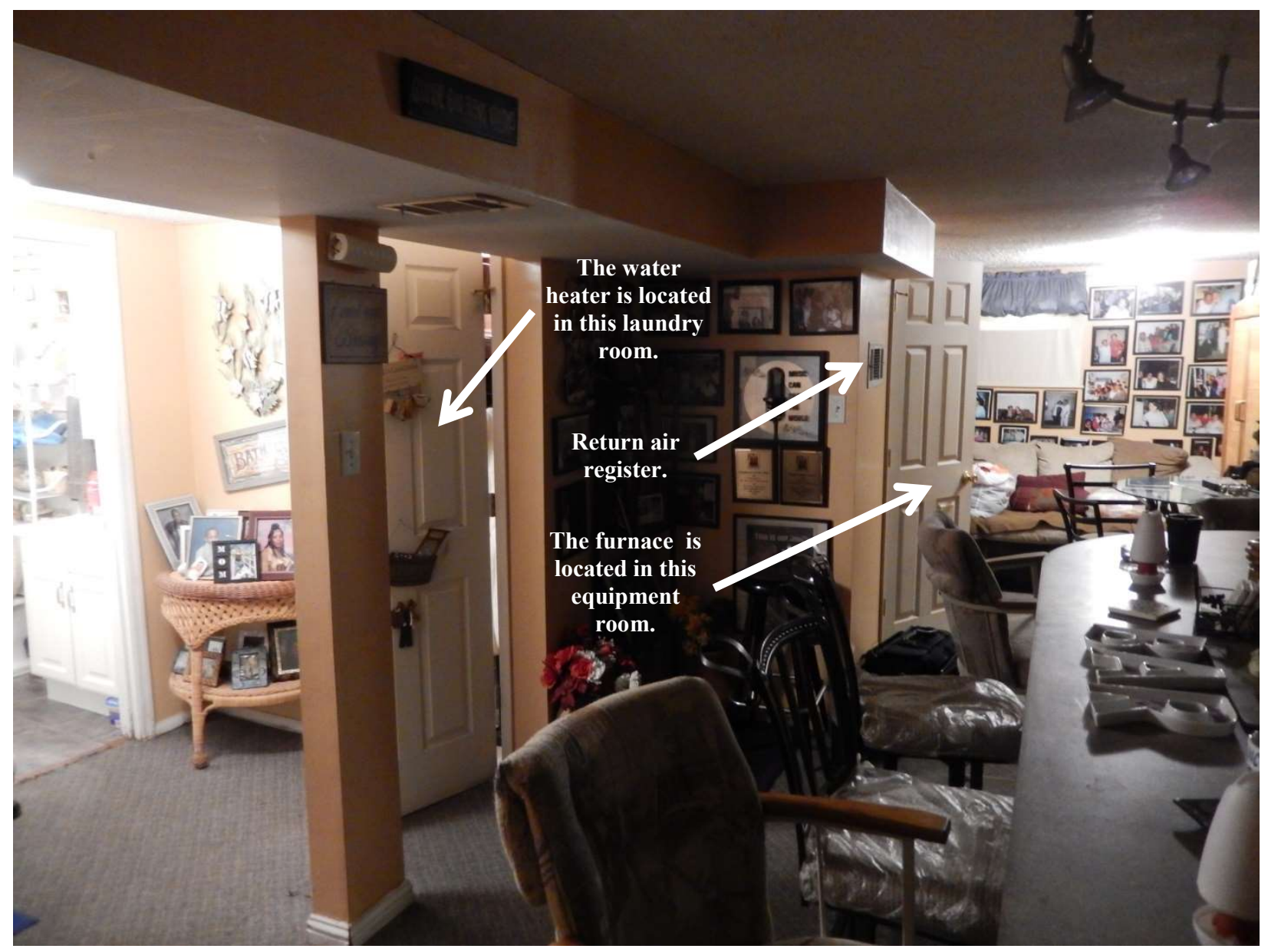

Figure 5.18. Basement equipment rooms in House MO3.

During the initial worst-case depressurization venting test taken at the beginning of the field demonstration, the time to establish the draft of just the water heater was measured to be 124 seconds. This indicated that the combustion air supply to the water heater was not adequate. Because doors were present on the water heater and furnace equipment rooms, passive grills were installed into these rooms about a week after the initial venting test to provide better air communication between the rooms and the basement. Also, a passive grill was installed above the basement door leading to these equipment rooms 
to ensure adequate combustion air supply. The venting test was then repeated. The results indicated that the venting had been improved, as it took just 10 seconds for the water heater to establish a draft in this post-remediation test.

However, the pre-retrofit monitoring data continued to show higher CAZ depressurization compared with other houses, which resulted in more frequent spillage events during the pre-retrofit period. On the day the condensing gas furnace and FasNSeal venting system were to be installed in House MO3, a worstcase depressurization venting diagnostic test performed before the retrofit was performed again measured a water heater spillage time in excess of 120 seconds, which indicated that the conventional venting system had again failed the test. It was noted that the first floor hallway bathroom exhaust fan used to provide whole-house ventilation in compliance with ASHRAE 62.2 was set at its maximum speed of $81 \mathrm{cfm}$ rather than a flowrate of $56 \mathrm{cfm}$ which had been calculated for the house per ASHRAE 62.2. To correct this, the exhaust fan was reset to $56 \mathrm{cfm}$. In addition, a small return register in the basement that had been open was closed to reduce the depressurization of the basement when the air handler was on (recall that a passive grill had been installed above the basement door to connect the basement to the rest of the house). The diagnostic test was then repeated. The results indicated that the venting system had again been improved, as the time it took for the water heater to stop spilling was reduced to 58 seconds.

The venting test performed after the condensing furnace and FasNSeal 80/90 venting system were installed (with the ventilation fan set to $56 \mathrm{cfm}$ and the basement return grill closed) measured 60 seconds for the water heater to stop spilling. As a result, the occupants were instructed to always leave the basement return register closed to ensure proper venting. Thus, the subsequent post-retrofit monitoring period was performed with the house configured differently from the pre-retrofit period, which likely contributed to the improvement in the performance of the ventilation system.

Although the improvement in the ventilation performance in House MO3 cannot be attributed to the FasNSeal 80/90 venting system, this does not negate the good venting performance observed for the FasNSeal $80 / 90$ venting system in the post-retrofit period. 


\section{VENTING SYSTEM INSTALLATION RESULTS AND FEEDBACK}

The crews that performed the installations of the new condensing furnaces and the FasNSeal 80/90 venting systems were asked to provide feedback on the installation and system. In-house staff performed the installations at two agencies, while contractors that the agencies routinely hired to perform equipmentrelated work for them were used to perform the installations at the other two agencies.

The crews provided feedback on the level of difficulty associated with the installation of the FasNSeal 80/90 venting system and identified installation issues they encountered. Ease of installation impacts the willingness of other contractors to utilize the product and helps determine if there are any training or product deficiencies.

Contractors estimated the time required to install the new venting system and the time that it would take once they had become proficient with its installation. Because the FasNSeal 80/90 venting system was new, the installing contractors did not have any previous experience with the product, resulting in longer than normal installation times. The contractors also estimated the possible time and material cost differences between using the new venting system and using a more standard side-wall venting approach (where feasible).

Finally, feedback was obtained from the contractors on whether they foresaw future use of the FasNSeal $80 / 90$ venting system by them or others.

\subsection{MATERIAL COSTS}

New condensing furnaces were installed in all 16 demonstration homes using the FasNSeal 80/90 venting system. Based on invoice and billing information provided by the four agencies, the average material cost associated with the installation of the new venting system itself was about \$678. ECA's and SRC's average costs of $\$ 726$ and $\$ 728$, respectively, were a little higher than ERC's and CAASTLC's average costs of $\$ 634$ and $\$ 625$, respectively. ECA bought their materials for all four houses at one time and were required to purchase a minimum order quantity for some items; thus, they had some material left over when the four houses were completed. Although they could use this extra material on future jobs, this did contribute to higher average costs being calculated for the four ECA jobs. SRC also noted that they had unused materials because of their unfamiliarity with the system, which again contributed to a higher average cost for this agency.

ERC's material costs in individual houses ranged from about $\$ 480$ to $\$ 724$. The other three agencies bought materials in bulk for all four houses, so individual costs per house could not be determined. A primary contributor to this variation in cost among houses was the cost of the flexible inner liner, which varied based on the length and diameter needed for the individual house.

ECA installed a new chimney liner in each of their four homes, even though this is not required for use of the FasNSeal 80/90 venting system. However, DuraVent does recommend in their installation instructions to inspect the physical condition of the existing B Vent and to clean and repair it as needed. In the two oldest homes (Houses PA3 and PA4), the existing B Vent was sufficiently rusty that a new chimney liner may have been warranted. Considering the lifetime of the new condensing furnace and how long the new venting system will remain in use in the house, installing a new chimney liner may be a good standard or preventive maintenance practice, especially in older homes. Installing the new chimney liner added about $\$ 150$ in material costs to the average costs provided above. 


\subsection{INSTALLATION TIME}

All four agencies used two-person crews to perform the installation of the FasNSeal 80/90 systems. The agencies estimated that the total time required to install the complete FasNSeal 80/90 venting system was about 2-2.5 hours and 4-5 person-hours (with an additional 0.5 hours and one person-hour required if a new B Vent was also installed). Three of the four agencies felt that this time could be reduced by $30-60$ minutes after crews became proficient in the installation of the FasNSeal 80/90 venting system.

ECA and ERC estimated that the installation of the flexible inner liner and vent cap took about 1 hour ( 2 person-hours) to complete. ECA estimated that removing the existing B Vent and installing a new one took an additional 30 minutes or 1 person-hour. ERC estimated that it took an additional hour (2 personhours) to connect the venting from the condensing furnace and water heater to the main venting system. ECA estimated that this work took about 1.5 hours ( 3 person-hours).

The agencies felt that two-person crews would generally be needed to install the FasNSeal 80/90 venting system, especially the installation of the flexible inner liner and vent cap. They felt that two people would be needed to navigate the flexible inner liner through the existing B Vent, especially if the inner liner was installed coming out of the branch of the wye at the bottom of the B Vent rather than exiting at the bottom of the wye or tee. Under this installation mode, one person is needed to feed the inner liner from the roof to keep it from being caught up on the edges at the top end of the B Vent while one person guides the liner into and through the branch of the wye. Use of a two-person crew would also be safer considering roof work and ladders. One agency noted that "one person might be able to perform this task, but they "wouldn't be happy." Once the flexible inner liner and vent cap are installed, the agencies did acknowledge that one person could complete the installation on their own.

\subsection{COMPARISON OF COSTS TO OTHER VENTING OPTIONS}

Feedback obtained from the agencies indicated that use of the FasNSeal 80/90 venting system may not significantly increase the cost associated with a condensing furnace installation, especially in certain applications. Of course, the FasNSeal venting system may be the only known option available if side-wall venting or installing a second vertical vent are not feasible.

Three of the agencies estimated that the material cost associated with a typical side-wall venting installation was about $\$ 100$ to $\$ 250$, or about $\$ 425$ to $\$ 575$ less than the FasNSeal $80 / 90$ venting system. The fourth agency estimated a smaller cost difference of only $\$ 200$ because they also routinely install a new 4 in. chimney liner for the water heater. One agency felt that as the industry moves from PVC to PolyPro in all applications, this price difference will decrease.

Several agencies indicated that it would take the same or less time (1 to 2 person-hours less) to install side-wall venting compared to installing the FasNSeal System in typical applications (e.g., when the equipment room is next to the side wall of the house). However, in difficult installations, (e.g., if the condensing furnace is not adjacent to an exterior wall or the exterior wall is brick), several agencies indicated that the installation time using the FasNSeal 80/90 venting system could be less than the time it takes to install side-wall venting. One agency also noted that, when side-wall venting is not possible, the FasNSeal 80/90 venting system would be faster to install compared with installing two PVC pipes out the roof. Therefore, the higher material costs associated with the FasNSeal 80/90 venting system could be balanced against reduced labor costs in some installations. 


\subsection{PRODUCT AND INSTALLATION FEEDBACK}

The agencies and contractors generally felt that the FasNSeal 80/90 venting system was a good product that they and other contractors would consider using once the product was approved for use by equipment manufacturers. The agencies felt that the FasNSeal 80/90 venting system could be especially useful in multifamily buildings or installations in which side-wall venting could not be installed, new holes could not be cut in a roof, or a basement that was completely underground. One agency indicated that the FasNSeal 80/90 venting system provided a cleaner installation than side-wall venting and that the crew liked the PolyPro piping such that they were "sold on it and would use it on any B Vent application," but another said they would use it "only as a last resort."

The agencies understood that there is always a learning curve with any new product, and the installation is always a little different from house to house. They generally felt that the installations were simpler, easier, and more straightforward after they had completed the first house, especially when a DuraVent representative had been present at the first house to address any issues that arose.

The agencies believed that other contractors would consider using the FasNSeal 80/90 venting system once the product became more mainstream and all the vendors in the supply chain became more aware of the product. Several agencies indicated that other contactors would be skeptical and have some initial concerns because of the uniqueness of the system. They felt that training would be vital and having the FasNSeal80/90 venting system and PolyPro material stocked locally would be important to reduce planning concerns. One agency noted that the product is "not average installer proof yet."

The agencies and contractors noted that weather and tall roofs could pose an installation issue for the FasNSeal 80/90 venting system because having safe access to the roof is required. Weather conditions can restrict access to the roof and create unsafe working conditions on the roof, although one contractor noted that this is no different from other installations because they are up on the roof anyway. Tall roofs are an issue because of safety concerns with getting personnel, tools, and material to the roof. One installation in the field demonstration had to be delayed a few days because it snowed on the originally scheduled installation day.

The agencies pointed out that the FasNSeal 80/90 venting system cannot always be installed in a house. The system could not be used if the existing B Vent has any "offsets" in it (e.g., a $90^{\circ}$ elbow installed to miss a roof peak) because the flexible inner liner cannot have more than a 45-degree slope while traveling through the existing B Vent. All the installations performed in the field demonstration used a straight B Vent, so it is not known how easy it would be to insert the flexible inner liner through bends with less than a $45^{\circ}$ slope in the B Vent. Other times the FasNSeal 80/90 venting system could not be installed if a $4 \mathrm{in}$. B Vent is currently installed or the capacity of the water heater is too big to vent through the annular space provided by the FasNSeal 80/90 venting system.

One major concern noted by one agency was that the DOE Weatherization Assistance Program administered in the state requires all new furnaces to be sealed combustion (i.e., combustion air must be drawn directly from the outside). The FasNSeal 80/90 venting system only addresses the venting issue when a replacement condensing furnace cannot be vented in the traditional manner through a side wall. If the condensing furnace cannot be side-wall vented, then a dedicated pipe for combustion air probably cannot be installed either.

The remainder of this section discusses feedback provided by the agencies and contractors on specific installation-related topics and the product literature and support. 


\section{Installation-Related Topics}

An important issue that arose at every agency was the connection of the PolyPro to the condensing furnace. The DuraVent literature available at the time two agencies ordered material for the March 2016 installations did not identify the availability and use of a "PolyPro Appliance Adapter for PVC Coupler." At one agency, the proper connector was provided by a DuraVent representative present at the first installation and used in three houses, while in the other house the PolyPro was run directly to the furnace blower inside the furnace cabinet. At the other agency, a rubber reducer was used to make the connection at three houses (see Figure 6.1a) and an alternative method was used at a fourth house (see Figure 6.1b). The remaining two agencies also had issues even though the adaptors were ordered based on updated DuraVent literature. One agency prematurely converted from PolyPro to PVC before reaching the condensing furnace because of their unfamiliarity with PolyPro. The other agency encountered an issue with the length of the adaptor and the clamp provided to secure the assembly. This agency used a small length of PVC to complete the installation (Figure 6.1c).

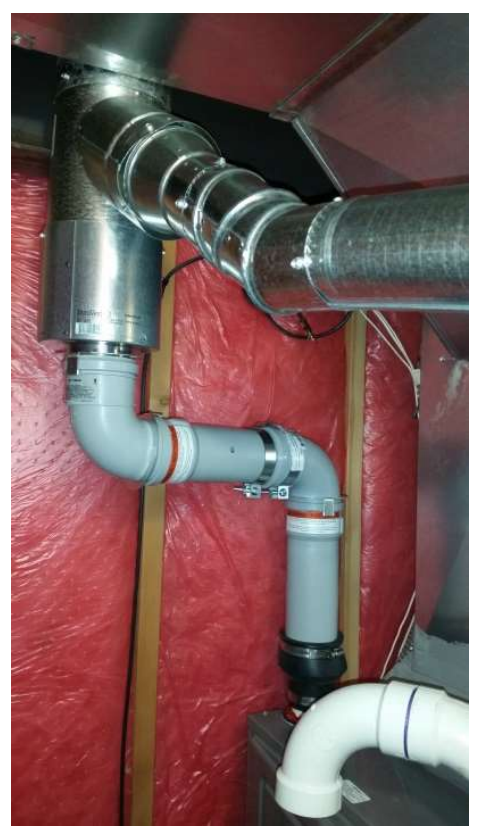

(a)

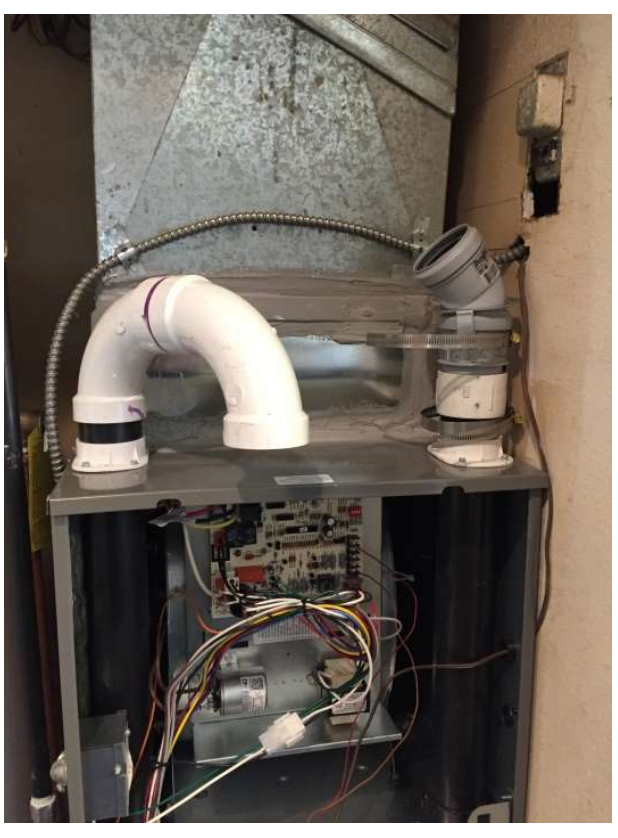

(b)

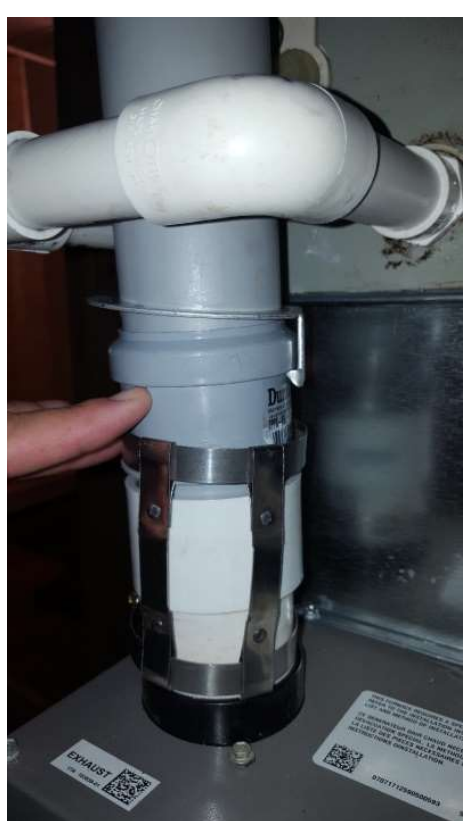

(c)

Figure 6.1. Alternative methods of connecting the PolyPro to the furnace.

A second major issue that arose at three of the agencies dealt with the tee/wye and universal adaptor at the bottom end of the B Vent (this issue did not occur at the fourth agency because it installed all new B Vents). The FasNSeal 80/90 venting system literature implies that a DuraVent tee/wye is needed if the existing tee-wye needs to be replaced, and a DuraVent female vent adaptor is needed if the existing B Vent is not DuraVent. Several contractors revealed that in some installations a tee-wye and/or adaptor would not have been needed or a fitting from another manufacturer, especially from the same manufacturer as the B Vent, would have worked just as well if not better. More problematic was that two agencies had trouble getting the universal adaptor to fit onto the existing B Vent tightly and securely in several houses. DuraVent provides different universal adaptors to accommodate different brands of B Vent. The selection of the correct adaptor was not clear, and the purchase of an incorrect adaptor may have contributed to the problem. However, DuraVent representatives who were on-site at two of these installations were unable to provide guidance or identify a fitting that would have worked better. 
Several agencies reported difficulty in connecting the 2 in. flexible inner liner to the vent cap. The vent cap may be designed to accept both a 2 in. and 3 in. inner liner, with a bushing used with the 2 in. inner liner to accommodate the smaller diameter. One agency reported that the worm-drive hose clamp (Figure 6.2a) forms an oval rather than a circle (Figure 6.2b) when tightened, which makes for a lessthan-secure fit. At the first house this agency worked on, the vent cap came loose from the liner on the first tightening attempt, although additional tightening produced a secure connection. A second agency found that they needed to use an impact drill to tighten the clamp sufficiently. At a third agency, a DuraVent representative who was on-site provided some instruction on how to overcome this problem: remove the exhaust screen, use a screwdriver to get the liner installed the 1 last $1 / 2$ in. into the vent cap, and then tighten the hose clamp. Additionally, one agency reported a concern with the amount of hightemperature sealant needed to seal the inner liner to the vent cap, possibly because they were doing so from the inside of the vent cap (i.e., from the perspective of Figure 6.2b) rather than from the top.

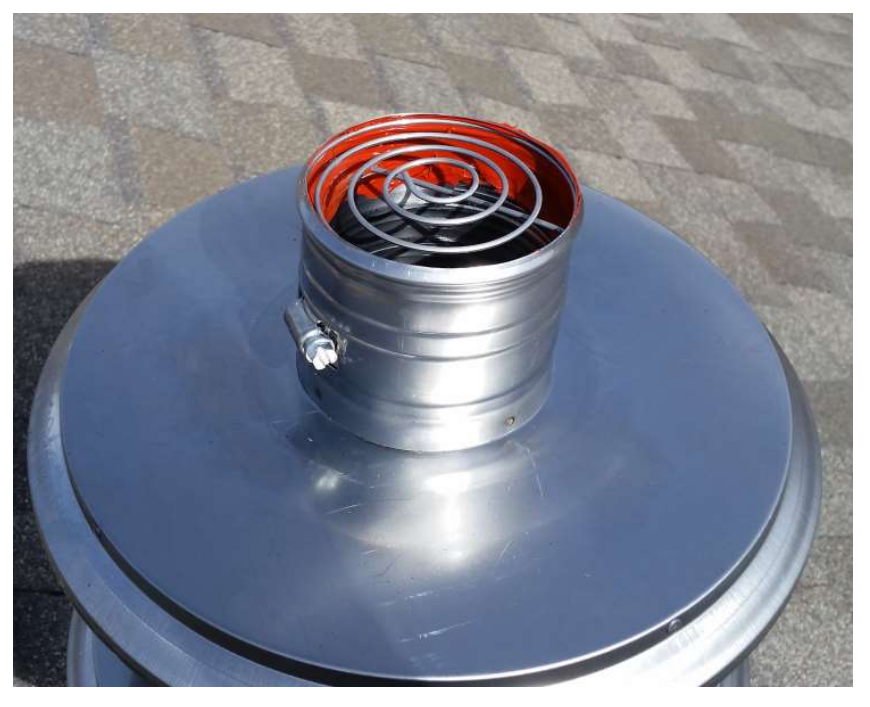

(a)

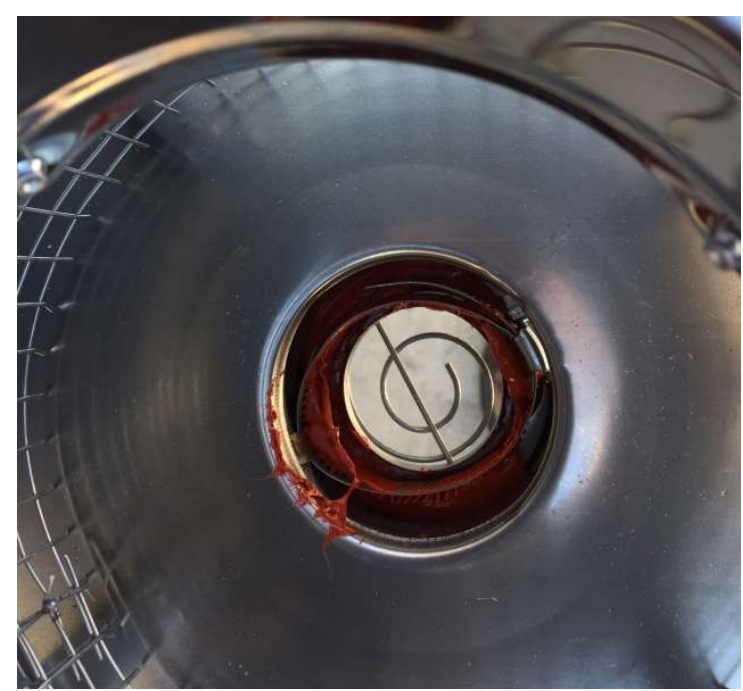

(b)

Figure 6.2. Vent cap's worm-drive hose clamp that becomes oval when tightened.

There were several minor issues reported with the installation of the fire stop which is installed over the adaptor that connects the flexible inner liner to the PolyPro. One agency reported that the hole is loose in the 2 in. fire stop (Figure 6.3a) where the PolyPro to inner liner adaptor penetrates, whereas the hole is a good, tight fit in the $3 \mathrm{in}$. fire stop (Figure $6.3 \mathrm{~b}$ ). This agency sealed the $1 / 4 \mathrm{in}$. gap with high-temperature caulk in this one house. Space limitations required this same agency to cut down the fire stop at two houses to facilitate better rise from the furnace. At a second agency, a DuraVent representative on site at the first house provided guidance on how to install the fire stop: turn it, twist it, and then cinch it up.

None of the agencies had any prior experience in using PolyPro. The agencies reported that extra planning was required in purchasing the PolyPro because it is directional, sold in fixed lengths, and not stocked locally. At least one agency reported some confusion about the clamps needed. Several agencies reported loose connections where the PolyPro connected to 45 or 90 degree connectors (with the metal connectors). One agency received some additional instruction on this from a DuraVent representative who was on-site at the first installation. One agency is concerned about the longevity of the rubber gasket seal used with the PolyPro connections due to acid from the flue gases. 


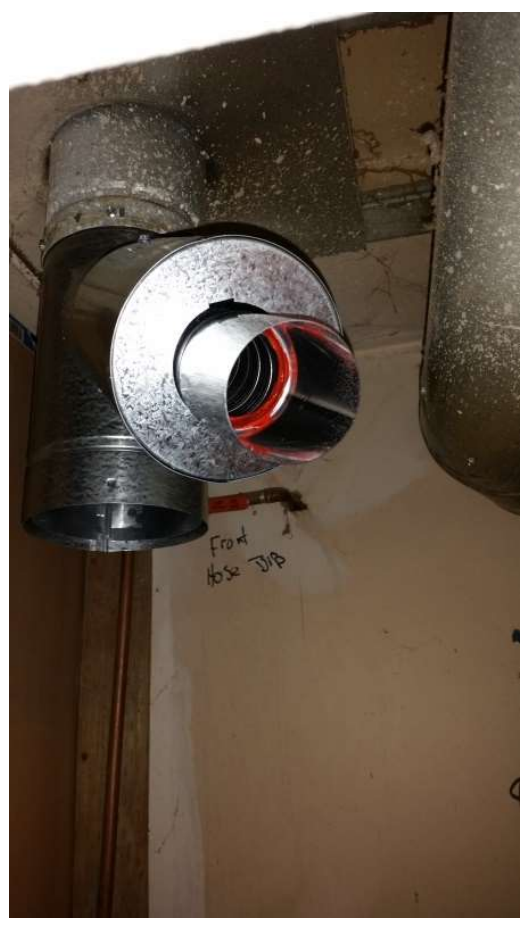

(a)

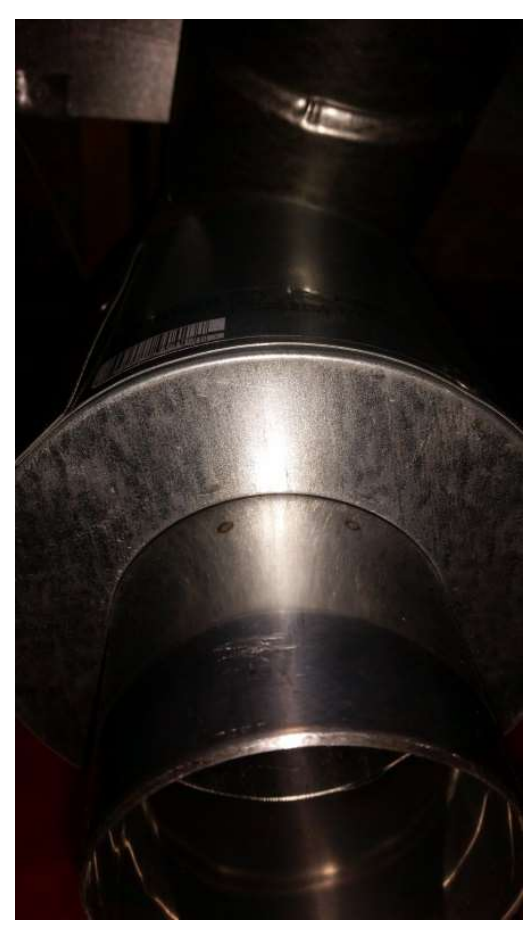

(b)

Figure 6.3. Loose fit in the 2 in. fire stop compared with the 3 in. fire stop.

Several other miscellaneous issues were also mentioned.

- One agency had a minor worry about cutting the flexible inner liner to the right length initially.

- One agency remains concerned that a 3 in. inner liner installed though a 5 in. B Vent may not provide enough annular area to vent a typical water heater (e.g., $40 \mathrm{kBtu} / \mathrm{h}$ ), especially when the length of the vent is long.

\section{DuraVent Literature and Support}

The agencies uniformly felt that DuraVent's purchasing-related literature needed to be improved so that a user would know exactly what materials needed to be ordered. The agencies that used the updated literature still felt that multiple catalogs were needed to identify all the required materials, especially regarding the PolyPro material and B Vent universal adaptors. An order form listing all the product options with part and model numbers would be useful.

The agencies felt that DuraVent's current installation instructions are easy to understand and clear and concise enough to generally learn how to install the system. However, additional details need to be provided on the following: the need to remove the existing B Vent or not, the connection of the inner liner to the vent cap, the need for and installation of a universal B Vent adaptor and the acceptability of other manufacturer options, the installation of the fire stop, the installation and use of PolyPro, and the connection of the PolyPro to the furnace. Additionally, one agency suggested that installation instructions specific to the FasNSeal 80/90 venting system along with general instructions for other typical uses be included with each component to avoid conflicting instructions. 
Because of the wide variations in B Vents, furnace specifications, water heaters, wyes and tees, reducers, etc., one agency indicated a need for more education specifically on the FasNSeal 80/90 product line and then the use of PolyPro (e.g., sizes, connectors).

A DuraVent representative was present at the first house the installation was performed in at each agency. In many cases, the representatives provided helpful installation instructions and materials as noted several times above. However, at several agencies, installation-related questions could not be answered, particularly regarding the use and installation of the universal B Vent adaptor. 



\section{CONCLUSIONS AND RECOMMENDATIONS}

\subsection{CONCLUSIONS}

The design of the FasNSeal 80/90 venting system provides adequate vent performance in the types of houses and climate conditions tested such that a condensing furnace and natural-draft water heater can be properly vented in the same vertical space using its pipe-within-a-pipe configuration (i.e., with the condensing furnace vented through the inner pipe and the natural-draft water heater vented through the annular space between the pipes). This conclusion is based on the observation that, barring any mechanical failures, a condensing furnace will always vent properly through the inner pipe of the FasNSeal system because it is connected directly to the furnace and extends directly to the outdoors. This conclusion is also based on the following field test results that showed that the FasNSeal 80/90 venting system successfully vented the natural-draft water heater in each of the 16 demonstration homes following the replacement of the non-condensing furnace with a condensing unit:

- Worst-case depressurization venting tests performed per the ANSI/BPI-1200-S-2015 Standard immediately after the installation of the condensing furnace in each house and several additional times during each house's post-retrofit monitoring period measured no spillage times at the water heater that exceeded the 2 minute (120 second) spillage limit for a water heater except for one measurement in one house. Three other measurements in this one house were less than the 120 second spillage limit. For comparison, two measurements taken on the existing water heaters before the condensing furnaces and FasNSeal 80/90 venting systems were installed exceeded the 120 second spillage limit.

- Instrumentation that continuously monitored the venting performance of each water heater measured water heater spillage cycles that exceeded 120 seconds in four houses following the installation of the FasNSeal 80/90 venting system. However, only one or two such cycles were measured in two of these houses, and just seven such cycles were measured in a third house over a year-long post-retrofit monitoring period. A leak in the return side of the furnace/air-conditioner air distribution system introduced when the condensing furnace was installed likely caused the spillage events measured in the fourth house. For comparison, one spillage cycle that exceeded 120 seconds was measured in three houses before retrofit, and 40 such cycles were measured in a fourth house during the preretrofit period.

- The frequency of spillage and average spillage time with non-zero spillage were about the same or better before and after retrofit for thirteen houses. For these houses, the average spillage times with non-zero spillage were less than 25 seconds before and after retrofit $(75$ seconds for one house before retrofit). The fractions of water heater cycles with spillage were generally less than 0.1 before and after retrofit, although they were 0.2 for one house and greater than 0.5 in three houses (although for these three houses the average spillage times were extremely short, on the order of 1 second). For these latter three houses, the high frequency of spillage was probably because the outdoor temperature range used for the houses to calculate these values was restricted to higher outdoor temperatures when it is more difficult to establish a draft. In the remaining three houses, anomalous post-retrofit venting performance could be explained by long or short venting runs and a duct leak introduced during the installation of the new condensing furnace.

- The patterns of the fraction of water heater cycles with spillage as a function of outdoor temperature were the same before and after retrofit in all houses except one. The fraction of water heater cycles with spillage was generally less than 0.2 at lower outdoor temperatures and became more frequent at higher outdoor temperatures in 11 houses, although the fraction of water heater cycles with spillage 
was always less than 0.2 in three houses while it was always greater than 0.2 in one house. The average spillage time for water heater cycles with non-zero spillage were generally less than 20 seconds at colder outdoor temperatures for all houses during the pre- and post-retrofit periods except for one house during each period (a different house each period). The spillage times were also usually less than 20 seconds at higher outdoor temperatures except for two houses during the pre-retrofit period and four houses during the post-retrofit period.

- As indicated above, the field demonstration found that the venting performance of the FasNSeal $80 / 90$ venting systems was generally comparable with the performance of the venting systems initially installed in the houses. Stated another way, minor spillage events, such as those described above for the FasNSeal 80/90 venting system, do not necessarily indicate unacceptable performance because comparable venting performance was observed before the FasNSeal 80/90 venting systems were installed, although not always in the same houses.

Trained crews can successfully install the FasNSeal 80/90 venting system, although literature and training materials could be improved. The field demonstration found that the installation is best performed by a two-person crew, especially when the flexible inner liner is inserted into the existing B Vent. The field demonstration also found that crews had some difficulty in understanding the complete set of materials needed to install the FasNSeal venting system and that there was a short learning curve to becoming proficient in the installation of the system, especially in the use of the PolyPro piping used to connect the condensing furnace to the flexible inner liner. Crews used to perform the installations for the field demonstration were not familiar with the availability of the system and felt that crews in general would need considerable exposure to the new system through demonstrations and training to become comfortable with using it. Several possible design improvements to the FasNSeal 80/90 venting system were identified as the field demonstration was performed. The methods for clamping the flexible inner liner to the vent cap and connecting the PolyPro to the condensing furnace should be further investigated.

The FasNSeal 80/90 venting system provides a potentially comparable or lower cost option in installations in which side-wall venting is difficult or a second vertical vent is required. Installation times were estimated to be 2-2.5 hours for a two-person crew, although agencies felt that this time could be reduced as crews gain experience with the new system. Material costs associated with the FasNSeal $80 / 90$ venting system were estimated to be about $\$ 678$. Costs associated with the purchase and installation of the FasNSeal 80/90 venting system were estimated to be higher compared to a typical sidewall venting installation (about 1 to 2 person-hours more and $\$ 200$ to $\$ 575$ more in material costs). However, agency personnel felt that total installation costs could be comparable or even less in those applications where side-wall venting installation is difficult, (e.g., if the condensing furnace is not adjacent to an exterior wall or the exterior wall is brick) or a second vertical vent would be required. In instances where side-wall venting or installing a second vertical vent are not feasible, the FasNSeal venting system may be the only known option available.

\subsection{RECOMMENDATIONS}

Research on the FasNSeal 80/90 venting system and other similar systems should continue. Continued field demonstrations are needed to further establish the performance of the FasNSeal 80/90 venting system by increasing the sample size and including additional climates. Studies in cooling climates are especially needed because this climate was not included in the current study and spillage is more likely to occur at higher outdoor temperatures. The installation and performance of the venting system in homes with bended existing B Vents should also be studied (the B Vent was all straight in the homes studied in this field demonstration). 
The field demonstration measured the performance of the FasNSeal 80/90 venting systems and was able to compare their performance with the performance of the existing venting systems that commonly vented the non-condensing furnaces and natural draft water heaters. However, the field demonstration was not designed to compare the venting performance of the FasNSeal 80/90 venting system with alternative venting systems, if any, that could be employed when a non-condensing furnace is replaced by a condensing furnace in an existing home. Such a field demonstration is recommended to fully understand the venting performance and benefits of the FasNSeal 80/90 venting system and other designs.

A model of the venting system should be developed to allow extrapolation of results to other climates and variations in house and chimney configurations. A model would also allow a sensitivity analyses to be performed to better understand venting performance and anomalies regarding climate, chimney characteristics, equipment locations within the house, and other factors. The continued field demonstrations recommended above would provide the additional data needed for model validation.

DuraVent should make some changes to their literature, training, and system design so that the FasNSeal $80 / 90$ venting system is easier to install, more secure, and more acceptable to installers. The DuraVent literature should be updated to make the ordering of materials clearer and easier and to address the few installation issues that were identified. An ordering brochure that was updated while the field demonstration was being performed already begins to address these recommendations. The design of the fastening systems and process used to connect the flexible inner liner to the vent cap and the PolyPro to the condensing furnace should be further investigated. DuraVent may also want to investigate a design that incorporates direct makeup air so that the health and safety advantages of condensing heating systems can be fully realized. More training of DuraVent representatives may be needed so they can better assist new installers with ordering and provide installation guidance. Marketing, trainings, and continued field demonstrations may be needed to better move the product into the market. 


\section{REFERENCES}

ACCA. Home Evaluation and Performance Improvement. ANSI/ACCA 12 QH-2014, Arlington, VA: Air Conditioning Contractors of America, 2014.

ASTM. Standard Guide for Assessing Depressurization-Induced Backdrafting and Spillage from Vented Combustion Appliances. ASTM E1998-11, West Conshohocken, PA: ASTM International, 2011.

BPI. Building Performance Institute Technical Standards for the Building Analyst Professional. v1/4/12, Building Performance Institute, Inc., 2012.

BPI Standards. Standard Practice for Basic Analysis of Buildings. ANSI/BPI-1200-S-2015, Building Performance Institute, Inc., 2015.

EIA. Annual Energy Outlook 2019. US Energy Information Administration, 2019. (https://www.eia.gov/outlooks/aeo/)

M\&G DuraVent. "FasNSeal 80/90." YouTube. February 23, 2015. https://www.youtube.com/watch?v=S2uDFuhE18o (accessed September 1, 2015).

Momen, Ayyoub Mehdizadeh, Jeffrey David Munk, and Patrick Hughes. Condensing Furnace Venting Part 2: Evaluation of Same-Chimney Vent Systems for Condensing Furnaces and Natural Draft Water Heaters, ORNL/TM-2014/656, 2015.

NFPA. National Fuel Gas Code. NFPA 54, ANSI Z223.1, Quincy, MA: National Fire Protection Association, 2015.

RESNET. RESNET Interim Guidelines for Combustion Appliance Testing and Writing Work Scope. 9/1/2010, Residential Energy Services Network, 2010. 



\section{APPENDIX A. WORST-CASE DEPRESSURIZATION VENTING DIAGNOSTIC TEST COMPARISON}





\section{APPENDIX A. WORST-CASE DEPRESSURIZATION TEST COMPARISON}

\begin{tabular}{|c|c|c|c|c|c|}
\hline & ASTM E1998 & BPI 2012 & BPI 2015 & ANSI/ACCA & RESNET \\
\hline & $\begin{array}{c}\text { Standard Guide for } \\
\quad \text { Assessing } \\
\text { Depressurization-Induced } \\
\text { Backdrafting and Spillage } \\
\text { from Vented Combustion } \\
\text { Appliances (ASTM 2011) }\end{array}$ & $\begin{array}{l}\text { Building Performance } \\
\text { Institute Technical } \\
\text { Standards for the Building } \\
\text { Analyst Professional } \\
\text { v1/4/12 (BPI 2012) }\end{array}$ & $\begin{array}{c}\text { ANSI/BPI-1200-S-2015: } \\
\text { Standard Practice for Basic } \\
\text { Analysis of Buildings (BPI } \\
\text { Standards 2015) }\end{array}$ & $\begin{array}{c}\text { ANSI/ACCA } 12 \text { QH-2014: } \\
\text { Home Evaluation and } \\
\text { Performance Improvement } \\
\text { (ACCA 2014) }\end{array}$ & $\begin{array}{l}\text { Interim Guidelines for } \\
\text { Combustion Appliance } \\
\text { Testing and Writing Work } \\
\text { Scope (RESNET 2010) }\end{array}$ \\
\hline Status & $\begin{array}{l}\text { Foundation documents for } \\
\text { many standards }\end{array}$ & Replaced by BPI 2015 & Current & - & $\begin{array}{c}\text { Phased out in Jan } 2015 ; \\
\text { Replaced by ACCA } \\
\text { Appendix A.3 and A.4 } \\
\end{array}$ \\
\hline Based upon/references & $\begin{array}{c}\text { CAN/CGSB-51.71, CMHC, } \\
\text { GRI-96/0303 }\end{array}$ & 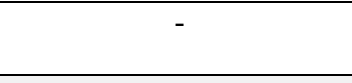 & 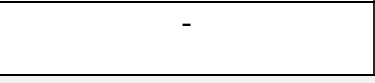 & $\begin{array}{l}\text { CAN/CGSB-51.71, NFPA } \\
54 \text { (Section G.6, 9.3, 11.6) }\end{array}$ & BPI + amendments \\
\hline \multicolumn{6}{|c|}{ OPENINGS TO OUTDOORS } \\
\hline Exterior doors, windows & $\begin{array}{c}\text { closed, tape over broken } \\
\text { windows and temporary } \\
\text { openings }\end{array}$ & closed & closed & $\begin{array}{c}\text { closed, tape over broken } \\
\text { windows and temporary } \\
\text { openings }\end{array}$ & closed \\
\hline Attic hatch & closed & - & - & closed & - \\
\hline Basement door & closed & - & - & - & - \\
\hline Crawlspace vents & closed & - & - & - & - \\
\hline Drain traps & Fill with water & - & - & Fill with water & - \\
\hline \multicolumn{6}{|l|}{ SYSTEMS/FANS } \\
\hline $\begin{array}{l}\text { Bath exhaust, range hood, } \\
\text { clothes dryer }\end{array}$ & $\mathrm{ON}$ & $\mathrm{ON}$ & $\mathrm{ON}$ & $\mathrm{ON}$ & $\mathrm{ON}$ \\
\hline $\begin{array}{l}\text { Powered attic ventilation } \\
\text { fan (if normally used) }\end{array}$ & $\mathrm{ON}$ & - & - & $\mathrm{ON}$ & - \\
\hline Whole house exhaust fan & $\begin{array}{c}\text { OFF if normally used with } \\
\text { windows open }\end{array}$ & - & OFF & OFF & - \\
\hline Air handler & $\begin{array}{c}\text { ON if that adds to the } \\
\text { negative pressure in CAZ }\end{array}$ & $\begin{array}{l}\text { ON if that adds to the } \\
\text { negative pressure in CAZ }\end{array}$ & $\begin{array}{c}\text { ON if that adds to the } \\
\text { negative pressure in CAZ }\end{array}$ & $\begin{array}{c}\text { ON if that adds to the } \\
\text { negative pressure in CAZ }\end{array}$ & $\begin{array}{c}\text { ON if that adds to the } \\
\text { negative pressure in CAZ }\end{array}$ \\
\hline Fireplace & $\begin{array}{l}\text { Damper open; Simulate } \\
\text { wood fireplace operation } \\
\text { with a camping stove, } \\
\text { ensure chimney venting } \\
\text { after } 5 \text { min; Turn on any } \\
\text { gas logs }\end{array}$ & closed & No fire, damper closed, & $\begin{array}{l}\text { Damper closed, or open } \\
\text { with a simulator (camping } \\
\text { stove) operating }\end{array}$ & $\begin{array}{l}\text { Damper closed; exhaust } \\
300 \mathrm{cfm} \text { using blower door } \\
\text { as if a fireplace is present }\end{array}$ \\
\hline $\begin{array}{l}\text { Make-up air supply (w/o } \\
\text { damper), combustion air } \\
\text { ducting, and ventilation } \\
\text { systems }\end{array}$ & As is & - & open & As is & - \\
\hline
\end{tabular}




\begin{tabular}{|c|c|c|c|c|c|}
\hline & ASTM E1998 & BPI 2012 & BPI 2015 & ANSI/ACCA & RESNET \\
\hline \multicolumn{6}{|c|}{ INTERIOR DOORS } \\
\hline Interior doors to $\mathrm{AHU}$ & - & - & \begin{tabular}{|c|} 
open \\
\end{tabular} & - & - \\
\hline Interior doors to $\mathrm{CAZ}$ & $\begin{array}{c}\text { open/close to maximize } \\
\text { depressurization }\end{array}$ & - & $\begin{array}{c}\text { open/close to maximize } \\
\text { depressurization }\end{array}$ & \multirow[t]{3}{*}{$\begin{array}{c}\text { open/close to maximize } \\
\text { depressurization }\end{array}$} & - \\
\hline $\begin{array}{l}\text { Interior doors to rooms with } \\
\text { exhaust fans }\end{array}$ & - & - & open & & - \\
\hline $\begin{array}{l}\text { Interior doors to other } \\
\text { rooms (w/ no exhaust } \\
\text { devices) }\end{array}$ & closed & $\begin{array}{c}\text { close the ones that add to } \\
\text { the negative pressure in } \\
\text { CAZ }\end{array}$ & closed & & $\begin{array}{c}\text { If air handler is ON, close } \\
\text { doors to rooms that have no } \\
\text { return registers }\end{array}$ \\
\hline \multicolumn{6}{|c|}{ TESTING } \\
\hline $\begin{array}{l}\text { Initial vent or flue } \\
\text { temperature }\end{array}$ & $\begin{array}{c}+/-5-10^{\circ} \mathrm{F} \text { of the room } \\
\text { temp. }\end{array}$ & - & - & Same as room temp. & - \\
\hline Order of test & $\begin{array}{l}\text { Start with the water heater, } \\
\text { turn it off, cool the vent, } \\
\text { and then test the furnace }\end{array}$ & $\begin{array}{c}\text { Start with the lowest Btu } \\
\text { input appliance; leave it on } \\
\text { while testing the next }\end{array}$ & $\begin{array}{l}\text { Start with the lowest Btu } \\
\text { input appliance; leave it on } \\
\text { while testing the next }\end{array}$ & $\begin{array}{c}\text { Start with the lowest Btu } \\
\text { input appliance; leave it on } \\
\text { while testing the next }\end{array}$ & - \\
\hline $\begin{array}{l}\text { Spillage/backdrafting/flue } \\
\text { CO measurement: elapsed } \\
\text { time }\end{array}$ & $\begin{array}{c}\text { Water heater spillage: } 5 \\
\text { min; Furnace backdrafting: } \\
5 \text { min }^{3}\end{array}$ & $\begin{array}{l}\text { Spillage: } 60 \mathrm{sec} \text {; CO: when } \\
\text { steady state is achieved } \\
(\max 10 \mathrm{~min})\end{array}$ & $\begin{array}{l}\text { Spillage: } 5 \text { min (cold vent } \\
\text { for furnace), } 2 \text { min (water } \\
\text { heater, warm vent for } \\
\text { furnace); CO: } 5 \mathrm{~min}\end{array}$ & Spillage and CO: $5 \mathrm{~min}^{4}$ & Spillage and CO: 5 min \\
\hline $\begin{array}{l}\text { Spillage/backdrafting/flue } \\
\text { CO measurement: test } \\
\text { location }\end{array}$ & $\begin{array}{c}\text { Spillage: drafthood; } \\
\text { Furnace backdrafting: water } \\
\text { heater drafthood if induced } \\
\text { draft furnace }\end{array}$ & $\begin{array}{c}\text { Spillage: water heater draft } \\
\text { diverter } \\
\text { Flue CO: in the throat or } \\
\text { flue of the appliance }\end{array}$ & - & $\begin{array}{l}\text { Complete circumference of } \\
\text { the drafthood; vent } \\
\text { connections }\end{array}$ & $\begin{array}{l}\text { CO: upstream of the draft } \\
\text { diverter }\end{array}$ \\
\hline \multicolumn{6}{|c|}{ PASS/FAIL CRITERIA } \\
\hline $\begin{array}{l}\text { Ambient CO (stop work } \\
\text { criteria) }\end{array}$ & NA & $35 \mathrm{ppm}$ & $\begin{array}{c}70 \mathrm{ppm} \\
\text { (may stop if 36-69 ppm) }\end{array}$ & $\begin{array}{c}25 \mathrm{ppm} \\
\text { (may stop if }>9 \mathrm{ppm} \text { for } \\
\text { more than } 15 \mathrm{~min} \text { ) }\end{array}$ & $35 \mathrm{ppm}$ \\
\hline Flue CO (air-free) & NA & $\begin{array}{c}100 \text { ppm (Action level } \\
\text { based on flue CO, spillage } \\
\text { and draft test results) }\end{array}$ & $\begin{array}{c}400 \mathrm{ppm} \text { for central furnace } \\
\text { (all categories); } 200 \mathrm{ppm} \\
\text { for water heater }\end{array}$ & $\begin{array}{c}400 \mathrm{ppm} \text { for central furnace } \\
\text { (all categories); } 200 \mathrm{ppm} \\
\text { for water heater }\end{array}$ & $100 \mathrm{ppm}$ \\
\hline CAZ depressurization limit & NA & Specified & No requirement & No requirement & $\begin{array}{c}-5 \mathrm{~Pa} \text { for atmospheric } \\
\text { vented oil or gas system }\end{array}$ \\
\hline Draft pressure & NA & $\begin{array}{c}\mathrm{To} / 40-2.75 \text { for } \mathrm{To}=10- \\
90^{\circ} \mathrm{F} ; \\
-2.5 \mathrm{~Pa} \text { for } \mathrm{To}<10^{\circ} \mathrm{F} \\
-0.5 \mathrm{~Pa} \text { for } \mathrm{To}>90^{\circ} \mathrm{F} \\
\end{array}$ & No requirement & No requirement & No requirement \\
\hline
\end{tabular}

\footnotetext{
$35 \mathrm{~min}$ is arbitrary; may use $3 \mathrm{~min}$ or $10 \mathrm{~min}$.

${ }^{4}$ Source: NFPA 54
} 
APPENDIX B. WORST-CASE DEPRESSURIZATION VENTING DIAGNOSTIC TEST PROCEDURE 



\section{APPENDIX B. DIAGNOSTIC TESTING ON WATER HEATER AND EXISTING FURNACE} Version: November 13, 2015

\section{Assumptions:}

1. Only the water heater and furnace are commonly vented.

2. The furnace is an induced draft furnace.

3. The Btu/h input rating for the furnace is higher than that for the water heater.

\section{Equipment Needed:}

1. Differential pressure meter and tubing

2. Temperature sensor

3. Ambient CO monitor

4. Smoke visualization equipment

5. Flue gas $\mathrm{CO}$ measuring device

6. Drill

7. Aluminum foil tape

\begin{tabular}{|c|l|c|}
\hline A & Baseline Set Up & $\square$ Yes $\square$ No \\
\hline 1 & Is it windy outside (wind speed $>8 \mathrm{mph}$ ) ${ }^{5}$ & \\
\hline 2 & Measure the outdoor air temperature. & ${ }^{\circ} \mathrm{Fpm}$ \\
\hline 3 & Measure the CO level in the outdoor air. & ppm \\
\hline 4 & Measure the CO level in the CAZ. Monitor the CO level in the CAZ at all times during the test ${ }^{6}$. & $\square$ \\
\hline 5 & $\begin{array}{l}\text { Place the water heater and furnace in the CAZ on standby mode. Note their current operational } \\
\text { modes and settings. }\end{array}$ & $\square$ \\
\hline 6 & Extinguish fires in woodstoves and/or fireplaces. Close fireplace dampers and doors. \\
\hline 7 & $\begin{array}{l}\text { Set up the differential pressure meter and tubing to measure the pressure in the combustion } \\
\text { appliance zone (CAZ) with reference to outside. }\end{array}$ & $\square$ \\
\hline 8 & Close all exterior doors and windows. Tape over broken windows and other short term openings. & $\square$ \\
\hline 9 & Close interior doors to basement if present. & $\square$ \\
\hline 10 & Close the attic hatch if present. & $\square$ \\
\hline 11 & Fill floor drains with water if present. & $\square$ \\
\hline 12 & Close interior doors to CAZ if present. & $\square$ \\
\hline 13 & Close interior doors of all rooms except for rooms with an exhaust fan or a central forced air \\
\hline 14 & system return. & $\square$ \\
\hline 15 & Turn off mechanical ventilation including bathroom fans, range hoods and clothes dryer. & $\square$ \\
\hline
\end{tabular}

\footnotetext{
${ }^{5}$ Ideal condition for performing the test is a period of low wind speeds (less than $2 \mathrm{~m} / \mathrm{s}$ or $5 \mathrm{mph}$ ). Wind speed less than or equal to $7 \mathrm{mph}$ : smoke drifts, leaves rustle, and wind felt on face. Wind speed $8 \mathrm{mph}$ or greater: flags extended, leaves move, dust and small branches move, and trees begin to sway.

${ }^{6}$ The $\mathrm{CO}$ level in the CAZ is not expected to reach unsafe level ( $70 \mathrm{ppm}$ or higher). If it exceeds 70 ppm at any time during the test, terminate the test, evacuate the house, and notify appropriate emergency service.
} 
16 Leave on any continuous ventilation system. Leave any sub-slab ventilation fans or subfloor ventilation systems for soil gas control as is.

17 Turn off forced air cooling or heating system blowers.

18 Measure the pressure in the CAZ with reference to outside.

B Worst-case Depressurization Set Up

1 Check and clean the clothes dryer filter. Look for blockage at the external vent damper.

2 Turn on exhaust equipment including clothes dryers, range hoods, bathroom fans, and other exhaust fans to the highest speed setting. Do not operate any whole house cooling exhaust fan.

3 Measure the pressure in the CAZ with reference to outside.

4 Turn on any central forced air system blowers in "fan only" mode.

5 Measure the pressure in the CAZ with reference to outside.

6 If the pressure in the $\mathrm{CAZ}$ becomes more negative with reference to outside after the blower is turned on, leave the blower on. Otherwise, turn off the blower.

7 Identify and open interior door(s) directly leading to the CAZ. Door 1:

Door 2:

Door 3: Door 4:

8 Measure the pressure in the $\mathrm{CAZ}$ with reference to outside.

9 If the pressure in the CAZ becomes more negative with reference to outside after the door(s) are opened, leave the door(s) open. Otherwise, close the interior CAZ door(s).

10 Note the final worst-case pressure in the CAZ with reference to outside. $\mathrm{Pa}$

\section{Spillage Assessment with Only the Water Heater Operating}

1 Verify that the common-vent temperature is within $5-10^{\circ} \mathrm{F}$ of room temperature. Attach a temperature sensor to the outside of the metal common vent, if needed. Allow more time for cooling, if needed.

2 Place the water heater in operation. Adjust the thermostat or control so the water heater will operate continuously. Note the exact time or start a stop watch when the water heater main burner ignites.

3 Assess the water heater for spillage over the complete circumference of the water heater drafthood. Note the elapsed time to establish a draft from the start of the main burner operation.

4 Measure the $\mathrm{CO}$ level in the undiluted flue gas of the water heater (i.e., at the throat of the flue for the water heater) at 5 minutes of main burner operation.

\section{Spillage Assessment with Furnace and Water Heater Operating}

1 Place the furnace in operation. Adjust the thermostat or control so the furnace will operate continuously while the water heater is still firing. Do not wait for the vent to cool. Note the exact time or start a stop watch when the furnace main burner ignites.

\footnotetext{
${ }^{7}$ If the elapsed time exceeds 2 minutes ( 5 minutes for furnace when water heater is not operating), address the cause for spillage if feasible. Possible causes for spillage are:

HVAC-induced imbalances, if the maximum CAZ depressurization is achieved with the air handler (B.7) ON.

Inadequate air transfer between the $\mathrm{CAZ}$ and the rest of the house, if the maximum CAZ depressurization is achieved with the door to the CAZ (B.9) closed.

Excessive exhaust.

Issue with the flue/venting system.

${ }^{8}$ The CO level in the flue gas is relevant only for safety. It is unlikely to exceed $200 \mathrm{ppm}$ airfree (for water heater) or $400 \mathrm{ppm}$ airfree (for furnace). If it does, terminate the test. Advise the occupant that the appliance should be serviced immediately.
} 
2 Assess the water heater for spillage over the complete circumference of the water heater drafthood. Note the elapsed time to establish a draft from the start of the furnace main burner operation.

3 Measure the $\mathrm{CO}$ level in the undiluted flue gas of the furnace (i.e., in the vent pipe 8" above the induced draft furnace) at 5 minutes of its main burner operation.

4 Seal the access hole drilled into the flue with aluminum tape.

\section{E Spillage Assessment with Only the Furnace Operating}

1 Turn off both the water heater and the furnace. Allow the vent to cool to within $5-10^{\circ} \mathrm{F}$ of room temperature by leaving the exhaust fans and appliances on for at least 5 min. Attach a temperature sensor to the outside of the metal common vent, if needed. Allow more time for cooling, if needed.

2 Place the furnace in operation. Adjust the thermostat or control so the furnace will operate continuously. Note the exact time or start a stop watch when the furnace main burner ignites.

3 Assess for backdrafting over the complete circumference of the water heater drafthood. Note the elapsed time for backdrafting to stop from the start of the furnace main burner operation.

\section{F Wrap up After Completing the Tests}

1 Place the water heater and furnace back to their original operational modes and settings.

2 Place the exterior doors and windows, interior doors, fireplace dampers and doors, attic hatch, and all fans and blowers in their original state. 

APPENDIX C. HOUSE DATA COLLECTION FORM 



\section{APPENDIX C. HOUSE DATA COLLECTION FORM}

Version: November 13, 2015

Agency Contact:

Site Address:

\begin{tabular}{|c|c|c|c|}
\hline $\mathbf{A}$ & House Characteristics & & \\
\hline 1 & House type & $\begin{array}{l}\square \text { Detached } \\
\square \text { Duplex } \\
\square \text { Apartment }\end{array}$ & $\begin{array}{l}\square \text { Row house } \\
\square \text { Fourplex } \\
\square \text { Other }\end{array}$ \\
\hline 2 & Previously weatherized? & $\square$ No & $\square$ Yes \\
\hline $2 \mathrm{a}$ & $\begin{array}{l}\text { Air tightness level, if known } \\
\text { (cfm@50 Pa) }\end{array}$ & & \\
\hline 3 & Number of floors in the building & & \\
\hline 4 & Conditioned floor area $\left(\mathrm{ft}^{2}\right)$ & & \\
\hline 5 & Total height of the building (ft) & & \\
\hline 6 & Basement & $\square$ Present & $\square$ Not present \\
\hline 7 & Number of bathroom exhaust fans & & \\
\hline 8 & Number of kitchen exhaust fans & & \\
\hline 9 & Clothes dryer & \multicolumn{2}{|c|}{$\square$ Located in the CAZ $\square$ Located elsewhere $\square$ Not present } \\
\hline 10 & Fireplace & $\square$ Present & $\square$ Not present \\
\hline 11 & Whole-house fan & $\square$ Present & $\square$ Not present \\
\hline 12 & Continuous ventilation & $\begin{array}{l}\square \text { Supply } \\
\square \text { Balanced }\end{array}$ & $\begin{array}{l}\square \text { Exhaust } \\
\square \text { None }\end{array}$ \\
\hline 13 & Safety inspection & \multicolumn{2}{|c|}{$\begin{array}{c}\square \quad \text { No trace of ambient } \mathrm{CO} \text { and combustion gases } \\
\square \quad \text { No deficiency in fuel piping system related to: } \\
\square \quad \text { Materials } \\
\square \text { Connections } \\
\square \text { Components } \\
\square \text { Supports }\end{array}$} \\
\hline B & Combustion Appliance Zone & & \\
\hline 1 & Location & $\square$ Basement & $\square$ Living space closet $\quad \square$ Garage \\
\hline 2 & Area $\left(\mathrm{ft}^{2}\right)$ & & \\
\hline 3 & Height (ft) & & \\
\hline 4 & $\begin{array}{l}\text { Area of opening for fresh air supply } \\
\text { (ft2) }\end{array}$ & & \\
\hline 5 & Safety inspection & $\begin{array}{ll}\square & \text { Safe stor } \\
\square & \text { No stora } \\
\square & \text { Adequat } \\
\square & \text { Code-co }\end{array}$ & $\begin{array}{l}\text { s, paper or other combustibles } \\
\text { ce from appliance and vent connectors } \\
\text { nstallation of appliances }\end{array}$ \\
\hline
\end{tabular}




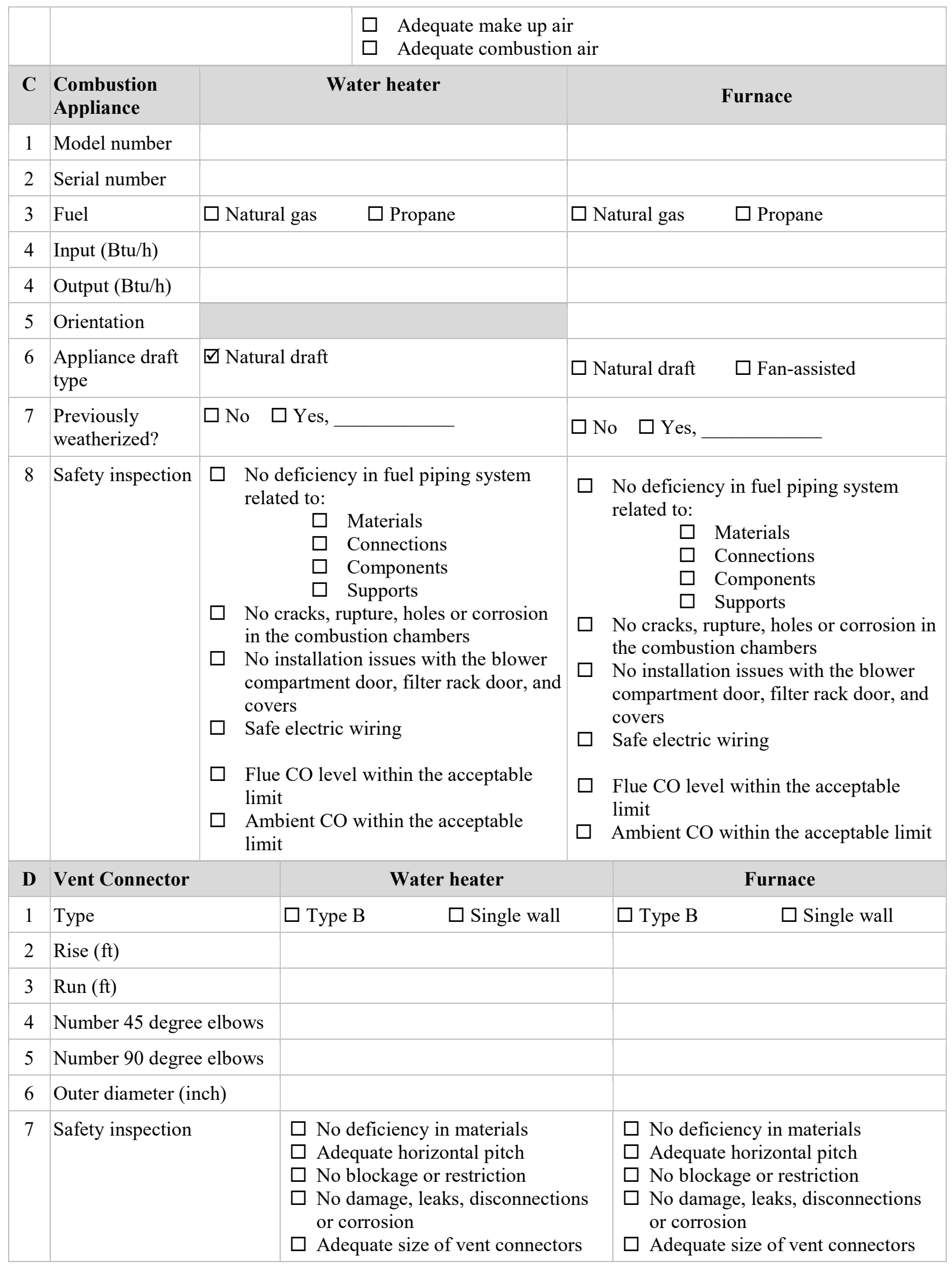




\begin{tabular}{|c|c|c|}
\hline $\mathbf{E}$ & Chimney & $\square$ Type B \\
\hline 1 & Chimney size (inch) & \\
\hline 2 & Height in the CAZ (ft) & \\
\hline 3 & Height above roof ( $\mathrm{ft}$ ) & \\
\hline 4 & Chimney location & $\square$ Exterior \\
\hline 5 & Vent chase construction & $\square$ Wood frame chase \\
\hline 6 & $\begin{array}{l}\text { Combustion appliances are } \\
\text { vented into: }\end{array}$ & $\begin{array}{l}\square \text { a common vertical chimney } \\
\square \text { a common horizontal vent connector }\end{array}$ \\
\hline $6 a$ & $\begin{array}{l}\text { If a common vertical } \\
\text { chimney: }\end{array}$ & $\begin{array}{l}\square \text { the furnace vent connector enters the chimney flue above the water heater } \\
\square \text { the water heater vent connector enters the chimney flue above the furnace } \\
\square \text { Water heater and furnace enter at the same horizontal point } \\
\square \text { Not applicable }\end{array}$ \\
\hline $6 b$ & $\begin{array}{l}\text { If a common horizontal vent } \\
\text { connector }\end{array}$ & $\begin{array}{l}\text { The vent piping diameter after the additional combustion appliance connection } \\
\text { into the vent piping: } \\
\square \text { Increases } \quad \square \text { Does not increase } \quad \square \text { Not applicable }\end{array}$ \\
\hline 7 & Safety inspection & $\begin{array}{l}\square \text { No deficiency in materials } \\
\square \text { No blockage or restriction } \\
\square \text { No damage, leaks, disconnections or corrosion } \\
\square \text { Presence of vent cap at the vent termination }\end{array}$ \\
\hline
\end{tabular}



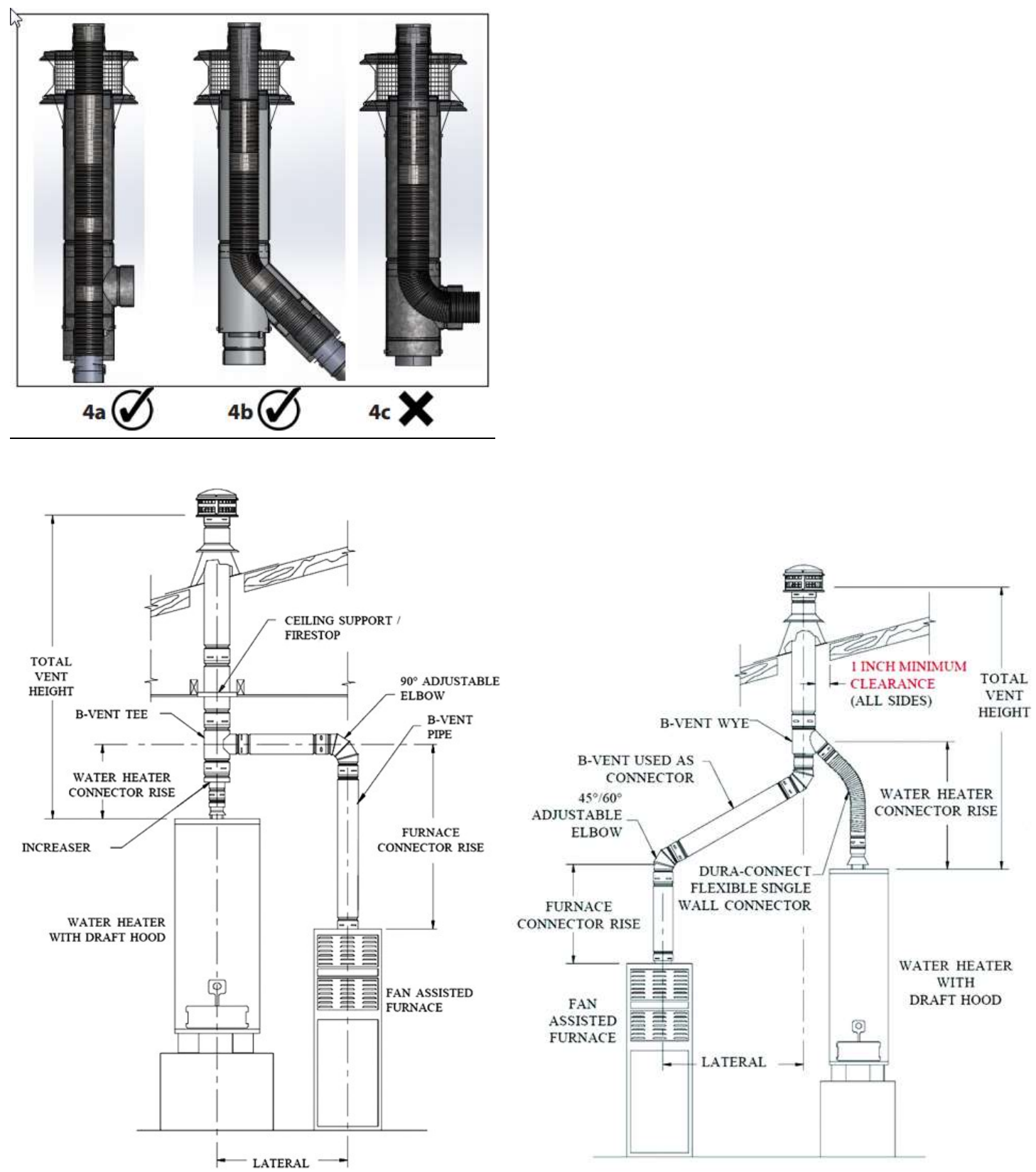
APPENDIX D. CONTRACTOR QUESTIONNAIRE 



\title{
APPENDIX D. FURNACE AND WATER HEATER VENTING FIELD DEMONSTRATION: CONTRACTOR QUESTIONNAIRE
}

\author{
March 14, 2016
}

As part of the field demonstration being performed by the Oak Ridge National Laboratory (ORNL) to study the new DuraVent FasNSeal 80/90 venting system for condensing gas furnaces and natural-draft gas water heaters, you were the HVAC contractor that installed the new venting system in several of the demonstration houses. As part of the field demonstration, we would like to obtain your feedback on the FasNSeal 80/90 system by answering the questions below. Please feel free to add any feedback not covered by the questions. If desired, you may call us to discuss your feedback rather than completing this questionnaire.

\section{TRAINING}

1. Was the training provided by ORNL on the FasNSeal 80/90 system sufficient to allow you to perform the installations? How could the training have been improved?

2. How useful were the DuraVent FasNSeal 80/90 installation instructions and related materials? What installation steps or details, if any, need clarification? How else could the installation instructions and/or related materials be improved?

3. Was it clear what FasNSeal 80/90 materials were needed for a given job?

4. Did you have to obtain additional FasNSeal 80/90 product or installation information before you could perform the installations and, if so, from whom did you get the needed information?

\section{INSTALLATION}

1. What problems, if any, did you encounter in installing the FasNSeal system? How were these problems resolved?

2. How many crew participated in the installation of the FasNSeal 80/90 system? Could the FasNSeal $80 / 90$ system be installed by one person, or is a two-person crew needed?

3. How much did the FasNSeal 80/90 system material cost (average per house)? How much more does the FasNSeal 80/90 material cost than the flue-related material that would be needed for a typical side-venting installation?

4. How many crew hours did it take to install the FasNSeal 80/90 system (average per house)? How many crew hours do you think it would take you to install the FasNSeal 80/90 system after you had time to become proficient in its installation? How many crew hours do you think the FasNSeal 80/90 system adds to the job compared to a typical side-venting installation?

\section{FUTURE USE}

1. Would you consider using the FasNSeal 80/90 system in future installations? If yes, in what types of applications/houses?

2. Can you foresee circumstances in which installing the FasNSeal 80/90 system might be problematic (e.g., weather, equipment types, equipment locations, house constructions)? 
3. One of the intents of the FasNSeal 809/90 system is to allow a condensing gas furnace to be installed in homes in which a condensing gas furnace could not otherwise be installed because of venting issues when the existing gas furnace and water heater are vented through a common B vent. Can you envision circumstances in which the FasNSeal 80/90 system would not resolve a venting issue associated with installing a condensing gas furnace when the existing gas furnace and water heater are vented through a common B vent?

4. Do you foresee other contractors being apprehensive in using the FasNSeal 80/90 system? If Yes, why? 


\section{APPENDIX E. SPILLAGE SUMMARY PLOTS}




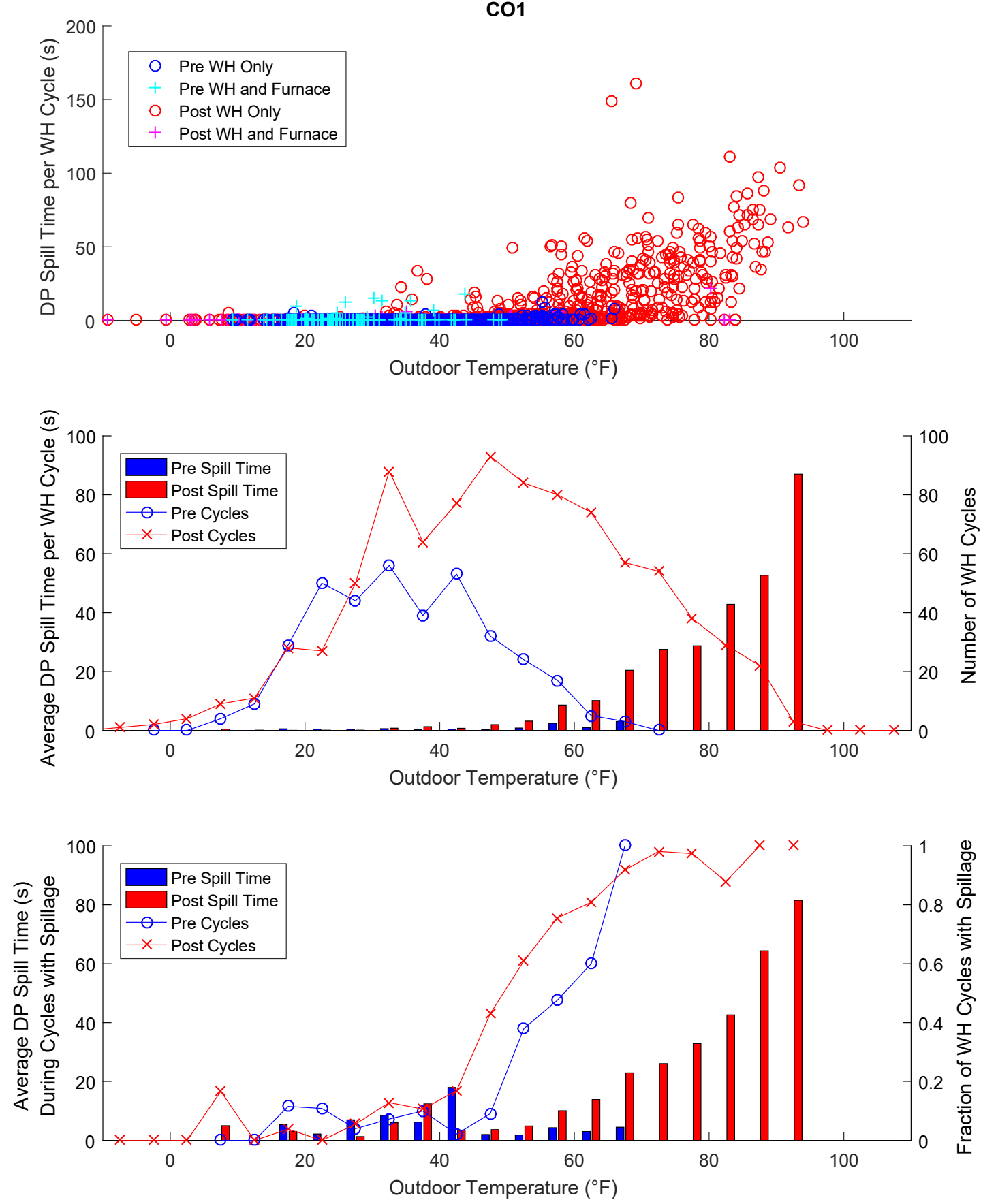

Figure E.1. Spillage summary plots for House CO1. 

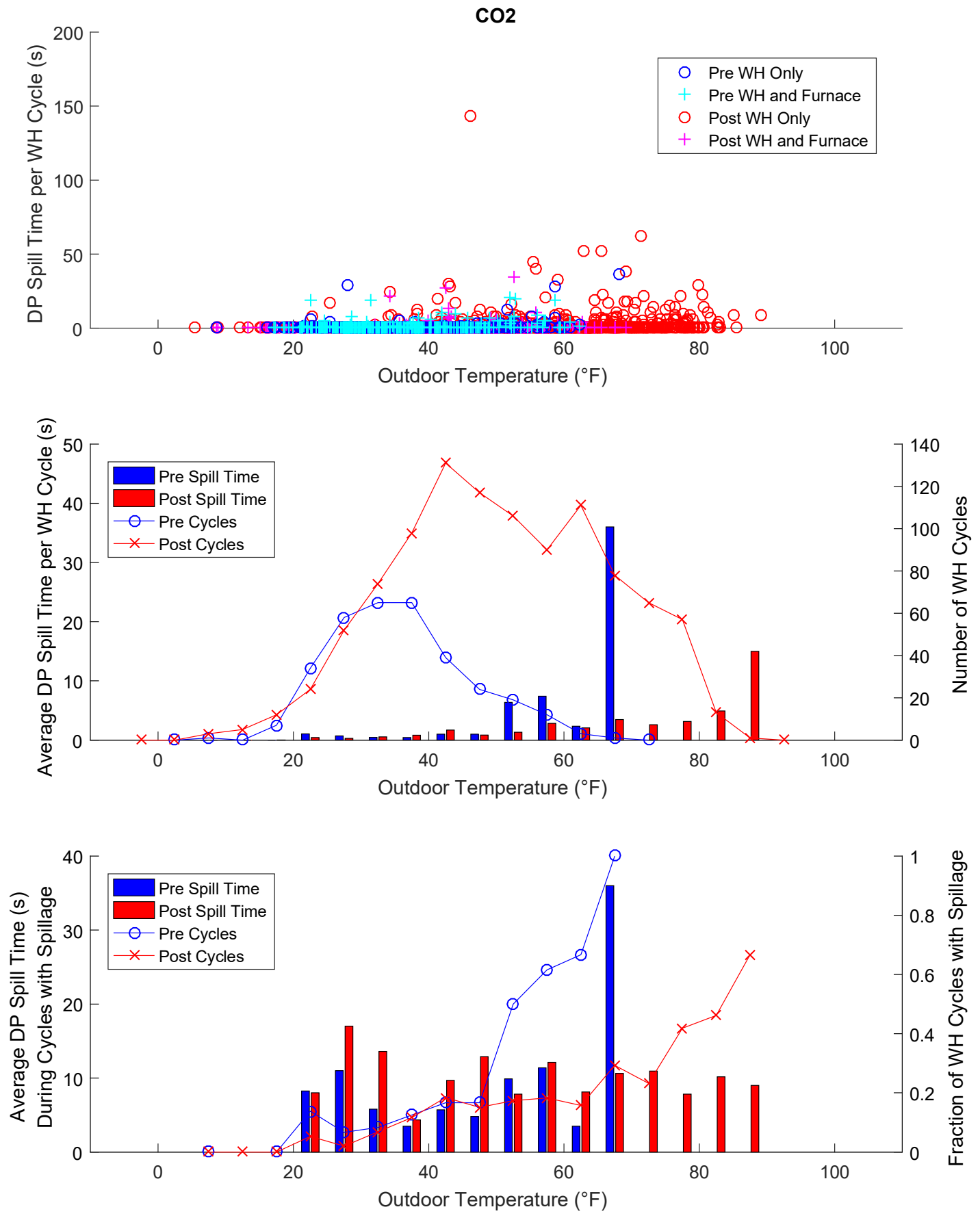

Figure E.2. Spillage summary plots for House CO2. 

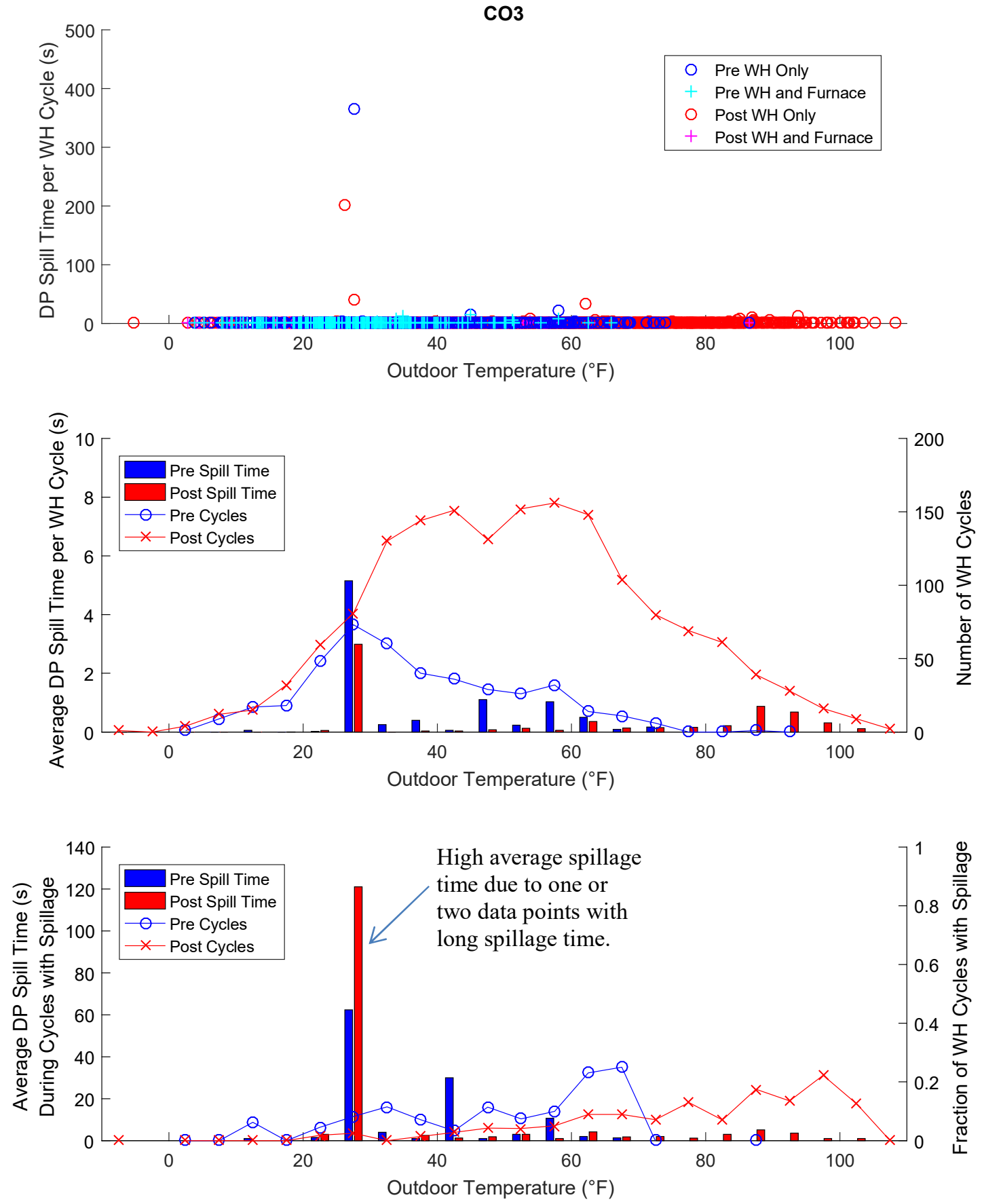

Figure E.3. Spillage summary plots for House CO3. 

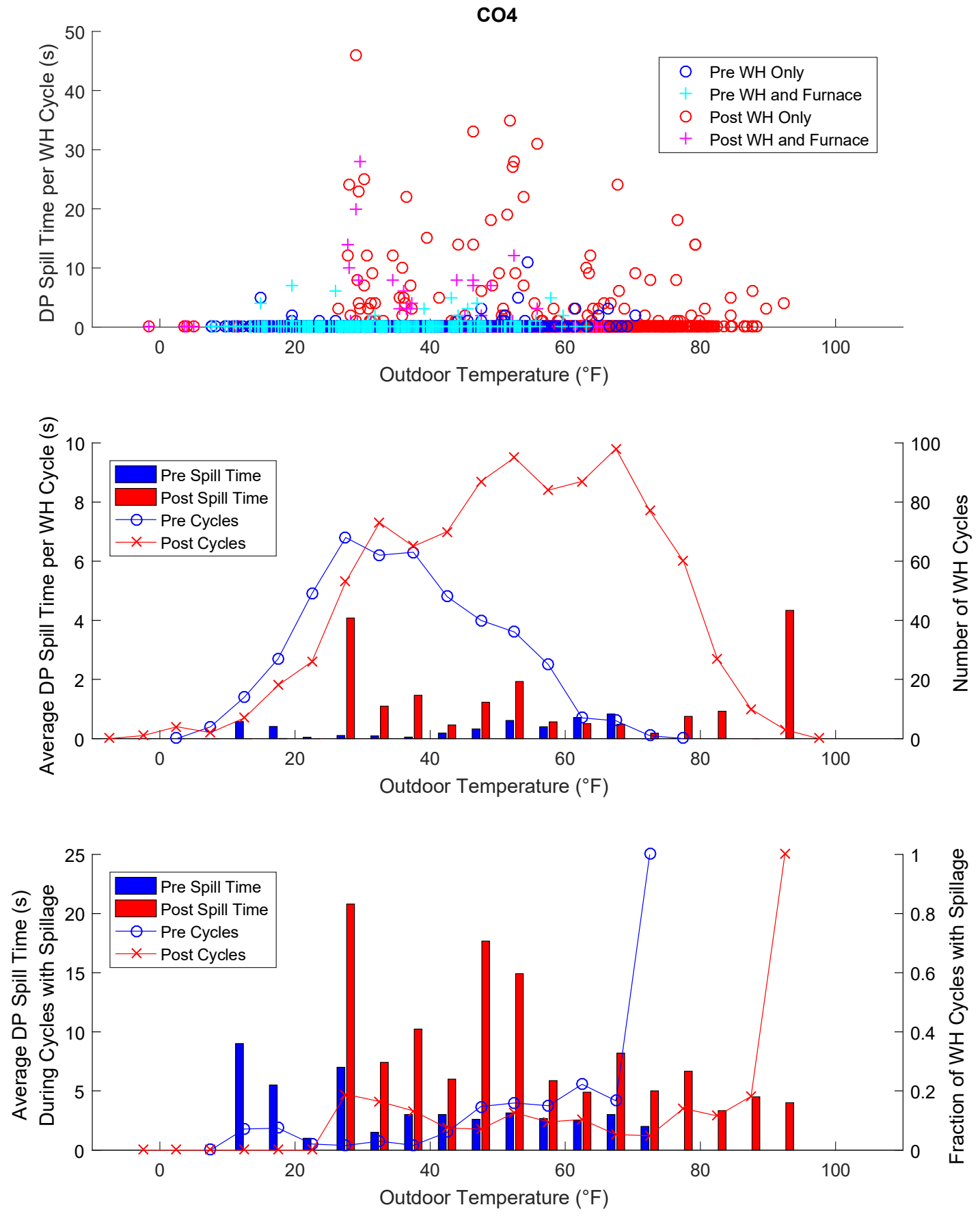

Figure E.4. Spillage summary plots for House CO4. 

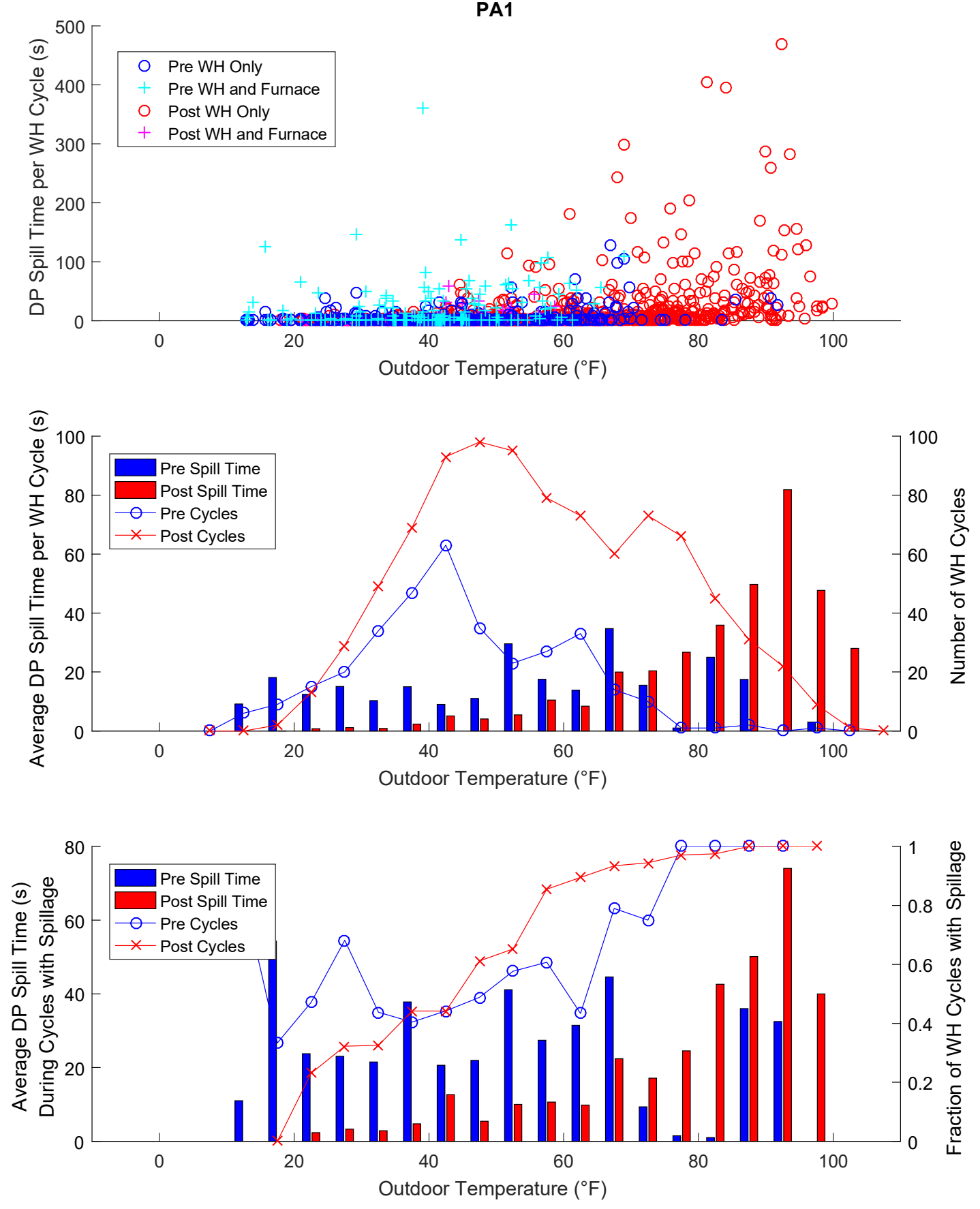

Figure E.5. Spillage summary plots for House PA1. 

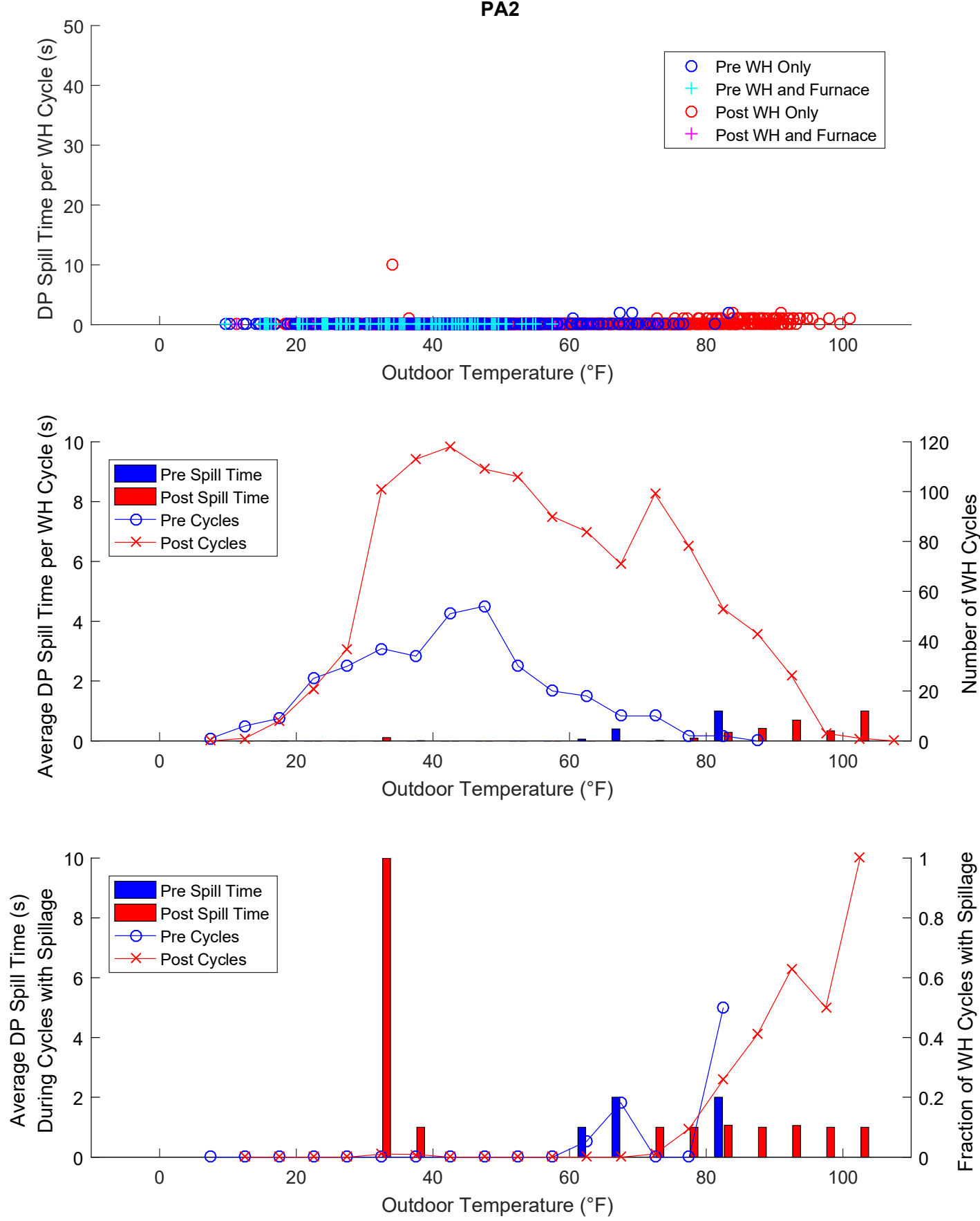

Figure E.6. Spillage summary plots for House PA2. 

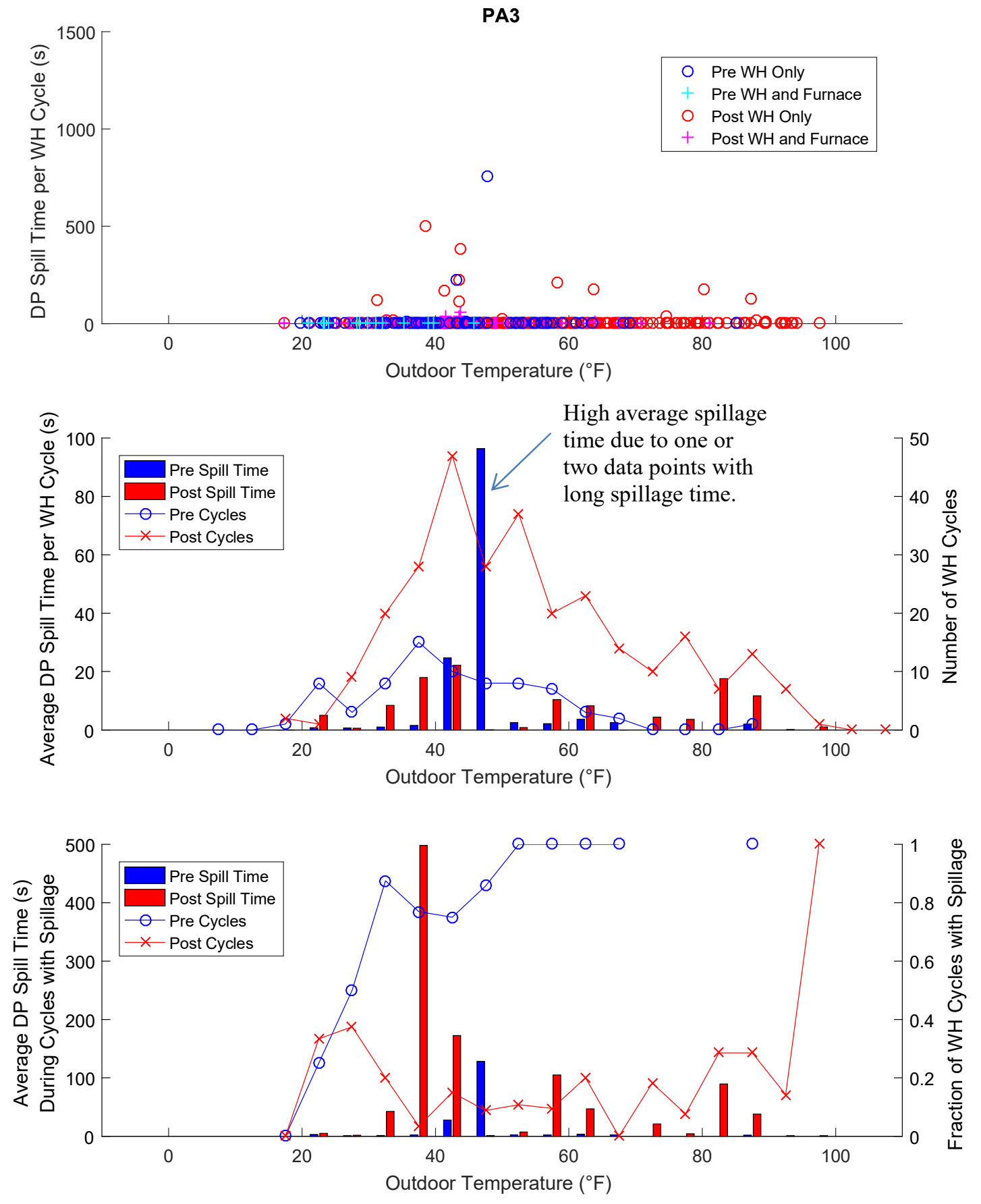

Figure E.7. Spillage summary plots for House PA3. 

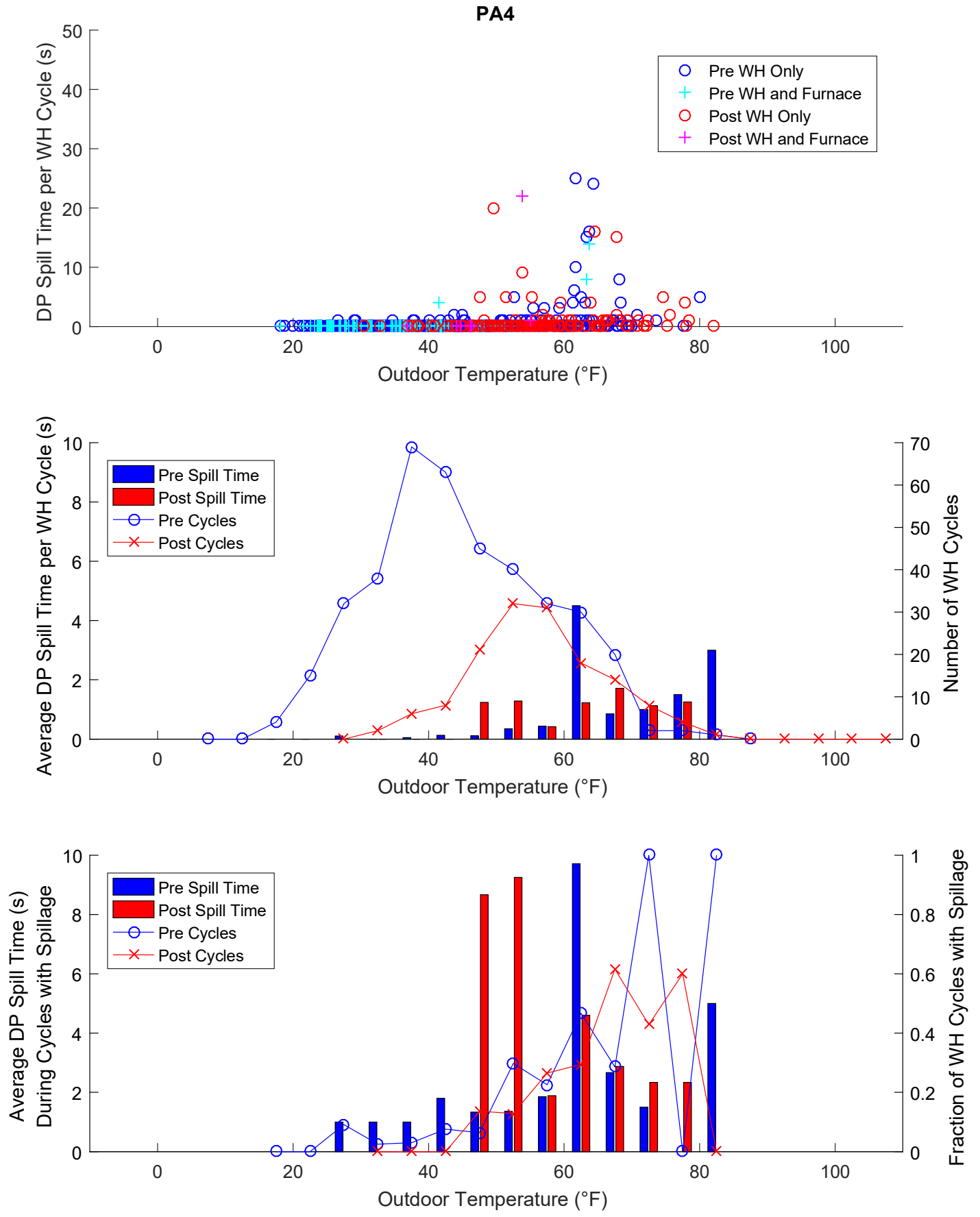

Figure E.8. Spillage summary plots for House PA4. 

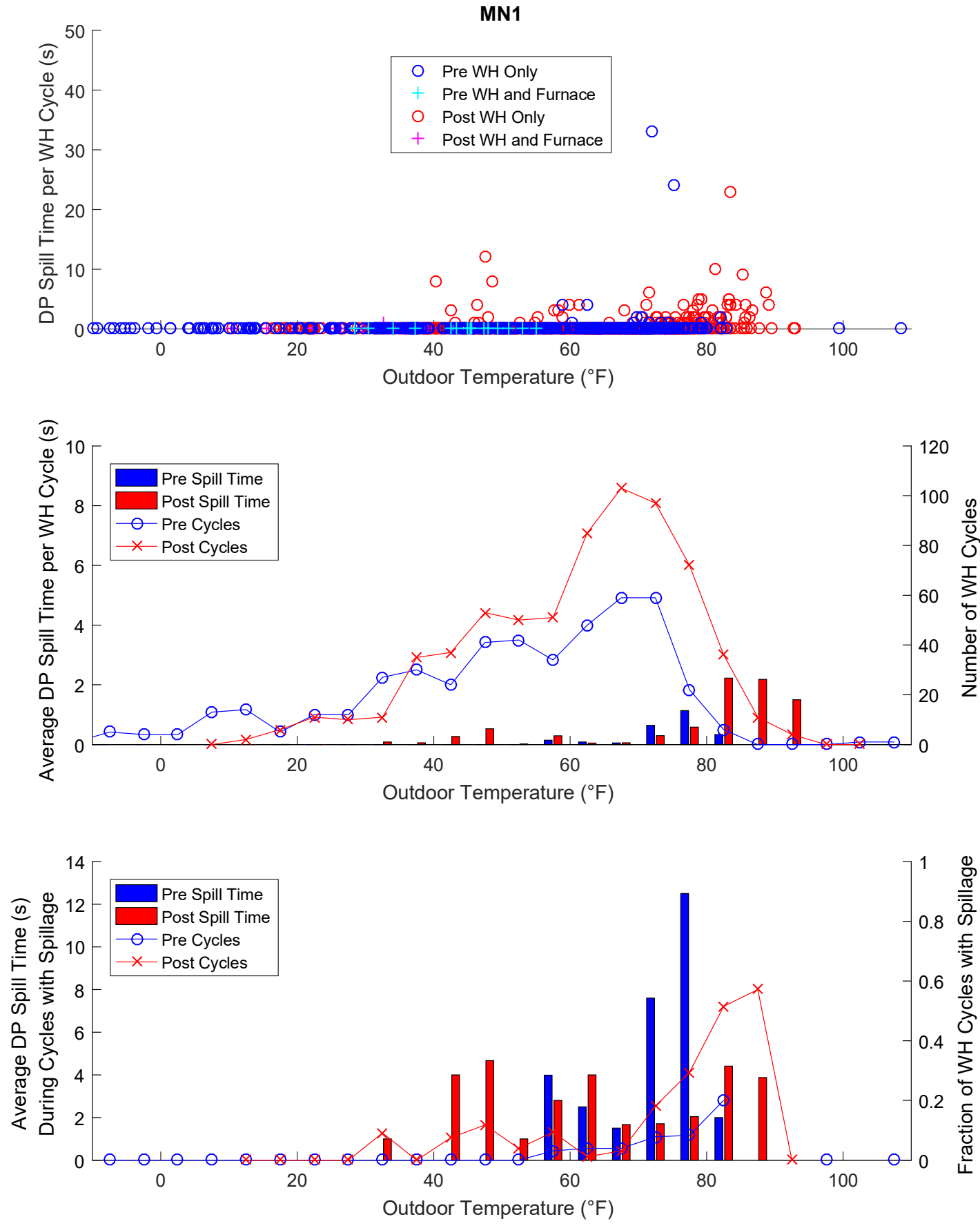

Figure E.9. Spillage summary plots for House MN1. 

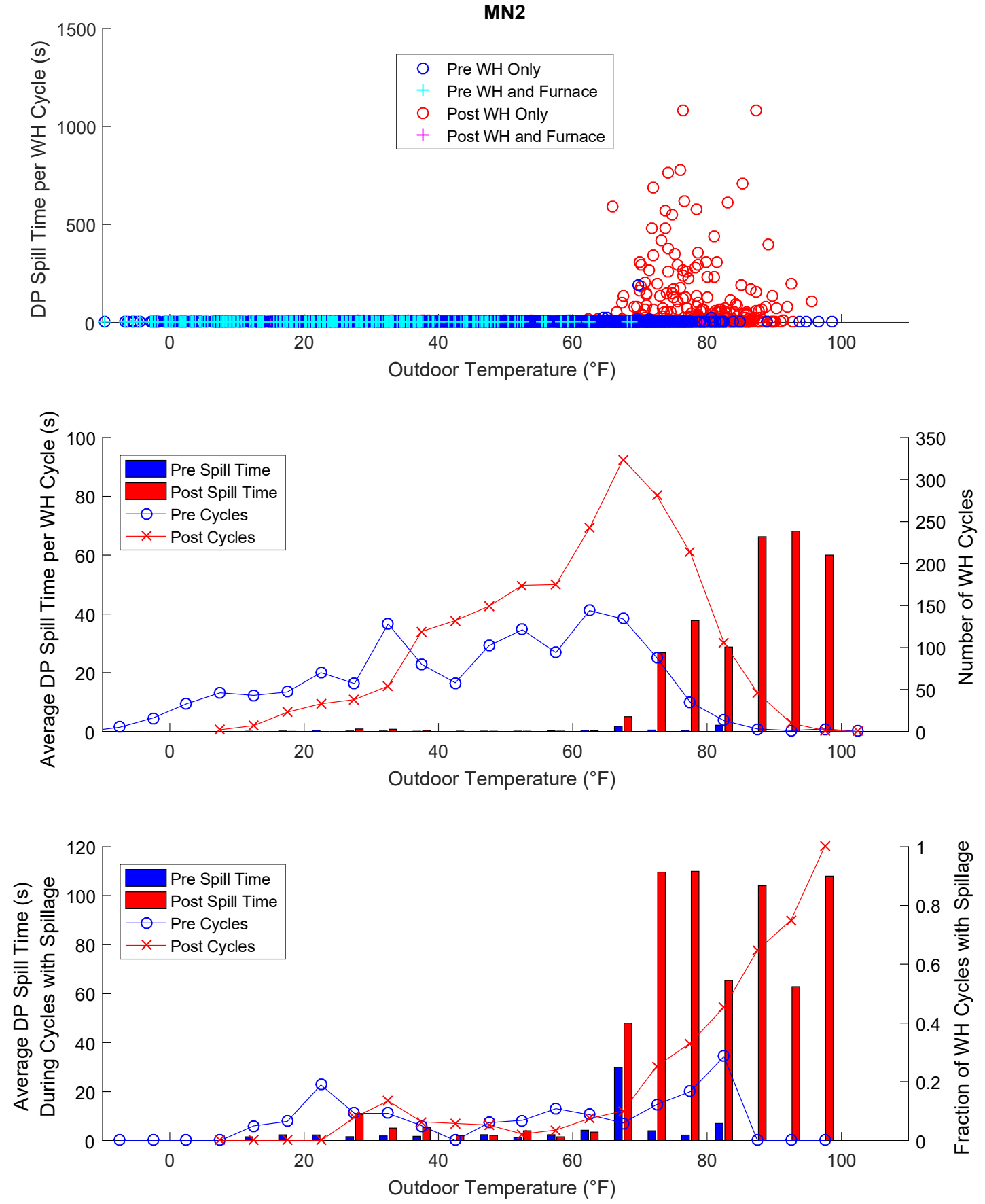

Figure E.10. Spillage summary plots for House MN2. 

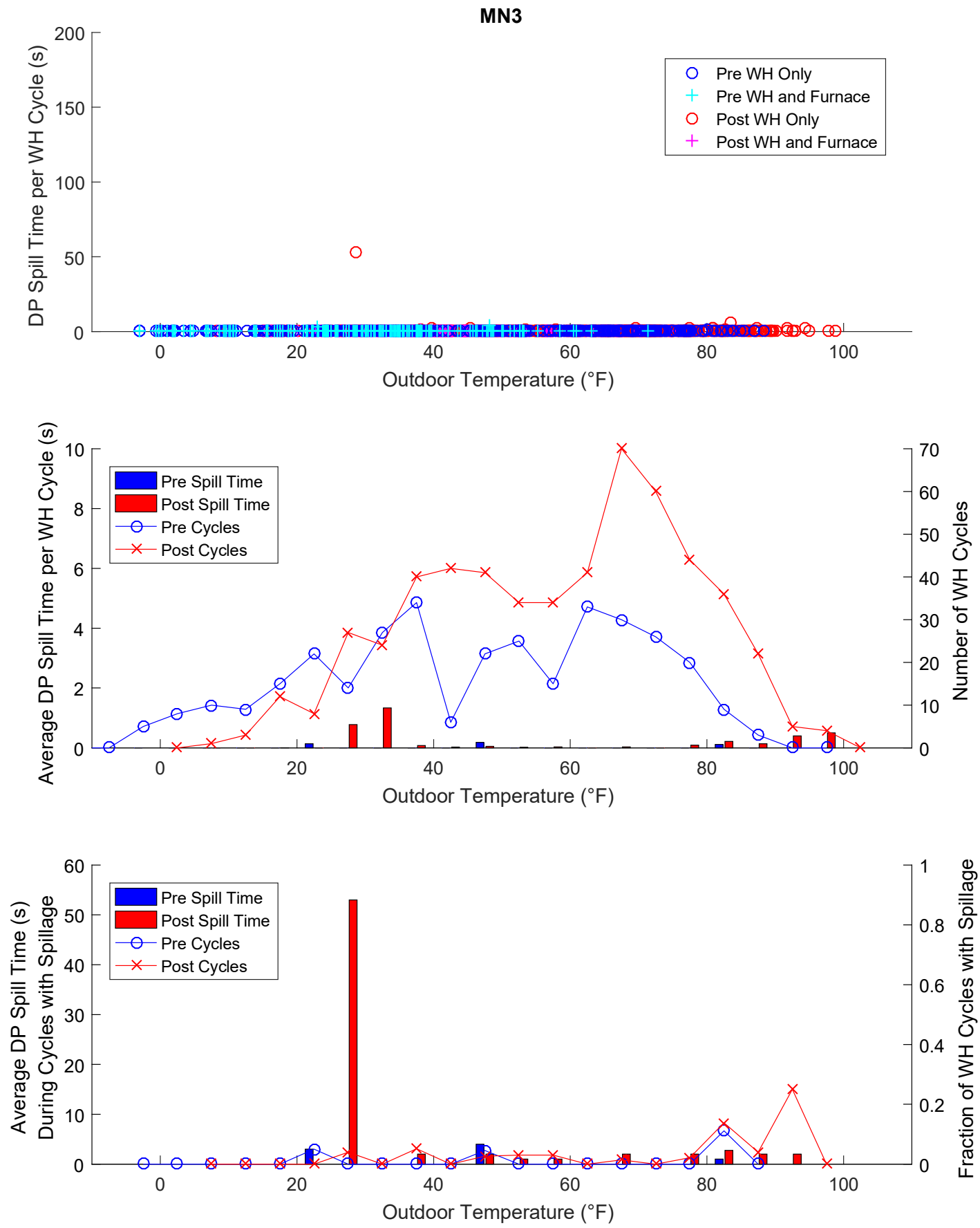

Figure E.11. Spillage summary plots for House MN3. 

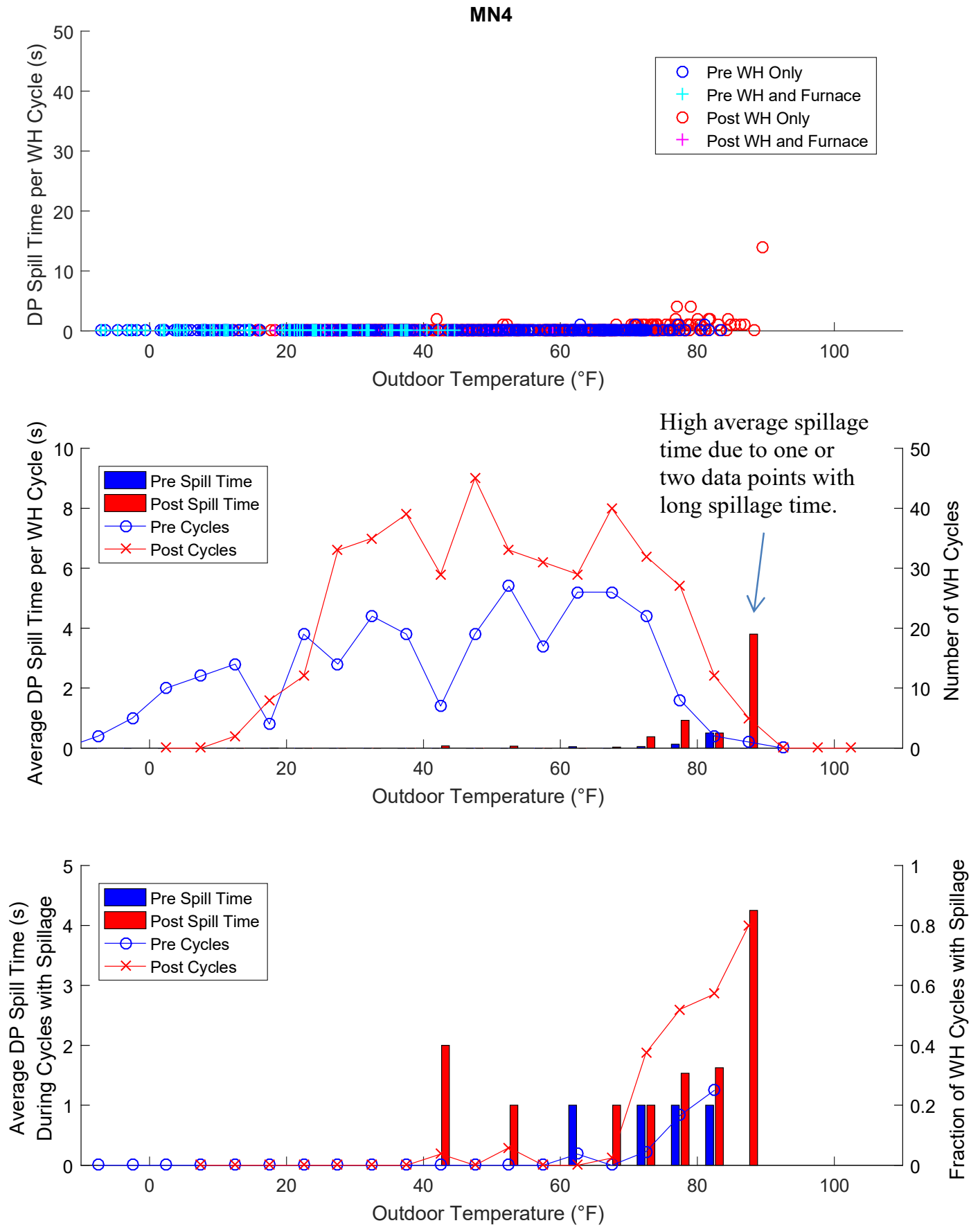

Figure E.12. Spillage summary plots for House MN4. 

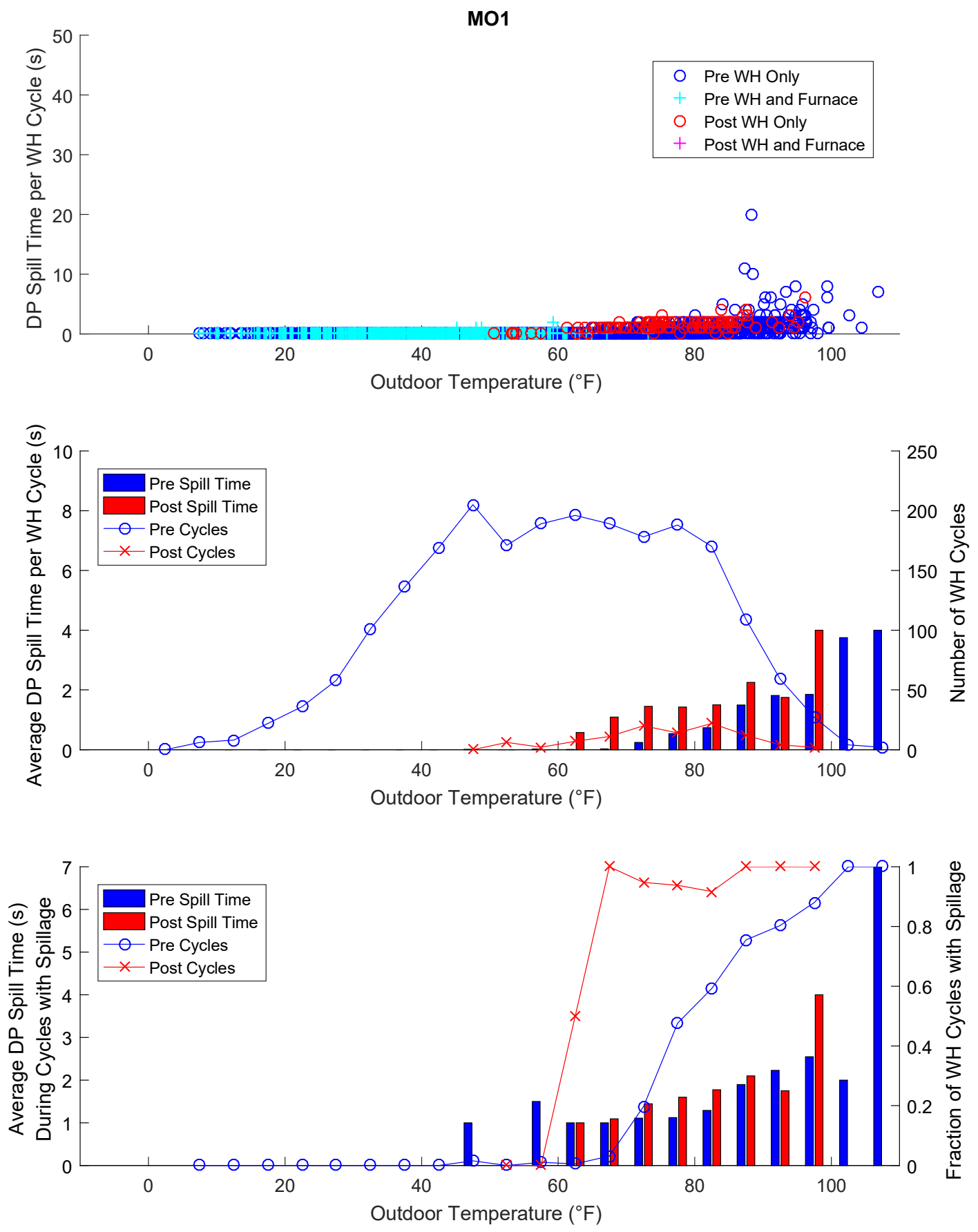

Figure E.13. Spillage summary plots for House MO1. 

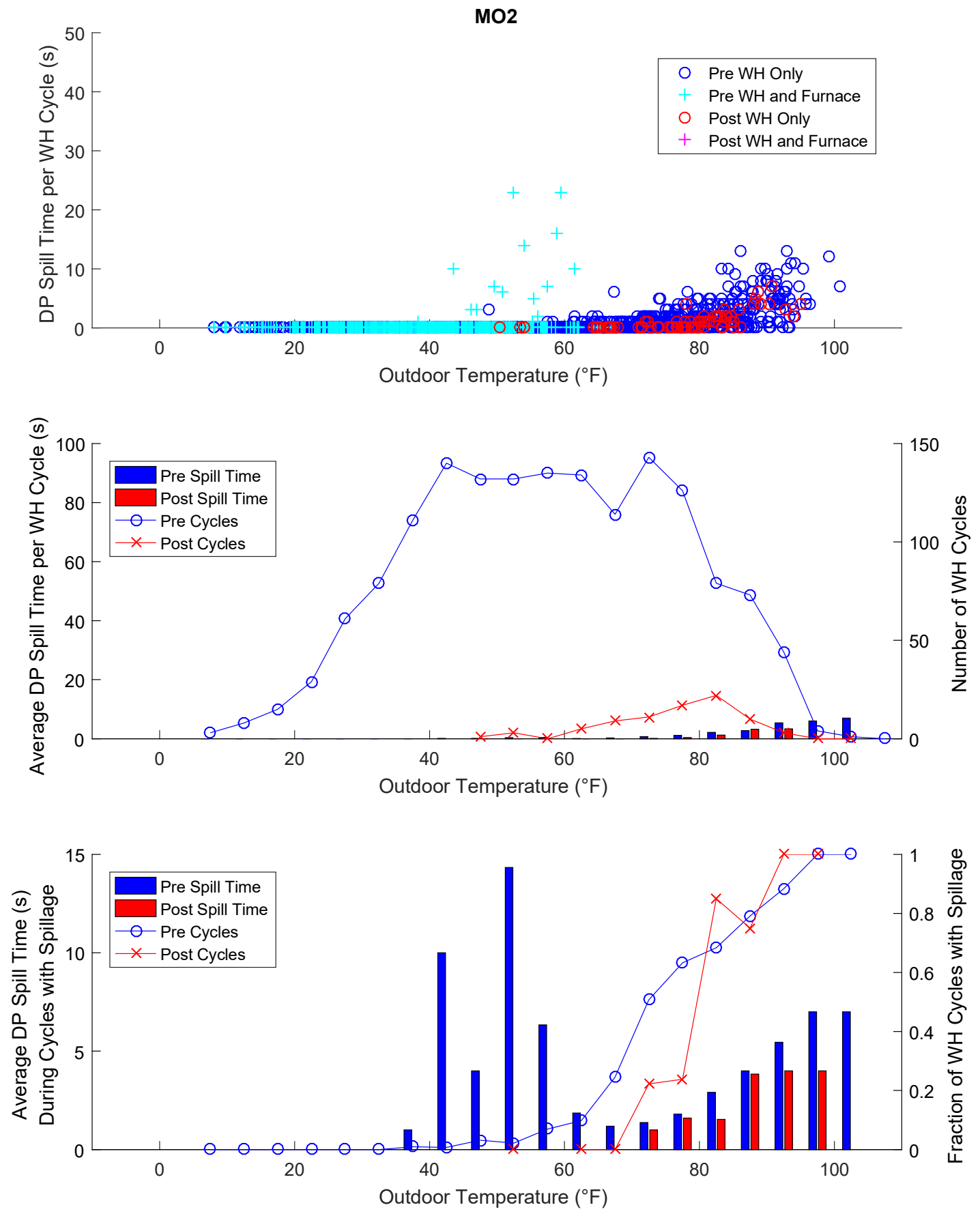

Figure E.14. Spillage summary plots for House MO2. 

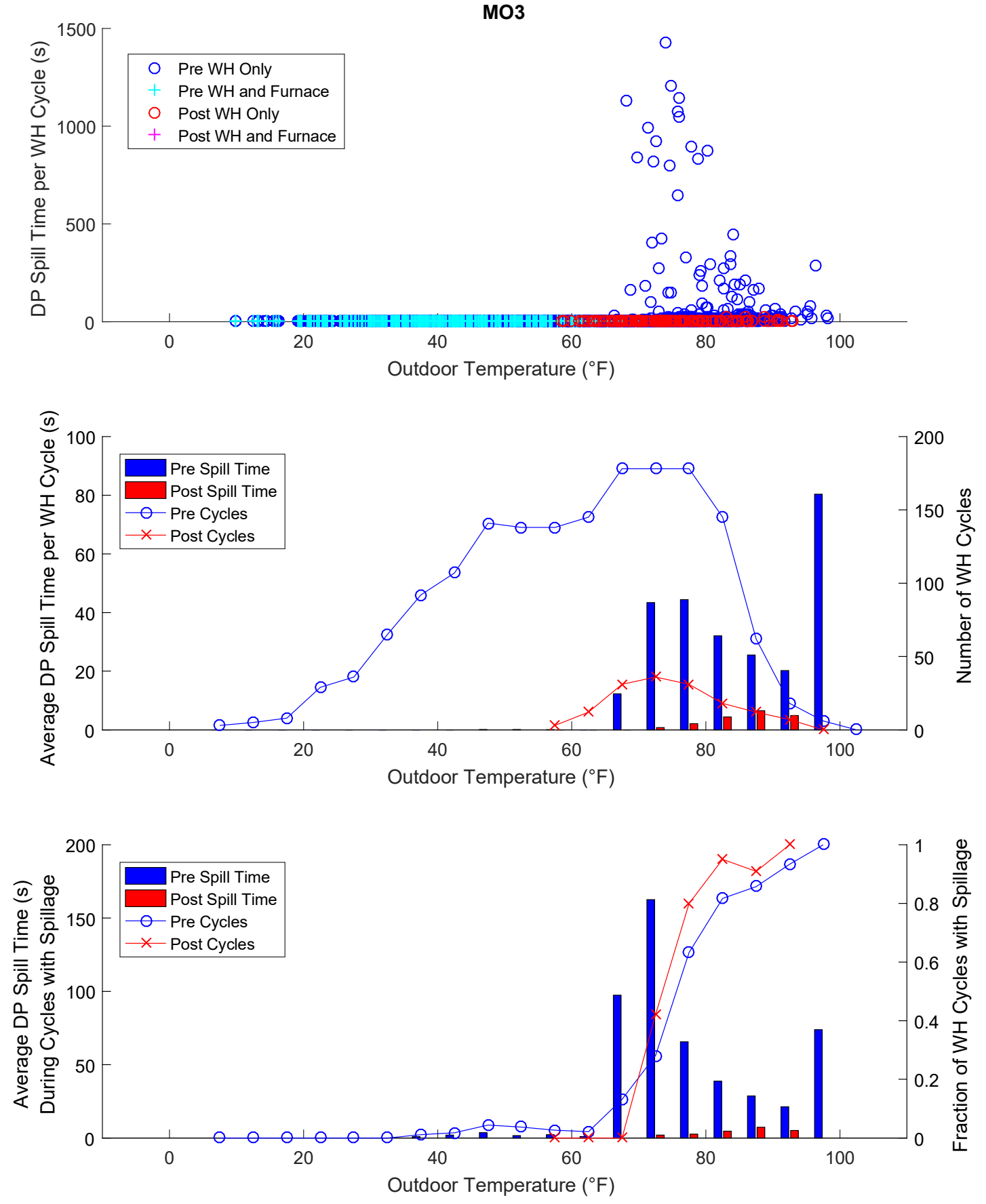

Figure E.15. Spillage summary plots for House MO3. 

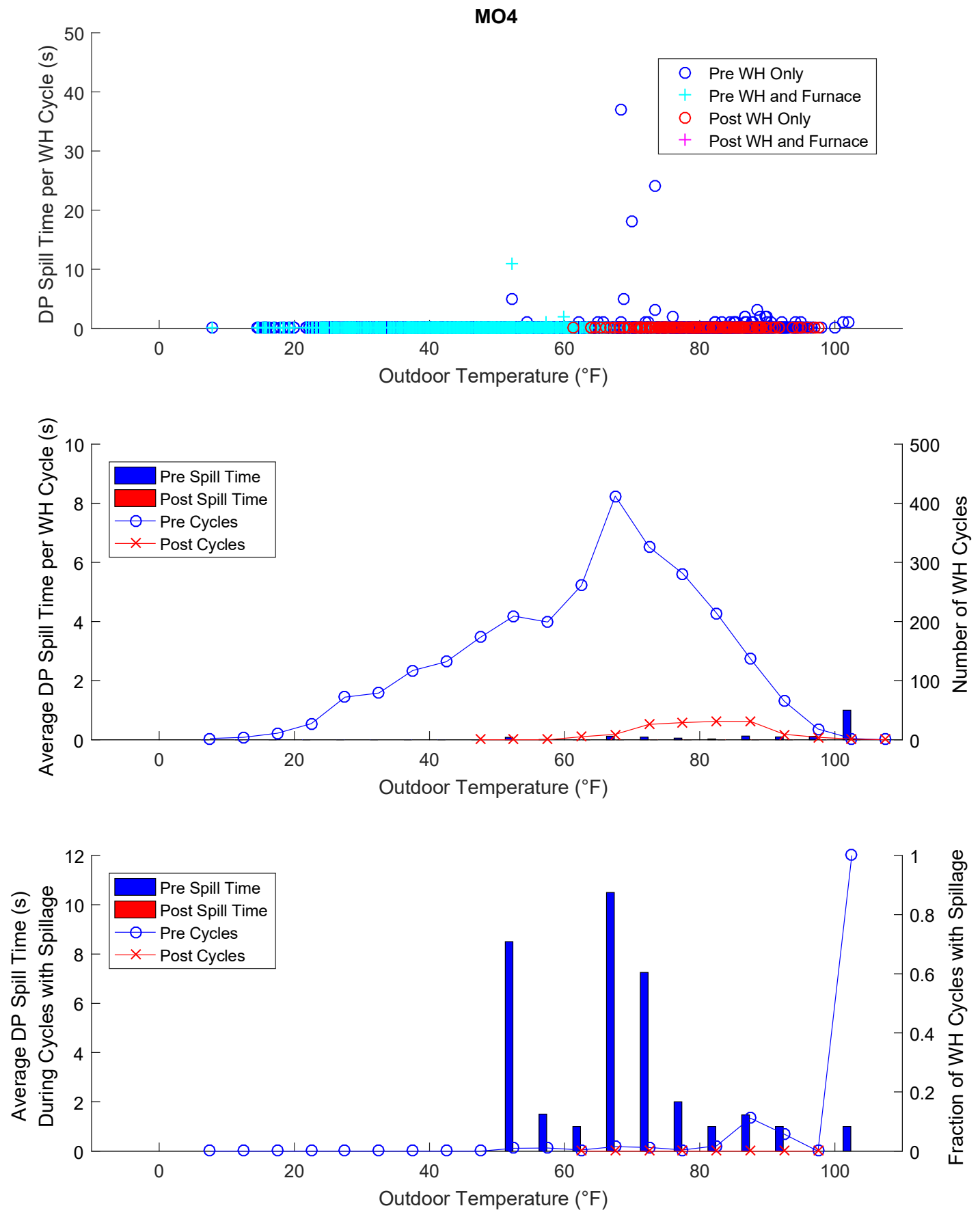

Figure E.16. Spillage summary plots for House MO4. 